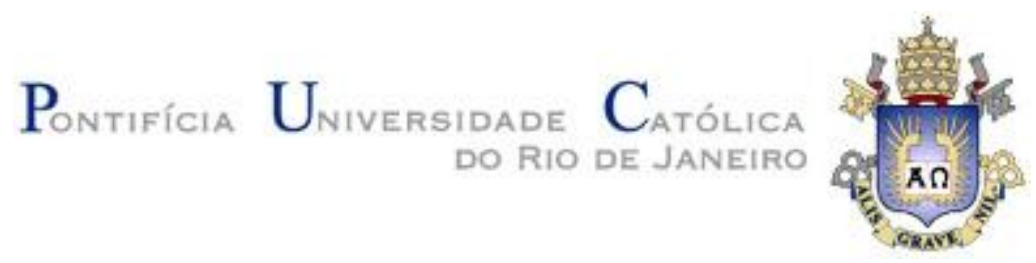

Amanda de Araujo Batista da Silva

Modelo de otimização para localização de hospitais de campanha para COVID-19

Dissertação de Mestrado

Dissertação apresentada como requisito parcial para obtenção do grau de Mestre pelo Programa de Pós-Graduação em Engenharia de Produção, do Departamento de Engenharia Industrial da PUC-Rio.

Orientador: Prof. Silvio Hamacher Co-orientadora: Prof. Janaina Figueira Marchesi

Rio de Janeiro setembro de 2020 
Amanda de Araujo Batista da Silva

\title{
Modelo de otimização para localização de hospitais de campanha para COVID-19
}

\begin{abstract}
Dissertação apresentada como requisito parcial para obtenção do grau de Mestre pelo Programa de Pósgraduação em Engenharia de Produção da PUC-Rio. Aprovada pela Comissão Examinadora abaixo:
\end{abstract}

\section{Prof. Silvio Hamacher}

Orientador

Departamento de Engenharia Industrial - PUC-Rio

Prof. Janaina Figueira Marchesi

Co-orientadora

Instituto Tecgraf/PUC-Rio

Prof. Julia Lima Fleck

Departamento de Engenharia Industrial - PUC-Rio

Prof. Fernando Augusto Bozza

Fundação Oswaldo Cruz - FIOCRUZ 
Todos os direitos reservados. É proibida a reprodução total ou parcial do trabalho sem autorização da universidade, da autora e do orientador.

\section{Amanda de Araujo Batista da Silva}

Graduou-se em Engenharia de Produção pela Universidade do Estado do Rio de Janeiro - UERJ, em 2018. Atuou como pesquisadora no Laboratório de Engenharia e Gestão em Saúde (LEGOS | UERJ), desempenhando atividades nas áreas de Engenharia de Operações e Processos da Produção, Pesquisa Operacional e Transporte e Logística. É pesquisadora do Instituto Tecgraf (PUC-Rio), atuando na Gerência de Sistemas de Apoio à Decisão e Supply Chain como integrante do Núcleo de Operações e Inteligência em Saúde (NOIS).

Ficha Catalográfica

Silva, Amanda de Araujo Batista da

Modelo de otimização para localização de hospitais de campanha para COVID-19 / Amanda de Araujo Batista da Silva ; orientador: Silvio Hamacher ; coorientadora: Janaina Figueira Marchesi. - 2020.

143 f. : il. color. ; $30 \mathrm{~cm}$

Dissertação (mestrado)-Pontifícia Universidade Católica do Rio de Janeiro, Departamento de Engenharia Industrial, 2020.

Inclui bibliografia

1. Engenharia Industrial - Teses. 2. Gestão de serviços de saúde. 3. Alocação de leitos. 4. Problema de localização. 5. COVID-19. I. Hamacher, Silvio. II. Marchesi, Janaina Figueira. III. Pontifícia Universidade Católica do Rio de Janeiro. Departamento de Engenharia Industrial. IV. Título. 


\section{Agradecimentos}

A Deus, por me conceder saúde, por iluminar meus caminhos e me permitir chegar até aqui.

Aos meus pais, Jorge e Edite, por acreditarem em mim e não medirem esforços para a concretização dos meus sonhos. Sem vocês, nada seria possível.

Ao Professor Silvio Hamacher por todo suporte, atenção, correções, incentivos e oportunidades durante o desenvolvimento da dissertação. Obrigada por todos os ensinamentos.

À Professora Janaina Marchesi pela ajuda na elaboração do trabalho, diversas orientações e revisões do texto, e por sempre estar disposta a me ajudar e orientar. Obrigada pelo cuidado.

Aos professores Julia Fleck e Fernando Bozza, por terem aceitado o convite para a banca. Agradeço não apenas a participação, mas os conselhos e ensinamentos ao longo da trajetória acadêmica e profissional.

À professora Thaís Spiegel, que me inspira a querer tornar o mundo um lugar melhor. Sempre foi um grande exemplo para mim, e hoje, agradeço por ter me incentivado a seguir no caminho da pós-graduação. Muito obrigada por tudo.

Aos amigos Rodrigo, Gustavo e Daniel que muitas vezes me ajudaram e me orientaram nessa jornada. Obrigada pela infinita paciência, por estarem sempre presentes, por nunca pouparem esforços para me ajudar e, principalmente, por me lembrar sempre que no final tudo dá certo.

Às amigas Hingred e Isabella pela amizade, por dividirem as dúvidas, experiências e por tornar toda essa trajetória um pouco mais fácil. À Thiago e Pedro, pelas horas de estudo e pelas discussões enriquecedoras. À Marla, Larissa e Brenda, por toda cumplicidade e ajuda desde o início desta jornada.

Aos amigos Bianca, Leila, Leonardo, Guilherme e João Pedro que muitas vezes me ajudaram e me orientaram, compartilharam importantes conhecimentos comigo e me ensinaram muitas coisas.

À amiga Soraida, obrigada pelo companheirismo, apoio, orientações e por ser tão solícita.

A todos os professores e funcionários da PUC-Rio, pelos conhecimentos transmitidos e ajuda fornecida. 
A todos os professores do Departamento de Engenharia Industrial da PUC-Rio, em especial as professoras Paula Maçaira e Fernanda Baião, por todo conhecimento compartilhado, oportunidades de aprendizado e incentivo em seguir essa jornada acadêmica.

Por fim, agradeço aqueles, que de alguma forma, contribuíram para a realização deste trabalho.

O presente trabalho foi realizado com apoio da Coordenação de Aperfeiçoamento de Pessoal de Nível Superior - Brasil (CAPES) - Código de Financiamento 001. 


\section{Resumo}

Silva, Amanda de Araujo Batista da; Hamacher, Silvio (Orientador); Marchesi, Janaina Figueira (Co-orientadora). Modelo de otimização para localização de hospitais de campanha para COVID-19. Rio de Janeiro, 2020. 143p. Dissertação de Mestrado - Departamento de Engenharia Industrial, Pontifícia Universidade Católica do Rio de Janeiro.

A pandemia de COVID-19 causada pelo novo coronavírus (Sars-CoV-2) tornouse um grande desafio à saúde pública. A rápida disseminação da doença em diferentes partes do mundo desafia os governos a controlar a transmissão do vírus e minimizar a insuficiência de recursos, além do seu impacto econômico. O presente trabalho tem como objetivo propor um modelo para localizar hospitais de campanha e alocar leitos públicos de unidades de terapia intensiva (UTI) e de enfermaria, e ventiladores mecânicos para oferecer o tratamento adequado aos pacientes. Para isso, inicialmente foi realizada a previsão dos novos casos de COVID-19 com base no modelo ARIMA (Autoregressive Integrated Moving Average) para o mês de maio. Em seguida, foi proposto um modelo de cobertura de conjuntos, cujo objetivo é atender toda a demanda, minimizando a distância percorrida pelo paciente e os custos envolvidos. Os dados de internação, notificação de casos confirmados, leitos e ventiladores mecânicos foram coletados do Departamento de Informática do SUS (DATASUS) e da Secretaria de Saúde do Estado do Rio de Janeiro (SESRJ). Quatro diferentes cenários são sugeridos aos tomadores de decisão, buscando minimizar a distância percorrida pelo paciente e o custo de instalação dos hospitais. Os resultados mostram que o planejamento inicial do governo do Estado do Rio de Janeiro, além de ser muito caro e não ter sido finalizado, anteciparia mais leitos do que o necessário. A implementação da solução proposta pode fornecer tratamento e estrutura ideais para a população em face de desafios semelhantes relacionados a emergências temporárias.

\section{Palavras-chave}

Gestão de Serviços de Saúde; Alocação de Leitos; Problema de Localização; COVID-19. 


\section{Abstract}

Silva, Amanda de Araujo Batista da; Hamacher, Silvio (Advisor); Marchesi, Janaina Figueira (Co-advisor). Optimization model to locate field hospitals for COVID-19. Rio de Janeiro, 2020. 143p. Dissertação de Mestrado Departamento de Engenharia Industrial, Pontifícia Universidade Católica do Rio de Janeiro.

The COVID-19 pandemic caused by a novel coronavirus (Sars-CoV-2) has become a major public health challenge. The rapid spread of the disease in different parts of the world has challenged the governments to control the virus transmission and minimize the insufficient supply of resources, besides its economic impact. We aimed to localize field hospitals as well as allocate public intensive care beds, ward beds, and mechanical ventilators to provide the appropriate treatment to patients. For this, firstly we estimated the number of confirmed cases based on ARIMA (Autoregressive Integrated Moving Average) for May 2020; then a set covering model was implemented aiming to attend the whole demand while minimizing the distance traveled by the patient and the costs involved. Data on hospitalization, notification of confirmed cases, beds, and mechanical ventilators was collected from DATASUS and the Rio de Janeiro State Health Department (SES-RJ). Four different scenarios were suggested to decision-makers, seeking to minimize the distance traveled by the patient and the cost of installing hospitals. According to our results, the initial planning of the government of Rio de Janeiro State was over-dimensioned and anticipated more beds than necessary. Our solution could provide the optimal treatment and structure to the population in the face of similar challenges regarding temporary emergencies.

\section{Keywords}

Health Care Management; Bed Allocation; Localization Problem; COVID-19. 


\section{Sumário}

1 Introdução 15

$\begin{array}{lr}1.1 \text { Objetivos e delimitação da pesquisa } & 15\end{array}$

$\begin{array}{ll}1.2 \text { Relevância do trabalho } & 16\end{array}$

$\begin{array}{ll}1.3 \text { Estrutura do documento } & 17\end{array}$

2 Referencial Teórico $\quad 18$

2.1 COVID-19 18

2.1.1 Tratamento 22

2.2 Modelos de localização de instalações aplicados a saúde 24

2.2.1 Modelos baseados em cobertura 25

2.2.1.1 Set covering $\quad 25$

2.2.1.2 Máxima cobertura $\quad 26$

2.2.1.3 Modelo p-centro $\quad 27$

2.2.2 Modelos baseados em mediana 29

2.2.2.1 Modelo p-mediana $\quad 29$

2.2.2.2 Modelo fixed charge $\quad 30$

$\begin{array}{ll}2.3 \text { Localização de instalações aplicada a saúde } & 31\end{array}$

2.4 Localização de instalações aplicada a COVID-19 33

3 Procedimentos Metodológicos $\quad 35$

3.1 Classificação da pesquisa $\quad 35$

$\begin{array}{ll}3.2 \text { Etapas da pesquisa } & 35\end{array}$

3.2.1 Compreensão das especificidades do problema 37

3.2.2 Coleta e tratamento de dados e informações 37

3.2.3 Análise descritiva e estatística do problema 38

3.2.3.1 Análise epidemiológica 38

3.2.4 Previsão dos casos confirmados de COVID-19 39

3.2.5 Estimativa de recursos 41

3.2.6 Modelagem matemática $\quad 42$

3.2.7 Análise e discussão dos resultados 43

4 Demanda de Recursos 44

4.1 Descrição do Problema 44

4.2 Projeção dos novos casos de COVID-19 47

4.3 Estimativa da necessidade de recursos $\quad 49$

4.3.1 Total de internados em hospitais públicos $\quad 50$

4.3.2 Tempo médio de permanência $\quad 50$

4.3.3 Estimativa do total de internados em UTI, em enfermaria e em uso de suporte ventilatório $\quad 52$

4.4 Resultados da estimativa de recursos $\quad 53$

4.4.1 Internações em UTI no Estado do Rio de Janeiro 54

4.4.2 Uso de Ventilação Mecânica Invasiva no Estado do RJ 55

4.4.3 Internações em enfermaria no Estado do RJ 56 
4.5 Comparação da estimativa com a real utilização dos recursos 57

4.5.1 Internações em UTI no Estado do RJ 58

4.5.2 Demanda de uso de VMI no Estado do RJ 58

4.5.3 Internações em enfermaria no Estado do RJ 59

5 Modelo Matemático $\quad 60$

$\begin{array}{ll}5.1 \text { Equacionamento } & 60\end{array}$

5.2 Resultados do modelo $\quad 63$

5.2.1 Caso Base $\quad 63$

$\begin{array}{ll}\text { 5.2.2 Caso } 1 & 67\end{array}$

$\begin{array}{ll}5.2 .3 \text { Caso } 2 & 71\end{array}$

$\begin{array}{ll}5.2 .4 \text { Caso } 3 & 74\end{array}$

$\begin{array}{ll}\text { 5.2.5 Comparação entre os cenários propostos } & 77\end{array}$

5.3 Análise da solução proposta 77

5.3.1 Hospitais de campanha instalados no Estado do Rio de Janeiro 78

5.3.2 Internações em UTI no Estado do RJ $\quad 80$

5.3.3 Internações em enfermaria no Estado do RJ 83

6 Considerações Finais $\quad 86$

$\begin{array}{lll}7 & \text { Referências Bibliográficas } & 87\end{array}$

APÊNDICE I - Localização de estabelecimentos de saúde 95

APÊNDICE II - Proporção do total de casos por município do estado do RJ 99

APÊNDICE III - Diagrama de filtragem da base de dados SRAG 102

APÊNDICE IV - Estimativa da demanda de leitos de UTI para o Estado do RJ 103

APÊNDICE V - Estimativa da demanda de leitos de UTI com uso de ventilação

$\begin{array}{ll}\text { mecânica para o Estado do RJ } & 104\end{array}$

APÊNDICE VI - Estimativa da demanda de leitos de enfermaria com uso de

ventilação mecânica para o Estado do RJ 105

APÊNDICE VII - Estimativa da demanda de leitos de enfermaria para o Estado do RJ 106

APÊNDICE VIII - Demanda estimada de leitos de UTI por município

APÊNDICE IX - Demanda estimada de uso de ventilação mecânica invasiva 111

APÊNDICE X - Demanda estimada por leitos de enfermaria 115

APÊNDICE XI - Perfil dos hospitais de campanha Erro! Indicador não definido.

APÊNDICE XII - Municípios candidatos do modelo matemático 119

APÊNDICE XIII - Informações sobre a performance do modelo matemático 122

APÊNDICE XIV - Alocação de leitos de UTI no Estado do RJ por município com

hospital de campanha - caso base 
APÊNDICE XV - Alocação de VMI no Estado do RJ por município com hospital de campanha - caso base

APÊNDICE XVI - Alocação de leitos de enfermaria no Estado do RJ por município com hospital de campanha - caso base

APÊNDICE XVII - Alocação de leitos de UTI no Estado do RJ por município com hospital de campanha - caso 1

APÊNDICE XVIII - Alocação de VMI no Estado do RJ por município com hospital de campanha - caso 1

APÊNDICE XIX - Alocação de leitos de enfermaria no Estado do RJ por município com hospital de campanha - caso 1

APÊNDICE XX - Alocação de leitos de UTI no Estado do RJ por município com hospital de campanha - caso 2

APÊNDICE XXI - Alocação de VMI no Estado do RJ por município com hospital de campanha - caso 2

APÊNDICE XXII - Alocação de leitos de enfermaria no Estado do RJ por município com hospital de campanha - caso 2

APÊNDICE XXIII - Alocação de leitos de UTI no Estado do RJ por município com hospital de campanha - caso 3 APÊNDICE XXIV - Alocação de VMI no Estado do RJ por município com hospital de campanha - caso 3 APÊNDICE XXV - Alocação de leitos de enfermaria no Estado do RJ por município com hospital de campanha - caso 3 


\section{Lista de Figuras}

Figura 1- Casos confirmados de COVID-19 no Brasil. 19

Figura 2 - Total de óbitos notificados por COVID-19 no Brasil. 20

Figura 3 - Casos confirmados de COVID-19 no estado do Rio de Janeiro. 21

Figura 4 - Total de óbitos notificados por COVID-19 no estado do Rio de Janeiro. 21

Figura 5 - Óbitos por COVID-19 por data de ocorrência e notificação no estado do Rio

$\begin{array}{ll}\text { de Janeiro. } & 22\end{array}$

Figura 6 - Classificação dos modelos de localização discretos. 25

Figura 7 - Etapas da pesquisa. 36

Figura 8 - Leitos SUS no Estado do Rio de Janeiro por região de saúde. 45

Figura 9 - Comparação dos modelos ARIMA e ETS para o período teste 48

Figura 10 - Previsão de casos cumulados de COVID-19 no Estado do Rio de Janeiro em maio 49

Figura 11 - Etapas da estimação de recursos $\quad 50$

Figura 12 - Internações SRAG até 30/04/2020 51

Figura 13 - Internações SRAG até 30/04/2020 52

Figura 14 - Exemplo numérico da estimativa de internação em UTI 53

Figura 15 - Demanda estimada de internações em UTI 54

Figura 16 - Comparação entre os resultados estimados e observados para Internações em leitos de UTI no mês de maio $\quad 55$

Figura 17 - Demanda estimada de uso de VMI 55

Figura 18 - Comparação entre os resultados estimados e observados para uso de VMI $\begin{array}{ll}\text { em maio } & 56\end{array}$

Figura 19 - Comparação entre os resultados estimados e observados para internações em leitos de enfermaria no mês de maio 57

Figura 20 - Distribuição dos Hospitais de Campanha por Região de Saúde para o caso base 64

Figura 21 - Distribuição dos Hospitais de Campanha por Região de Saúde para o caso 1

Figura 22 - Distribuição dos Hospitais de Campanha por Região de Saúde para o caso 
Figura 23 - Distribuição dos Hospitais de Campanha por Região de Saúde para o caso 3 


\section{Lista de Tabelas}

Tabela 1- Taxa de incidência de COVID-19 por 100 mil habitantes no Estado do RJ .45

Tabela 2- Taxa de mortalidade por COVID-19 por 100 mil habitantes no Estado do RJ. 46

Tabela 3 - Comparação das internações de SRAG em UTI por região de saúde ......58 Tabela 4 - Comparação do uso de VMIs por pacientes com SRAG por região de saúde .58

Tabela 5 - Comparação das internações de SRAG em leitos de enfermaria por região

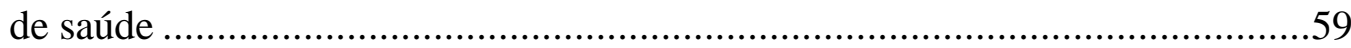

Tabela 6 - Conjuntos e seus domínios correspondentes ......................................60

Tabela 7 - Parâmetros do modelo .............................................................................60

Tabela 8 - Variáveis do modelo.............................................................................61

Tabela 9 - Perfil dos hospitais de campanha ......................................................61

Tabela 10 - Localização dos Hospitais de Campanha para o caso base ....................63

Tabela 11 - Utilização e capacidade de recursos para o caso base .........................66

Tabela 12 - Localização dos Hospitais de Campanha para o caso 1.......................67

Tabela 13 - Utilização e capacidade de recursos para o caso 1 ................................70

Tabela 14 - Localização dos Hospitais de Campanha para o caso 2 ........................71

Tabela 15 - Utilização e capacidade de recursos para o caso 2 ..............................73

Tabela 16 - Localização dos Hospitais de Campanha para o caso 3 .......................74

Tabela 17 - Utilização e capacidade de recursos para o caso 3 ...............................76

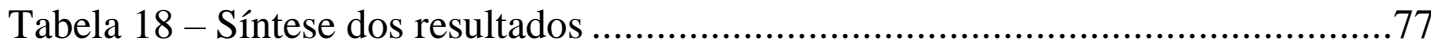

Tabela 19 - Hospitais de campanha implementados no Estado do Rio de Janeiro....79

Tabela 20 - Comparação das internações de SRAG em UTI por região de saúde ...81

Tabela 21 - Comparação das distâncias percorridas por pacientes com demanda de

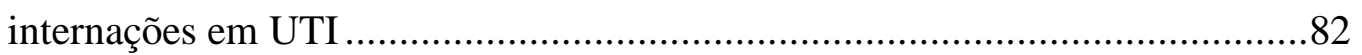

Tabela 22 - Comparação das internações de SRAG em leitos de enfermaria por região de saúde 
Conheça todas as teorias, domine todas as técnicas, mas ao tocar uma alma humana, seja apenas outra alma humana.

Carl Gustav Jung 


\section{Introdução}

A doença infecciosa Coronavirus disease 2019 (COVID-19), nome científico denominado pela Organização Mundial da Saúde (OMS) (HARAPAN et al., 2020), é causada pelo agente etiológico SARS-CoV-2 e surgiu no final do ano de 2019 na China, mas especificamente na província de Wuhan (CHEN et al., 2020b; LU; STRATTON; TANG, 2020). Relatos desde 8 de dezembro de 2019 mostraram que os habitantes da região deram entrada em unidades de saúde locais apresentando diagnóstico de caso de pneumonia grave com causa desconhecida e muitos deles trabalhavam ou moravam no mercado atacadista local de frutos do mar (LU; STRATTON; TANG, 2020).

Os números impressionam pelo rápido atingimento da doença em outros países e regiões, vindo a tornar-se um problema de saúde pública em todo o mundo (SOHRABI et al., 2020). Em 30 de janeiro de 2020, havia 7.736 casos confirmados e 12.167 suspeitos na China, além de 82 casos confirmados identificados em outros 18 países (BURK, 2020). Por conseguinte, a OMS(2020) declarou no mesmo dia que o surto se tornou uma emergência de saúde pública global.

No Brasil, o Ministério da Saúde (MS) iniciou sua preparação para enfrentamento da pandemia no mês de janeiro, por meio de um planejamento que englobava a ampliação da capacidade existente dos sistemas de saúde dos estados. (OLIVEIRA et al., 2020).

\section{1}

\section{Objetivos e delimitação da pesquisa}

Em razão da necessidade de se atender uma nova demanda de pacientes, o presente trabalho tem como objetivo principal propor uma metodologia para localizar hospitais de campanha para tratar pacientes com COVID-19 no Estado do Rio de Janeiro. Os hospitais devem ser distribuídos segundo as regiões de saúde existentes e ter os seguintes recursos alocados: leitos de UTI, leitos de enfermaria e respiradores. A metodologia é composta por um modelo estatístico para predição do número de 
infectados por COVID-19 e por um modelo de otimização para localização de instalações.

Determinou-se como período de análise o mês de maio de 2020, visto que as autoridades de vigilância em saúde apontaram que o estado deveria atingir o maior número de casos acumulados de COVID-19 nesse mês (CRODA et al., 2020).

A delimitação de escopo se deu com a análise das internações notificadas como SRAG (Síndrome Respiratória Aguda Grave), dado que todos os pacientes graves com suspeita ou confirmados de COVID-19 integram essa base de dados e mesmo aqueles que tem a confirmação descartada seguem os mesmos protocolos iniciais de atendimento e concorrem pelos mesmos recursos.

A presente pesquisa também visa atingir alguns objetivos secundários, a saber:

- Entender como se deu a evolução da doença no Estado do Rio de Janeiro;

- Projetar os números de casos de COVID-19;

- Estimar a demanda de internações e necessidade de uso de Ventilação Mecânica Invasiva (VMI);

- Dimensionar a quantidade de recursos a ser alocada em cada região.

\section{2 \\ Relevância do trabalho}

Embora as discussões a respeito dos problemas de alocação de instalações tenham sido formalmente iniciadas em 1909 com Alfred Weber (OWEN; DASKIN, 1998) e exista uma grande quantidade de publicações sobre o tema, ainda há um avanço contido quando se trata da aplicação da temática ao contexto saúde. Em especial, há um número reduzido de trabalhos que tratem da localização de instalações aplicadas ao contexto de epidemias.

Além disso, a presente pesquisa visa atender eventos que embora não ocorram frequentemente, acontecem de modo repentino e demandam de um amplo conjunto de serviços de emergência (AHMADI-JAVID; SEYEDI; SYAM, 2017). Assim, a aplicação dessa técnica de planejamento de instalações se faz necessária para mitigar riscos e reduzir o tempo de resposta em situações de desastre catastrófico ou grandes emergências. 


\section{3 \\ Estrutura do documento}

Este trabalho encontra-se dividido em seis capítulos. O primeiro capítulo dedicase à contextualização do tema, objetivos, justificativa, relevância, delimitações do escopo e a estrutura do estudo.

O segundo capítulo apresenta o referencial teórico, esclarecendo os conceitos associados ao tema, a sintetização do estado da arte da literatura a respeito dos modelos de localização existentes e uma breve exposição daqueles escolhidos para solucionar os problemas apresentados.

O terceiro capítulo descreve os procedimentos metodológicos empregados no desenvolvimento da pesquisa, explicitando o método utilizado, incluindo os instrumentos utilizados na coleta, tratamento e análise dos dados.

O quarto aborda a descrição do problema, expondo as informações encontradas e as questões a serem analisadas para o planejamento do tratamento da COVID-19 no Estado do Rio de Janeiro. Em seguida, expõe a projeção de novos casos da doença estimados para o mês de maio. Subsequentemente, apresenta a estimativa de recursos elaborada, comparando-a ao que de fato ocorreu no período.

O quinto capítulo retrata a modelagem matemática, apresentando o modelo de localização de instalações desenvolvido, seguido das análises de sensibilidade para os cenários pressupostos.

Por fim, o último capítulo tratará das considerações finais e das proposições de trabalhos futuros. 


\section{2 \\ Referencial Teórico}

Neste capítulo serão apresentados os principais conceitos do tema abordado. Em seguida, será relatado como é a realizado o diagnóstico da doença e que tipos de recurso o paciente com COVID-19 demanda. Por fim, busca-se identificar o arcabouço teórico a respeito dos modelos de localização de instalações aplicados à saúde e mais especificadamente ao contexto de epidemias.

\section{1}

COVID-19

A COVID-19, doença semelhante a causada pelo coronavírus da síndrome respiratória aguda grave (do inglês, SARS-CoV) (HUANG et al., 2020; XU et al., 2020), pode causar doença respiratória grave. Segundo Huang et al. (2020), os principais sintomas apresentados no início da doença são tosse, febre, mialgia ou fadiga. A transmissão se dá por meio do contato de pessoa a pessoa, os quais transmitem o vírus por contato direto ou gotículas (HONE et al., 2019).

A inexistência de uma vacina para prevenção e a falta de imunidade prévia da população fazem com que a doença se espalhe rapidamente e apresente um número de casos com crescimento exponencial (ANDERSON et al., 2020). Governantes e autoridades sanitárias vêm sendo desafiados a controlar a transmissibilidade do vírus por meio da adoção de intervenções não farmacêuticas, isto é, ações praticadas por pessoas e comunidades visando conter, mitigar ou suprimir a propagação de doenças infecciosas (LASRY et al., 2020; SHAH et al., 2020).

O primeiro caso de coronavírus no Brasil foi notificado no Estado de São Paulo no dia 26 de fevereiro de 2020 (MS, 2020a; PARAGUASSU; MANDL, 2020). A evolução da doença concentrou-se inicialmente nas grandes capitais, sendo os primeiros casos classificados como importados, oriundos de países estrangeiros (OMS, 2020). 
A Figura 1 apresenta a curva de casos acumulados no Brasil desde a primeira data de reporte até 30/06/2020.

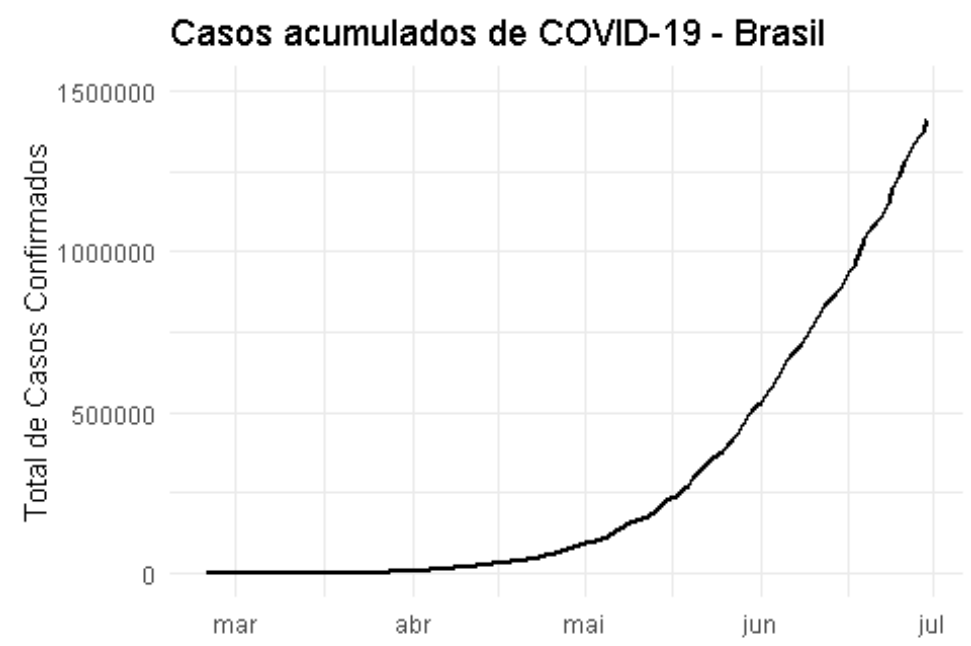

Figura 1- Casos confirmados de COVID-19 no Brasil.

Fonte: Ministério da Saúde, obtido em (COTA, 2020).

Medidas de controle foram tomadas em todo o país visando retardar o crescimento da curva de casos. Contudo, elas não foram estabelecidas no âmbito nacional, cabendo a cada Estado, iniciando por São Paulo e Rio de Janeiro, a decisão de determinar medidas de isolamento social, tais como fechamento dos shopping centers e academias, e suspensão de todos os eventos (ANTUNES et al., 2020).

Conforme pode ser observado na figura anterior, o número de casos no Brasil continuou a crescer desde o início da pandemia. Não sendo observado ao longo dos quatro meses nenhuma queda no total de infectados reportados. O número de óbitos comportou-se da mesma maneira, sendo observado um crescimento ao longo do período observado (Figura 2). 


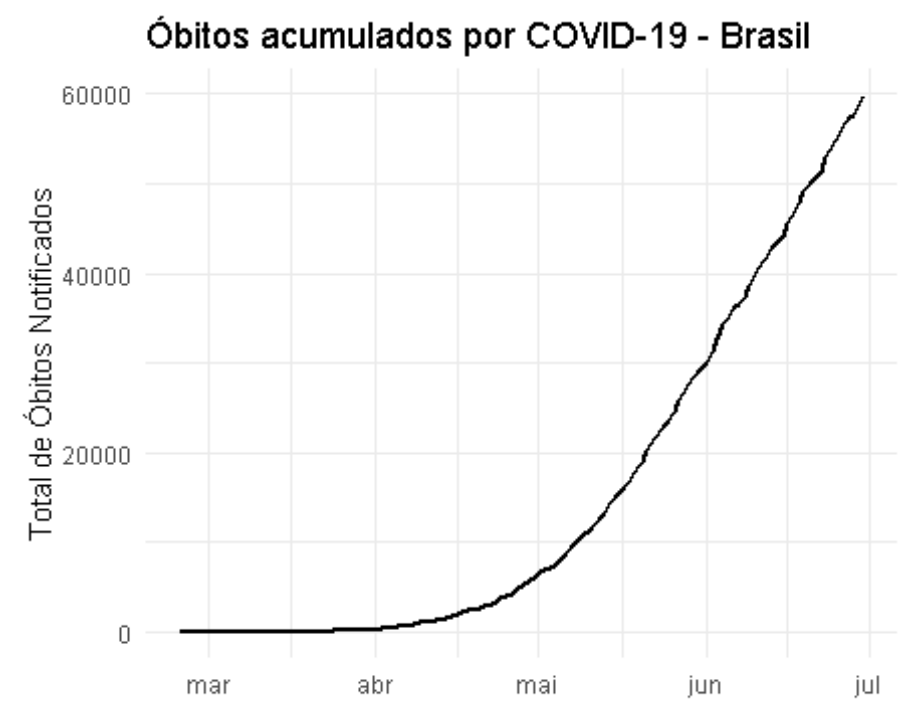

Figura 2 - Total de óbitos notificados por COVID-19 no Brasil.

Fonte: Ministério da Saúde, obtido em (COTA, 2020).

Além de alcançar altos números de óbitos em decorrência da doença, em meados de junho o país atingiu o patamar de segundo com maior número de mortes ficando atrás somente dos Estados Unidos (RITCHIE et al., 2020).

No Estado do Rio de Janeiro, o primeiro caso foi confirmado pela Secretaria de Estado de Saúde (SESRJ) no dia 05 de março de 2020, sendo o mesmo perfil de paciente advindo do exterior (SESRJ, 2020a). Nesse mesmo dia, o MS confirmou os primeiros dois casos de transmissão local, no Estado de São Paulo, e oito dias depois regulamentou critérios de isolamento e quarentena (MS, 2020b), devido aos casos de transmissão comunitária do novo coronavírus nas cidades do Rio de Janeiro e de São Paulo.

Em 02 de março de 2020 a SESRJ já havia publicado um plano de resposta do estado ao coronavírus, sistematizando ações e procedimentos a serem tomados antecipadamente ou no decorrer de situações fora de normalidade (SESRJ, 2020b). No plano constam recomendações para a identificação do vírus, estabelecimento de classificação de níveis de ativação da contingência, ações a serem tomadas pela secretaria e responsabilidades e atribuições de cada esfera de atenção à saúde.

Como é possível observar na Figura 3, o crescimento dos números de casos no Estado do RJ foi controlado no início. Contudo, tal comportamento não se manteve por muito tempo. Fato este que pode ser explicado em razão da autonomia dada pela União Federal e divergências as ações tomadas por diferentes governos (PIRES, 2020), 
causando assim imprecisão nas orientações e dúvidas nas atitudes a serem seguidas por parte da população.

Casos acumulados de COVID-19 - RJ

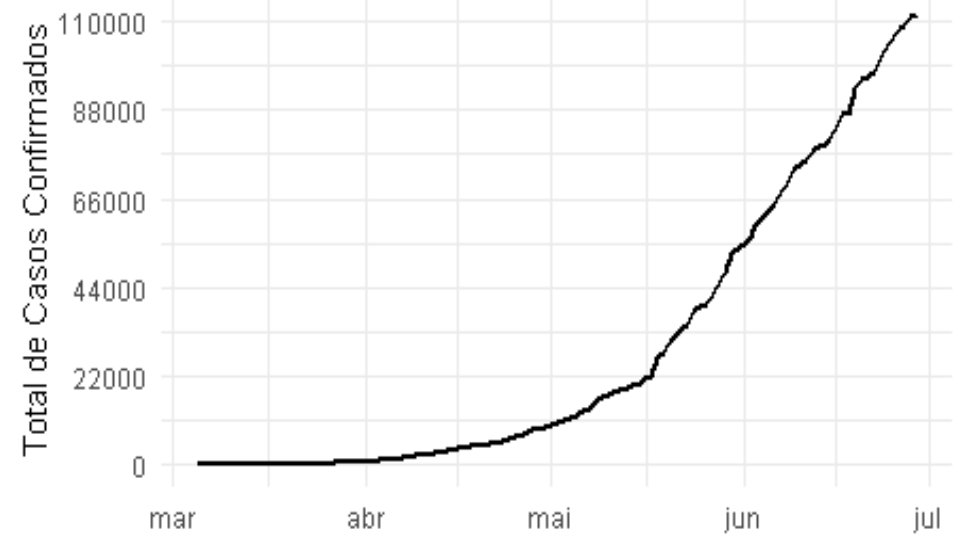

Figura 3 - Casos confirmados de COVID-19 no estado do Rio de Janeiro.

Fonte: Ministério da Saúde obtido em (COTA, 2020).

A SESRJ (2020c) confirmou o primeiro óbito por COVID-19 no estado no dia 19 de março de 2020. Desde então, nota-se um aumento nas notificações de óbitos causados pela doença, conforme apresentado na Figura 4.

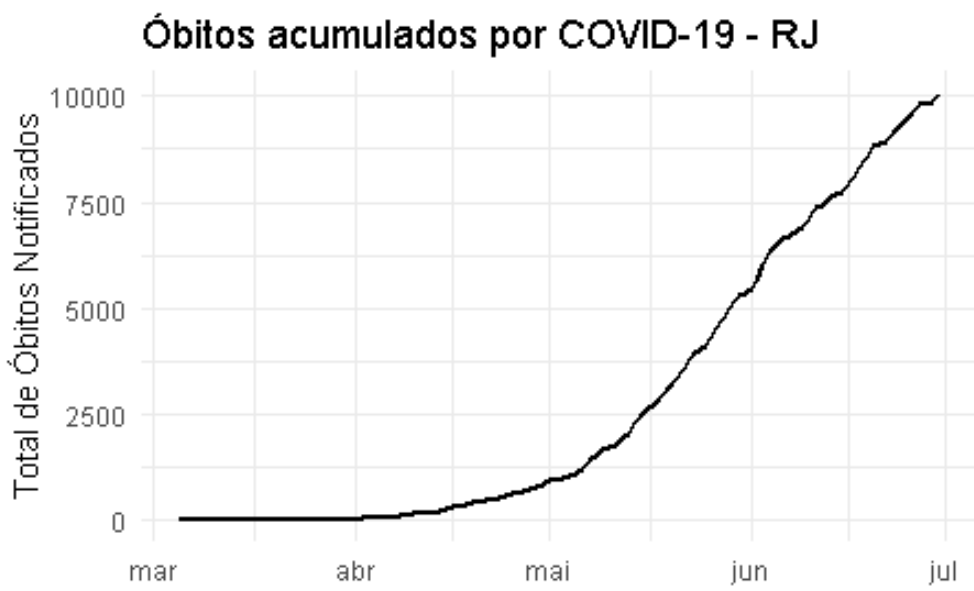

Figura 4 - Total de óbitos notificados por COVID-19 no estado do Rio de Janeiro.

Fonte: Ministério da Saúde obtido em (COTA, 2020).

Vale ressaltar que os números acima expostos, tanto de casos confirmados quanto de notificações de óbito, detêm de um atraso nas suas divulgações decorrentes 
da dificuldade de mensuração próprias do sistema e que se evidenciam durante uma pandemia (BASTOS et al., 2019).

A Figura 5 retrata o atraso presente entre o momento do óbito e seu registro nos sistemas oficiais do governo.

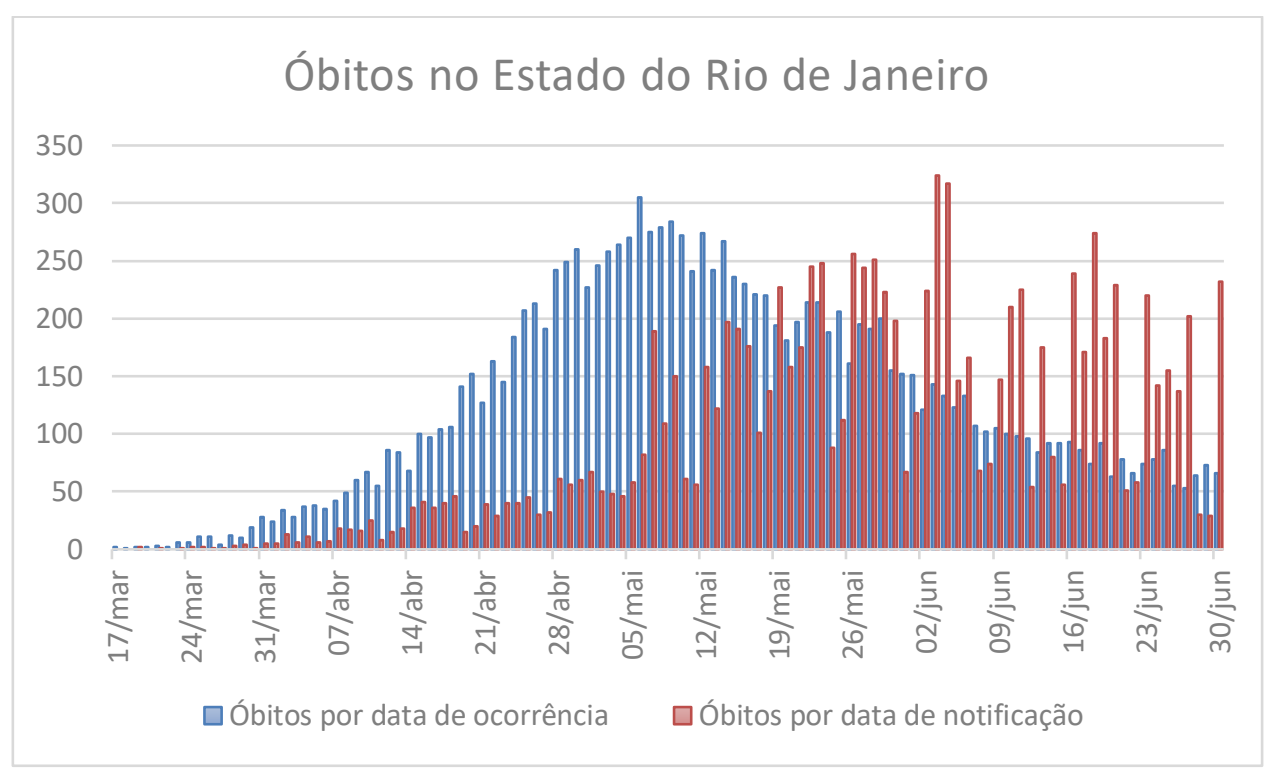

Figura 5 - Óbitos por COVID-19 por data de ocorrência e notificação no estado do Rio de Janeiro.

Fonte: Ministério da Saúde obtido em (COTA, 2020) e SESRJ obtido em (SESRJ, 2020d)

\subsection{1}

\section{Tratamento}

A COVID-19 apresenta uma taxa de mortalidade relativamente alta, embora seja considerada uma doença moderadamente infecciosa (HARAPAN et al., 2020). Assim como as doenças causas pelos vírus MERS-CoV e SARS-CoV, ainda não existe um tratamento antiviral específico para tratar essa patologia (TANG; TAMBYAH; HUI, 2020).

O reconhecimento precoce de suspeição da doença e, também, o controle da sua disseminação por meio do isolamento dos casos suspeitos ou confirmados é de suma importância para o controle da doença e tratamento dos infectados em estágios iniciais de evolução (OMS, 2020). O infecto demanda isolamento, cuidados de suporte e gerenciamento de sintomas, tais como oxigenoterapia, controle de líquidos e tratamento com antibióticos para tratar infecções secundárias (CHEN et al., 2020a; HUANG et al., 2020). 
Vale ressaltar que alguns casos evoluem rapidamente apresentando complicações graves tais como: Síndrome do Desconforto Respiratório Agudo (SDRA); choque séptico; hipoxemia; arritmia; choque; lesão cardíaca aguda; e lesão renal aguda (CHEN et al., 2020b; HUANG et al., 2020), demandando tratamento em Unidades de Terapia Intensiva (UTI) e uso de ventiladores mecânicos, recursos esses que frequentemente são insuficientes a todos os pacientes (HALPERN; MILLER, 2020).

Espera-se que $30 \%$ de toda a população não apresente sintomas, $55 \%$ venha a ter sintomas leves e moderados, $10 \%$ tenha sintomas graves e 5\% encontre-se em uma situação seja crítica com 50\% de chance de vir a óbito (FERGUSON et al., 2020; LAUER et al., 2020).

A lotação dos hospitais vivenciada por todos os países durante a pandemia ocasiona o aumento da capacidade interna dos estabelecimentos para atender a população. Esse acréscimo de oferta pode ser observado na adaptação dos serviços fornecidos nas unidades e mudanças de layout, de forma a aumentar o total de leitos disponibilizados, contratar mais profissionais de saúde, entre outros (WERNECK; CARVALHO, 2020).

Contudo, a adaptação dos hospitais não se mostrou suficiente, fazendo com que governos e autoridades de saúde utilizassem de outras estratégias para atender a população (FERGUSON et al., 2020). Pode-se citar como exemplo principal os hospitais de campanha, unidades flexíveis montadas por um período, porém também são utilizados de navios e hotéis visando o isolamento dos pacientes (BROWN et al., 2020).

Os hospitais de campanha consistem em estruturas modulares de fácil monte e desmonte, os quais têm como função atender as necessidades de determinada população por um período (SALMAN; GÜL, 2014). Apresentam somente o mínimo de estrutura necessária, de forma que se torne possível o deslocamento para regiões mais afastadas. Ainda assim, esse perfil de hospital possibilita desde pequenos procedimentos até cirurgias de alta complexidade e internações de pacientes provisoriamente (OLIVEIRA, 2016).

O MS iniciou sua preparação para enfrentamento da pandemia por meio de um planejamento que englobava a ampliação da capacidade existente dos sistemas de saúde de cada estado, por meio da aquisição e redistribuição de equipamentos e insumos - principalmente produção e aquisição de ventiladores mecânicos -, 
construção de novas unidades hospitalares, montagem de hospitais de campanha e contratação de leitos em hospitais privados (OLIVEIRA et al., 2020).

Assim sendo, para tratar o paciente com COVID-19 é necessário dispor de leitos de enfermaria para os casos mais leves e leitos de UTI para os casos mais graves. Além disso, uma vez que haja desconforto respiratório faz-se necessário o uso de ventilação mecânica, tornando esse equipamento essencial para o tratamento de casos de alta complexidade.

\section{2}

\section{Modelos de localização de instalações aplicados a saúde}

A discussão a respeito de localização de instalações é apresentada tanto para a indústria quanto para a saúde. Segundo Daskin e Dean (2004), na indústria localizar mal uma instalação, ofertar produtos em excesso ou de forma insuficiente podem causar aumento de despesas e/ou perda de qualidade no atendimento ao cliente. Se muitas instalações forem implantadas, os custos provavelmente excederão o valor desejável. Se poucas instalações forem usadas, o atendimento ao cliente poderá ser comprometido. Mesmo se o número correto de instalações for usado, instalações com localização ruim resultarão em um mau atendimento.

No setor de saúde uma má localização resulta em aumento de morbidade e mortalidade. Assim, a modelagem da localização das instalações apresenta uma importância ainda maior quando aplicada à localização das unidades de saúde (HILLIER et al., 2004)

Os modelos de localização discretos foram classificados por Daskin (2008) em modelos baseados em cobertura, em medianas e aqueles que não se enquadram em nenhuma dessas categorias (Figura 6). O primeiro grupo apresenta como limitação uma distância máxima, a qual inviabiliza a solução se ela não for respeitada. Já o segundo tem como objetivo minimizar a soma dos custos de distribuição, interpretado como distância entre oferta e demanda. Por fim, a última categoria pode ser exemplificada por modelos p-dispersão, aqueles cuja distância mínima entre qualquer par de instalações deve ser maximizada. Ademais, Hillier et al. (2004) assinalam que os principais modelos de localização utilizados no planejamento de localização de instalações no setor de saúde são: modelos de máxima cobertura, set covering ou cobertura de conjuntos e p-mediana. 


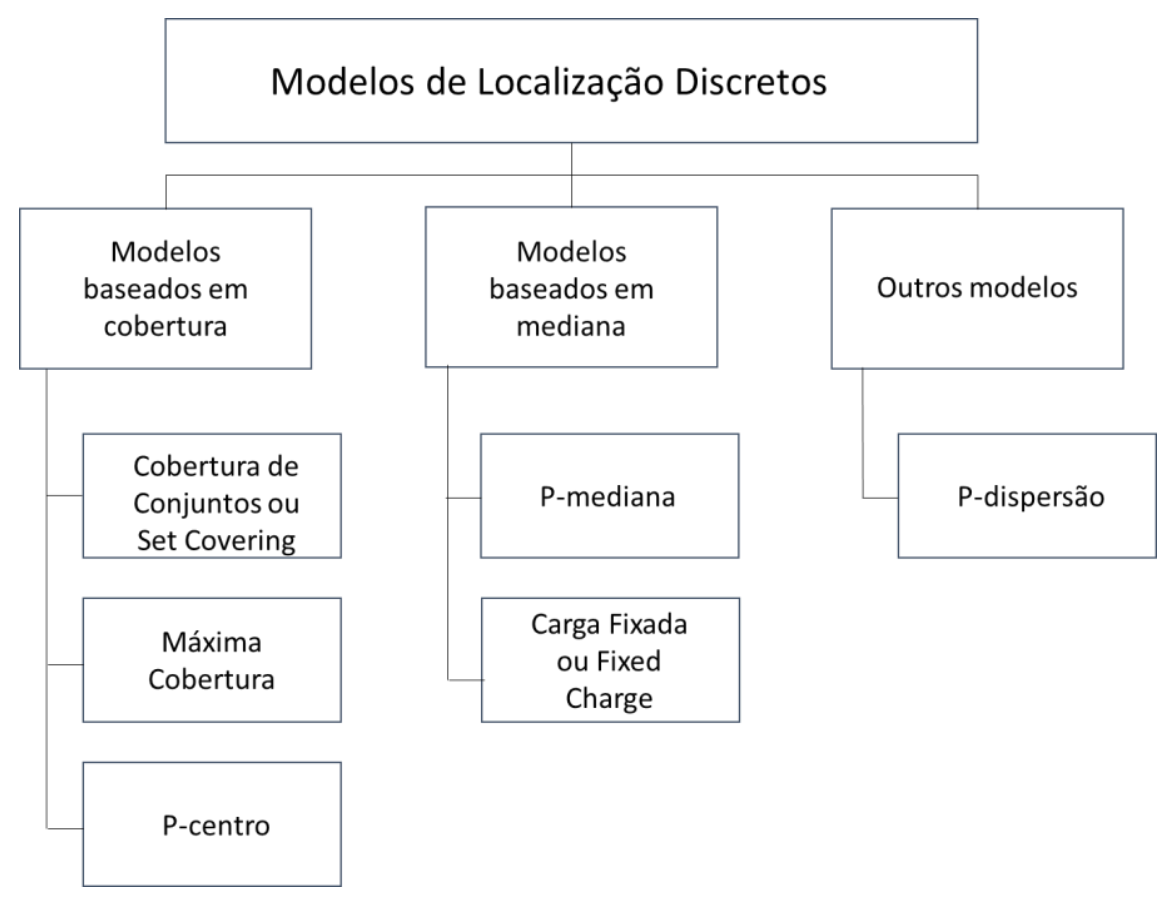

Figura 6 - Classificação dos modelos de localização discretos.

\subsection{1}

Fonte: Adaptado de Daskin (2008)

\section{Modelos baseados em cobertura}

Têm como limitação uma distância máxima, a qual inviabiliza a solução se ela não for respeitada. Tal problema apresenta como variações: a cobertura de conjuntos, com objetivo de minimizar o número de instalações, desde que atenda toda a demanda; cobertura máxima, onde maximiza a cobertura com um número de instalações prédefinido; e o p-centro, modelo cujo objetivo é minimizar a distância necessária para cobrir toda a demanda

\subsubsection{1}

\section{Set covering}

O problema de set covering ou cobertura de conjunto consiste na busca por um grupo de instalações, dentre um conjunto finito de candidatas, que apresente o menor custo e atenda toda demanda, isto é, cada nó de demanda deve ser atendido por pelo menos uma instalação (DASKIN, 2013).

\section{Parâmetros}

$a_{i j}=\left\{\begin{array}{l}1 \text { se local candidato } j \in J \text { pode cobrir a demanda do nó } i \in I \\ 0 \text { se não }\end{array}\right.$

$f_{j}=$ custo de localizar a instalação no local candidato $j \in J$ 


\section{Variáveis de Decisão}

$$
X_{j}=\left\{\begin{array}{l}
1 \text { se localizo a instalação no local candidato } j \in J \\
0 \text { se não }
\end{array}\right.
$$

\section{Função objetivo}

$$
\text { Minimizar } \quad \sum_{j \in J} f_{j} X_{j}
$$

\section{Sujeito a}

$$
\begin{aligned}
& \sum_{j \in J} a_{i j} X_{j} \geq 1 \forall i \in I \\
& X_{j} \in\{0,1\} \forall j \in J
\end{aligned}
$$

A função objetivo (2.1) minimiza o custo total de instalação das facilidades selecionadas. A restrição (2.2) determina que cada nó de demanda $\boldsymbol{i}$ deve ser coberto por pelo menos uma facilidade. Por fim, (2.3) é a restrição de integralidade da variável de decisão.

\subsubsection{2}

\section{Máxima cobertura}

Este modelo tem como objetivo atender o máximo possível de demanda de com o menor número de instalações possível. Um valor fixo de instalações e uma distância máxima entre cada instalação e sua demanda são pré-determinados,

De acordo com Farahani e Hekmatfar (2009), esse é o modelo de cobertura mais usual. Formulado por Church e ReVelle (1974), o modelo tem como objetivo maximizar o total de demandas atendidas, considerando um número máximo de instalações possível.

\section{Parâmetros}

$h_{i}=$ demandado nó $i \in I$

$a_{i j}=\left\{\begin{array}{l}1 \text { se local candidato } j \in J \text { pode cobrir a demanda do nó } i \in I \\ 0 \text { se não }\end{array}\right.$ 
$P=$ número de instalações para alocar

\section{Variáveis de Decisão}

$X_{j}=\left\{\begin{array}{l}1 \text { se localizo a instalação no local candidato } j \epsilon J \\ 0 \text { se não }\end{array}\right.$

$Z_{i}=\left\{\begin{array}{l}1 \text { se o nó } i \in I \text { é coberto } \\ 0 \text { se } n \text { ão }\end{array}\right.$

\section{Função objetivo}

$$
\text { Maximizar } \sum_{i \in I} h_{i} Z_{i}
$$

\section{Sujeito a}

$$
\begin{gathered}
Z_{i} \leq \sum_{j \in J} a_{i j} X_{j} \quad \forall j=i \in I \\
\sum_{j \in J} X_{j} \leq P \\
X_{j} \in\{0,1\} \forall j \in J \\
Z_{i} \in\{0,1\} \forall i \in I
\end{gathered}
$$

A função objetivo (2.4) maximiza o número de demanda coberta. A restrição (2.5) estabelece que a demanda do nó $\boldsymbol{i}$ só pode ser atendida se pelo menos um dos locais da instalação que cobre o nó $\boldsymbol{i}$ esteja selecionado e, também, fornece o número de instalações selecionadas que podem cobrir o nó $\boldsymbol{i}$. A restrição (2.6) estipula que não devem ser localizadas mais do que $\boldsymbol{P}$ instalações. Finalmente, as restrições (2.7) e (2.8) correspondem ao tipo binário das variáveis.

\subsubsection{3}

\section{Modelo p-centro}

Também conhecido como modelo minmax, o modelo p-centro tem como objetivo localizar uma quantidade de instalações $\boldsymbol{P}$, previamente definidas, de forma 
que todos os nós de demanda sejam atendidos e a distância máxima entre um nó de demanda e a instalação mais próxima seja minimizada (DASKIN, 2013).

\section{Parâmetros}

$D=$ distância entre um ponto de demanda e a instalação mais próximo

$d_{i j}=$ distância entre a demanda $i \in I$ e o local candidato $j \in J$

\section{Variáveis de Decisão}

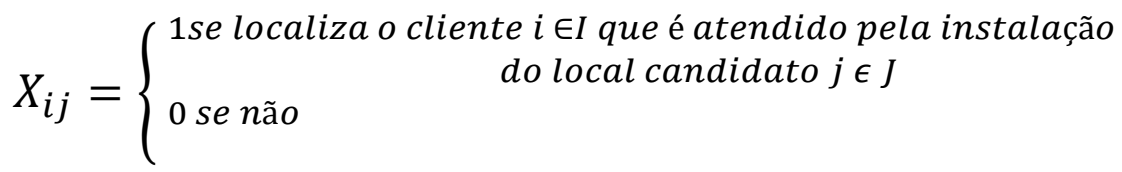

$$
\begin{aligned}
& Y_{j}=\left\{\begin{array}{l}
1 \text { se abro a instalçao no local candidato } j \in J \\
0 \text { se não }
\end{array}\right.
\end{aligned}
$$

\section{Função objetivo}

$$
\text { Minimizar D }
$$

\section{Sujeito a}

$$
\begin{aligned}
& \sum_{j \in J} X_{i j}=1 \quad \forall i \in I \\
& \sum_{j \in J} X_{i j} \leq Y_{j} \forall i \in I ; j \in J \\
& D \geq \sum_{j \in J} d_{i j} X_{i j} \forall i \in I \\
& X_{i j} \in\{0,1\} \forall i \in I ; j \in J \\
& Y_{j} \in\{0,1\} \forall i \in I ; j \in J
\end{aligned}
$$

A função objetivo (2.9) minimiza a distância máxima entre a demanda e a instalação que oferece o serviço a ela. A restrição (2.10) impõe que cada cliente $\boldsymbol{i} \in \boldsymbol{I}$ é associado a uma única instalação. Em (2.11) temos a garantia de que os nós de demanda só podem ser servidos por pontos onde haja uma instalação localizada. A restrição (2.12) define $\boldsymbol{D}$ como a máxima distância entre um ponto de demanda e a instalação mais próxima. Em (2.13) e em (2.14) temos as restrições de integralidade das variáveis de decisão. 


\subsection{2}

\section{Modelos baseados em mediana}

Os modelos baseados em mediana têm como objetivo minimizar a distância média ponderada pela demanda entre um nó de demanda e o recurso ao qual está associado. São exemplos o problema p-mediana e o problema de carga fixa sem capacidade.

\subsubsection{1}

\section{Modelo p-mediana}

O modelo de p-medianas visa minimizar a soma dos custos de distribuição, interpretado como distância entre oferta e demanda. Para isso, busca-se localizar uma quantidade $P$ de instalações, determinada a priori, de modo que minimize a distância entre os pontos de demanda e os pontos de oferta (DASKIN, 2013).

\section{Parâmetros}

$h_{i}=$ demandado nó $i \in I$

$d_{i j}=$ distância entre a demanda $i$ e a instalação candida $j$

$P=$ número de instalações para alocar

\section{Variáveis de Decisão}

$X_{j}=\left\{\begin{array}{l}1 \text { se localizo a instalação no local candidato } j \in J \\ 0 \text { se não }\end{array}\right.$

$Y_{i j}=\left\{\begin{array}{l}1 \text { se o nó de demanda } i \in I \text { é atendido pela instalação no local } \\ 0 \text { se não } \\ \text { candidato } j \in J\end{array}\right.$

\section{Função objetivo}

$$
\sum_{j \in J} \sum_{i \in I} h_{i} d_{i j} Y_{i j}
$$

\section{Sujeito a}

$$
\sum_{j \in J} Y_{i j}=1 \quad \forall i \in I
$$




$$
\begin{array}{ll}
Y_{i j}-X_{j} \leq 0 & \forall i \in I ; \forall j \in J \\
\sum_{j \in J} X_{j}=P & \\
X_{j} \in\{0,1\} & \forall j \in J \\
Y_{i j} \in\{0,1\} & \forall i \in I ; j \in J
\end{array}
$$

A função objetivo (2.15) minimiza a distância total ponderada pela demanda. A restrição (2.16) estabelece que cada nó de demanda deve ser servido por uma facilidade. Em (2.17) temos que o nó de demanda só pode ser atribuído a uma instalação que foi aberta. A restrição (2.18) garante que o número de instalações abertas não ultrapasse a quantidade $\boldsymbol{P}$. Por fim, em (2.19) e em (2.20) temos as restrições de integralidade das variáveis de decisão.

\subsubsection{2 \\ Modelo fixed charge}

O problema é encontrar os locais das instalações e o padrão de remessa entre as instalações e os clientes para minimizar a localização combinada das instalações e os custos de remessa sujeitos a um requisito de que todas as demandas dos clientes sejam atendidas (Daskin et al., 2004).

\section{Parâmetros}

$h_{i}=$ demandado nó $i \in I$

$f_{j}=$ custo de localizar a instalação no local candidato $j \in J$

$c_{i j}=$ custo unitário de transporte entre a demanda do nó $i \in I$ e

a instalação no local candidato $j \in J$

\section{Variáveis de Decisão}

$X_{j}=\left\{\begin{array}{l}1 \text { se intala no local candidato } j \in J \\ 0 \text { se não }\end{array}\right.$

$Y_{i j=}$ Fração da demanda no local do cliente $i \in I$ que é atendida por uma instalação no local $j \in J$ 


\section{Função objetivo}

$$
\operatorname{Minimizar} \sum_{j \in J} f_{j} X_{j}+\sum_{j \in J} \sum_{i \in I} h_{i} c_{i j} Y_{i j}
$$

\section{Sujeito a}

$$
\begin{aligned}
& \sum_{j \in J} Y_{i j}=1 \forall i \in I \\
& Y_{i j}-X_{j} \leq 0 \forall i \in I ; j \in J \\
& X_{j} \in\{0,1\} \quad \forall j \in J \\
& Y_{i j} \geq 0 \quad \forall i \in I ; j \in J
\end{aligned}
$$

A função objetivo (2.21) minimiza o custo total (localização da instalação fixada e transporte). Em (2.22) é determinado que cada nó de demanda deve ser completamente atribuído a uma instalação. Na restrição (2.23) temos que o nó de demanda só pode ser atribuído a uma instalação que foi aberta. As restrições (2.24) e (2.25) representam a integralidade das variáveis de decisão.

\subsection{Localização de instalações aplicada a saúde}

Embora as aplicações de localização de instalações na área da saúde apresentem um crescimento contido, quando comparado a outras áreas, nota-se o aumento das aplicações de problemas discretos de localização de rede no contexto da assistência médica, considerada uma das questões estratégicas mais importantes em sistemas de saúde (AHMADI-JAVID; SEYEDI; SYAM, 2017).

Güneş et al. (2019) classificam os problemas de localização em saúde em três grandes áreas: localização da unidade, planejamento de ambulâncias e problemas de layout do hospital. O primeiro, mais clássico, como o próprio nome já diz, refere-se à determinação do local que a unidade de saúde será situada. Já o segundo, trata além da localização ou realocação de ambulâncias, dando enfoque ao intervalo de tempo entre a chamada de emergência e a transferência do paciente até uma unidade de saúde que oferte o serviço necessário. Por fim, está o posicionamento das unidades dentro de um 
mesmo edifício, no caso os hospitais, buscando a redução dos transportes e custos relacionados aos deslocamentos.

Shariff et al. (2012) enfatizaram que para se atingir um alto padrão de atendimento na área da saúde, faz-se necessário um planejamento sistemático e eficiente do sistema. Consequentemente, a localização de novas unidades de saúde demanda cada vez mais de métodos que facilitem o processo de decisão dos planejadores (Zhang et al. 2016).

Haase et al. (2019) apresentaram o estado da arte a respeito da localização de estabelecimentos de saúde. Foi realizada uma atualização desse trabalho, constatandose a existência de uma variedade de aplicações, embora todas tratem de localização de instalações de unidades de saúde. A compilação dos resultados encontrados pelos autores, até o ano de 2018, acrescida da sua atualização elaborada nesta pesquisa podem ser observados no Apêndice I.

Shariff et al. (2012) usam a abordagem clássica de máxima cobertura com instalações capacitadas para localizar as unidades de saúde, enquanto Zhang et al. (2016) propõem uma solução para o mesmo problema, porém com três objetivos: maximizar a equidade da acessibilidade, minimizar a população fora da faixa de cobertura e o custo de instalação das novas unidades. Kim \& Kim (2013) trazem uma solução de localização de instalações voltada para o atendimento de pacientes de baixa renda, de modo que o máximo de pacientes seja atendido, respeitando suas preferências e o orçamento disponível.

Uma outra categoria é o modelo de alocação e localização. Basu et al. (2018) também se preocupam com os pacientes com menor renda, visando quantificar a lacuna existente no acesso aos serviços de saúde. A solução encontrada determina a quantidade de novas instalações públicas necessárias para o atendimento desse perfil de paciente e expõe que é possível aumentar a cobertura. Nota-se também outros dois modelos desse tipo propostos por Mestre et al. (2015) para tratar as incertezas eminentes no planejamento estratégico de uma rede hospitalar. A reorganização dos sistemas da rede é buscada por meio da minimização do tempo de transporte, entendido como a melhoria do acesso geográfico, e dos custos. Ouyang et al. (2020) também apresentam um modelo de localização de estabelecimentos de saúde e alocação de pacientes, o qual visa minimizar os custos totais de construção e manutenção das instalações. Já Nasrabadi et al. (2020) buscam, além de localizar as instalações de saúde, alocar seus serviços e determinar as capacidades dessas instalações. Djenic et 
al. (2016) apresentaram uma metaheurística para minimizar o número máximo de pacientes atendidos por uma instalação.

Além de iniciativas que buscam apoiar diretamente as atividades médicas, existem uma grande discussão sobre saúde preventiva. Abordada por Zhang et al. (2012) e Haase \& Müller (2015), os modelos apresentam diferentes soluções, porém ambas como objetivo de maximizar a participação do programa de saúde preventiva. Tavakkoli-Moghaddam et al. (2019) desenvolveram um modelo de localização de instalações associado ao design de rede, buscando minimizar o custo total de transporte e construção de instalações e maximizar os impactos sociais do estabelecimento localizado.

Vries et al. (2020) preocuparam-se com a localização de unidade de saúde beneficiando aqueles que apresentam dificuldades em acessar os sistemas de saúde, os caminhoneiros. O modelo desenvolvido visa maximizar o volume de pacientes nas unidades e a efetividade da prestação de serviços de saúde, mediante uma análise voltada a um perfil de paciente que não é estático.

Além disso, Vries et al. (2020) discutiram o design de redes de suprimento de sangue, insumo de grande importância no tratamento hospitalar. A proposição visa localizar os componentes do banco de sangue em uma rede alocando de forma efetiva os seus componentes (locais de doação, laboratórios de teste e processamento, bancos de sangue e pontos de demanda).

Sendo assim, observa-se uma grande variação nos modelos desenvolvidos para oferecer serviços de saúde a uma determinada população. Embora todos tratem de localização de instalações, observa-se que as abordagens incluem cada vez mais fatores de decisão relevantes tornando os modelos mais realistas (HAASE et al., 2019). Ademais, Güneş et al. (2019) evidencia que o tema tratado receberá ainda mais atenção nas próximas décadas, em virtude do envelhecimento da população, fato este que indica a crescente demanda da população por uma gestão de recursos no setor de saúde cada vez mais eficiente.

\subsection{Localização de instalações aplicada a COVID-19}

Devido a novidade do tema discutido, até o momento não foram encontradas pesquisas sobre modelos de localização de instalações aplicados ao tratamento de pacientes com COVID-19. Todavia, ressalta-se a importância da aplicação da Pesquisa 
Operacional para solucionar questões manifestadas em decorrência do surto, como modelos de otimização e simulação.

Yu et al. (2020) propuseram um projeto de uma rede de logística reversa epidêmica para lidar com resíduos médicos em Wuhan, baseado na formulação inteira mista multiobjetivo e multiperíodo. O modelo tem como objetivo gerenciar de modo eficaz o desperdício médico, o qual é acrescido de modo exponencial durante um período de surto. Os resultados encontrados sugerem a instalação de incineradores temporários e enfatizam que a seleção de local deles apresenta importância significativa.

Mehrotra et al. (2020) desenvolveram um modelo de otimização estocástica para alocar estoque de ventiladores para tratamento de pacientes com COVID-19 em diversos estados dos Estados Unidos, comparando as quantidades de ventiladores disponibilizadas a pacientes com e sem COVID-19 e possibilitando ao tomador de decisão conhecer quais cenários será possível atender ou não as necessidades dos pacientes. Çetin et al. (2020), inspirados no problema de atribuição de alvos de armas, elaboraram dois modelos de otimização cuja finalidade é maximizar a proteção total contra-ataques de epidemia, pandemia ou bioterrorismo. A aplicação em dados reais estabelece um protocolo individual e em massa para garantir a proteção do indivíduo ou de uma comunidade a partir do uso de intervenções farmacêuticas e nãofarmacêuticas.

Currie et al. (2020) apresentaram a importância da modelagem, mais especificamente a simulação, no auxílio a tomada de decisão em busca da melhor estratégia para minimizar os efeitos provocados pela pandemia de COVID-19, além de apontar a sua adoção por diversos governos nacionais e até a OMS. Wood (2020) destacou o adiamento de tratamentos eletivos a fim de tratar as demandas relacionadas a COVID-19, propondo, por meio simulação, uma previsão de aumento dos tempos de espera e mensurando, também, o esforço necessário para retornar aos níveis de desempenho existentes antes da pandemia. 


\section{3 \\ Procedimentos Metodológicos}

Este capítulo aborda os procedimentos metodológicos adotados nesta pesquisa, discorrendo a respeito de sua classificação, as etapas percorridas na sua elaboração e os métodos empregados.

\section{1}

\section{Classificação da pesquisa}

A pesquisa é de natureza aplicada, caracterizando-se por ter uma abordagem quantitativa e qualitativa, uma vez que emprega ambos os métodos para atingir seu propósito (CAUCHICK MIGUEL, 2007).

Quanto ao objetivo, a presente pesquisa pode ser classificada como descritiva e explicativa (GIL, 2008), visto que procura descrever e analisar o comportamento da pandemia de COVID-19 no estado do Rio de Janeiro, buscando evidências que esclareçam os fatores que contribuem para a assistência à população e, em seguida, oportunidades de melhoria e uma proposição de solução para o problema.

Por fim, o procedimento técnico para a confecção desta pesquisa é a modelagem estatística e em programação matemática, a qual objetiva compreender como um sistema funciona (BERTRAND; FRANSOO, 2002).

\section{2}

\section{Etapas da pesquisa}

A pesquisa sucedeu-se em sete etapas. Inicialmente, precisou-se compreender como a rede de atenção deve funcionar em meio a uma pandemia e, paralelamente, coletar dados secundários e informações do banco de dados do SUS e do repositório de dados de acesso aberto tanto do MS quanto da SESRJ. Esses dados precisaram ser manipulados e tratados antes de iniciar as análises. Assim, foi possível realizar a quarta etapa, ou seja, a análise descritiva e estatística do problema. Em seguida, elaborou-se 
o modelo de predição de casos de COVID-19. Então, chegou-se na estimativa de necessidade de recursos.

Isto posto, foi realizada a seleção dos modelos matemáticos, seguida da construção da modelagem. Por fim, foram feitas as análises e discussões dos resultados.

A Figura 7 expõe as macro atividades realizadas em cada etapa citada anteriormente.

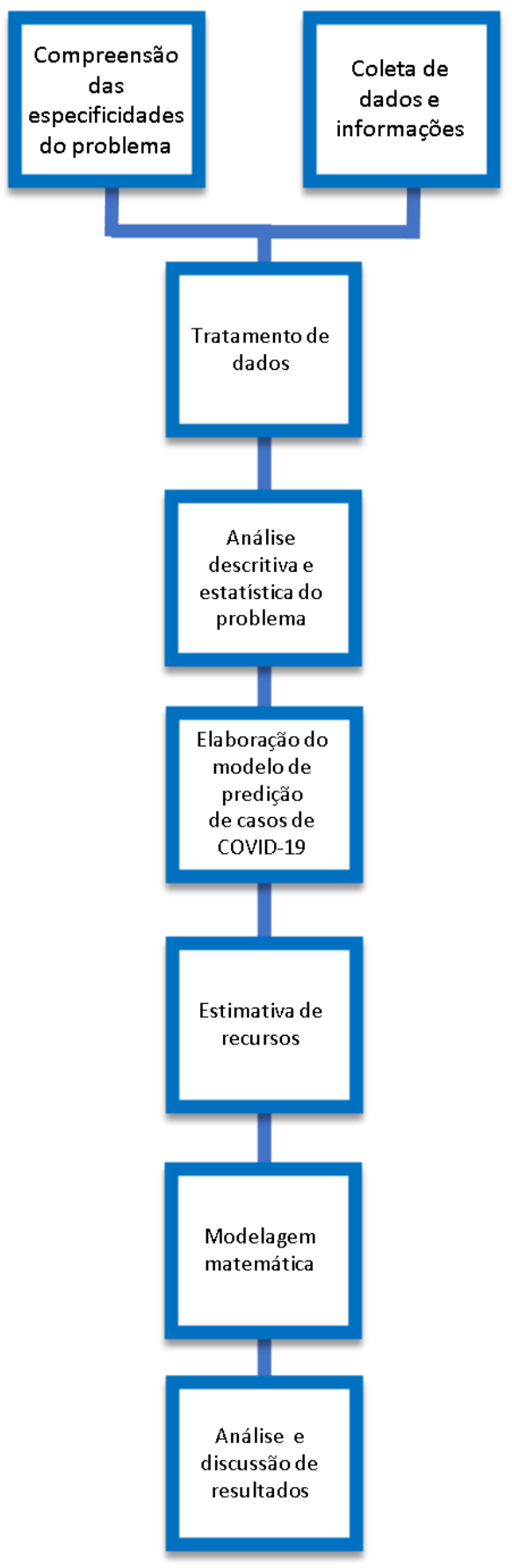

Figura 7 - Etapas da pesquisa.

Fonte: Elaboração própria. 


\subsection{1}

\section{Compreensão das especificidades do problema}

Nesta etapa, foram realizadas entrevistas com especialistas para entender o funcionamento da rede de atenção, buscas na literatura objetivando o entendimento da transmissibilidade da doença e estratégias de contenção do surto e, também, consultas a normativos referenciais do MS e da SESRJ, além de seus painéis de dados sobre a COVID-19.

\section{2 .2}

\section{Coleta e tratamento de dados e informações}

A principal fonte de consulta para esta pesquisa foi o DATASUS, órgão do MS, essencial para o setor de saúde brasileiro. Nele constam informações sobre eventos em internação hospitalar, atendimento ambulatorial, procedimentos de alta complexidade, imunização, óbitos, nascimentos, vigilância em saúde, entre outros (LIMA, 2016).

Para elaborar esta pesquisa, foi necessário obter as seguintes informações para o Estado do Rio de Janeiro: histórico do número de casos da doença, total de pacientes hospitalizados, panorama de leitos e respiradores disponibilizados e padrão de hospitais de campanha empregados pela SESRJ.

As informações referentes à transmissibilidade da doença advieram de comunicações oficiais divulgadas pelo MS e compiladas em (COTA, 2020), onde constam os números de casos confirmados e óbitos notificados por COVID-19.

Os dados relacionados às internações e uso de recursos foram obtidos por meio das notificações de Síndrome Respiratória Aguda Grave (SRAG). Essas notificações estão presentes no Sistema de Informação da Vigilância Epidemiológica da Gripe (SIVEP-Gripe), o qual apresenta uma extensa base de dados cujo objetivo principal é monitorar os casos de SRAG e encontram-se disponíveis no repositório OpenDataSUS (MS, 2020c).

Os tipos de hospitais adotados pela SESRJ com seus respectivos portes e custos foram obtidos através do contrato firmado com a empresa de prestação do serviço (GOVERNO DO ESTADO DO RIO DE JANEIRO, 2020). Além disso, devido à falta de divulgação do planejamento de inauguração dos hospitais de campanha, fez-se necessário a consulta de notícias divulgadas pela mídia sobre as datas de abertura 
previstas e efetivas, bem como as quantidades de leitos a serem disponibilizados por tipo e taxas de ocupação.

Os dados precisaram ser tratados para posterior manipulação, sendo elaborados os seguintes estágios: decodificação, categorização e agrupamento. Para verificar o comportamento da doença e disponibilidade de recursos na região estudada, utilizouse de filtros, para cada base de dados, buscando identificar o total de notificações, casos com necessidade de internação, tratamento realizado e desfecho.

\section{2 .3}

\section{Análise descritiva e estatística do problema}

A partir das informações obtidas do MS, foi possível analisar as seguintes situações e seus marcos temporais: notificações de casos confirmados de COVID-19, internações em leitos de enfermaria ou de UTI, e desfecho do caso, entendido como alta ou óbito.

\subsubsection{1}

\section{Análise epidemiológica}

Buscando identificar características epidemiológicas deste perfil de paciente, efetuaram-se cálculo e análise dos indicadores de incidência e de mortalidade. Eles são fontes de informação para verificar o comportamento da doença e realizar análises comparativas da disseminação da doença entre diferentes regiões.

A incidência indica a quantidade de novos casos de uma doença que ocorreram em determinada população presente em uma área geográfica. Já a mortalidade é calculada a partir do quantitativo de óbitos de uma mesma causa em uma dada população existente em uma região.

Os métodos estatísticos empregados nesse trabalho foram:

- Distribuição percentual:

Frequência relativa do total de novos eventos (incidência ou mortalidade) com relação ao total de casos.

- Taxa bruta:

Total de eventos sobre uma população de referência em determinado período. 
Vale ressaltar que todas as taxas brutas foram multiplicadas por 100.000 para se tornar possível uma análise comparativa entre as diferentes regiões estudadas.

\subsection{4}

\section{Previsão dos casos confirmados de COVID-19}

A previsão do número de casos confirmados de COVID-19 foi realizada usando os seguintes métodos de previsão de séries temporais: suavização exponencial (do inglês, Exponential Smoothing - ETS) e modelos ARIMA.

Os dados foram separados em conjuntos de treinamento e de teste na proporção de 70:30, respectivamente. Depois de treinar os modelos, eles foram usados na estimação do número de novos casos confirmados diários no conjunto teste.

As previsões dos diferentes modelos foram avaliadas pela métrica de erro percentual absoluto médio (MAPE). A fórmula matemática do MAPE está representada na equação (3.2).

$$
\text { MAPE }=\frac{\sum_{t=1}^{n} \frac{\left|\left(y_{t}-\hat{y}_{t}\right)\right|}{y_{t}}}{n}
$$

Onde:

$y_{t}:$ Valor observado

$\hat{\mathrm{y}}_{t}:$ Previsão

$t$ : Período (dia) do dado

$n$ : Número de total de observações

O cálculo do MAPE compreende a razão do desvio da previsão (valor observado - valor previsto) pelo valor observado, obtendo-se um desvio percentual. Realiza-se esta operação para todas as observações da série e, ao fim, calcula-se a média dos desvios percentuais.

Desse modo, escolheu-se o modelo para realizar a previsão dos novos casos 30 dias a frente de acordo com a melhor performance obtida no MAPE, isto é, entre o modelo ETS e o modelo ARIMA selecionou-se aquele modelo que apresentou o menor valor para a métrica. 


\subsubsection{1}

\section{Método linear de Holt com erro aditivo}

O método linear de Holt, extensão do método de suavização exponencial simples, é caracterizado por fornecer uma tendência constante que pode aumentar ou diminuir indefinidamente ao longo do tempo (HOLT, 2004).

Tal método foi escolhido por ser adequado a previsão de dados que apresentem um padrão de tendência claro. Nesse caso, tendência de crescimento. As expressões gerais deste método são encontradas a seguir:

Nível: $L_{t}=\alpha Y_{t}+(1-\alpha)\left(L_{t-1}+T_{t-1}\right)$

Tendência: $T_{t}=\beta\left(L_{t}-L_{t-1}\right)+(1-\beta) T_{t-1}$

Previsão: $\widehat{Y}_{t+h \mid t}=L_{t}+h T_{t}$

Onde:

$L_{t}:$ nível estimado no tempo $\mathrm{t}$

$Y_{t}$ : valor observado em $\mathrm{t}$

$T_{t}$ : é a tendência estimada (inclinação) no tempo t

$\alpha$ : parâmetro de suavização para o nível $(0 \leq \alpha \leq 1)$

$\beta$ : parâmetro de suavização para a tendência $(0 \leq \beta \leq 1)$

$\widehat{Y}_{t+h \mid t}:$ previsão $h$ passos à frente

\subsubsection{2}

\section{Modelo ARIMA}

O modelo ARIMA (do inglês, Autoregressive Integrated Moving Average), desenvolvido por Box e Jenkins em 1975 (BOX et al., 2015) apresenta uma metodologia a qual segue quatro etapas: identificação, que seleciona um modelo para tratar a série em questão; estimação, para determinar os parâmetros do modelo escolhido; verificação do modelo, onde é apurado, por meio de estatística e análise de resíduos, se o modelo elegido é adequado; e previsão dos valores futuros da série. Destaca-se que essa metodologia é iterativa e, uma vez que o modelo escolhido não seja satisfatório, reinicia-se a partir da etapa inicial.

O modelo ARIMA (p, d, q) apresenta como fórmula geral a equação (3.4). 


$$
\varphi(B) Z_{t}=\phi(B) \nabla^{d} Z_{t}=\theta_{0}+\theta(B) a_{t}
$$

Onde:

t: tempo

$\varphi$ (B): operador autorregressivo generalizado

$Z_{t}:$ série temporal

$\phi(\mathrm{B})$ : operador autorregressivo, ou seja, $\phi(\mathrm{B})=\left(1-\phi_{1} B-\phi_{2} B^{2}-\ldots-\phi_{p} B^{p}\right)$

$\nabla$ : operador de diferença, definido como $\nabla^{d} Z_{t}=Z_{t}-Z_{t-1}$

$\theta(B)$ : operador de médias-móveis, isto é, $\theta(\mathrm{B})=\left(1-\theta_{1} B-\theta_{2} B^{2}-\ldots-\theta_{q} B^{q}\right)$

$a_{t}$ : erro aleatório, conhecido também como ruído branco

A estatística utilizada para a seleção do melhor modelo $\operatorname{ARIMA}(p, d, q)$ foi o critério de informação de Akaike (do inglês, Akaike's information criterion - AIC) por se tratar de um bom indicativo para a seleção de modelos não-lineares (COLLETT, 2003).

$$
A I C=-2 \log (L)+2(p+q+P+Q+k)
$$

Onde:

$k=\left\{\begin{array}{l}1, \text { se } \phi \neq 0 \\ 0, \text { se } \text { não }\end{array}\right.$

$L$ : é a probabilidade máxima do modelo ajustado

$P$ e $Q$ : são considerados zero para séries não-sazonais

\section{2 .5}

\section{Estimativa de recursos}

A partir do total de casos previstos, estima-se a proporção de novos pacientes com SRAG que necessitarão de leitos de UTI, leitos de enfermaria e Ventilação Mecânica Invasiva (VMI).

Para isso, é necessário avaliar o histórico de hospitalizações realizadas nos hospitais públicos, entendidos aqui como hospitais de administração pública abertos para atendimento pelo SUS conforme registro no CNES. Essas informações de internações foram obtidas por meio das notificações SRAG. 
Vale destacar que se assumiu que essas internações possuem equivalência de uso de recurso com os casos da COVID-19, dado que ambos os casos concorrem pelo mesmo recurso.

Em seguida, selecionou-se todos os casos de internações com desfecho até o final do mês de abril e calculou-se a média de tempo de permanência de todos os casos. O percentual de internações de casos de internação por dia é estimado considerando as seguintes informações: tempo de permanência esperado; projeção de novos casos diários confirmados da doença; e total de hospitalizados em terapia intensiva, enfermaria ou em uso de suporte ventilatório.

Destaca-se que para a estimativa de leitos de UTI considerou-se além dos pacientes internados em UTI, aqueles que utilizaram de suporte ventilatório invasivo fora da terapia intensiva, já que não houve leitos suficientes para atender toda a demanda por internações em UTI (GOULART, 2020). Analogamente, o total de demanda de VMI estimada é resultado da estimação de paciente em suporte ventilatório dentro da UTI acrescida da estimação de pacientes que utilizaram VMI fora da UTI.

Logo depois, compara-se os resultados obtidos na estimativa com as internações que de fato aconteceram por meio da métrica de erro percentual.

\subsection{6}

\section{Modelagem matemática}

Uma vez conhecidos o funcionamento da rede e como é feita geração de informações, iniciou-se a escolha do modelo de localização ideal para propor uma nova estruturação no atendimento aos casos de internação notificados como SRAG.

A escolha do modelo set-covering é resultado de uma seleção de modelos desenvolvidos por outros pesquisadores, com aplicações na área da saúde, que apresentam grande relevância para a área. Sua construção considerou restrições referentes ao atendimento da demanda e premissas estabelecidas e pelas políticas de atenção à saúde especificadas pelo MS.

O objetivo do modelo é localizar hospitais de campanha que ofereçam três diferentes tipos de recursos: leitos de enfermaria, leitos de UTI e ventiladores mecânicos para o tratamento de pacientes com SRAG, de modo que atendam a demanda por hospitais públicos de todo o estado do Rio de Janeiro. 
Destaca-se que o objetivo da pesquisa é tornar os hospitais de campanha referência no enfrentamento da doença. Uma vez que o cenário anterior à pandemia era de altas taxas de ocupação de leitos, escolheu-se considerar a capacidade atual não disponível para esse perfil de paciente.

\subsection{7}

Análise e discussão dos resultados

Concluiu-se a pesquisa analisando os resultados obtidos e discutindo como seria sua implantação. Para mais, o cenário proposto foi contraposto com o planejamento da SESRJ e sua real implementação. 


\section{Demanda de Recursos}

O presente capítulo retrata a necessidade de recursos demanda por pacientes com SRAG. Inicia-se pela descrição do problema, onde é contextualizado o tratamento dos pacientes e a necessidade de instalação de hospitais de campanha. Em seguida, apresenta-se a projeção dos novos casos de COVID-19. Por fim, aborda-se a estimativa para a demanda de internações em UTI, em enfermaria e de uso de Ventilação Mecânica Invasiva (VMI).

\section{1}

\section{Descrição do Problema}

Noronha et al. (2020) afirmaram que conforme o coronavírus se propagasse, automaticamente aumentaria a demanda pelo Sistema Único de Saúde (SUS), e os pacientes deixariam de ser apenas aqueles de classes média e alta, os quais acessam o sistema privado. A Agência Nacional de Saúde Suplementar (ANS) registrou em abril de 2020 que apenas 24,3\% da população brasileira possuía plano de saúde (ANS, 2020). Ainda assim, salienta-se que mesmo aqueles que contratam planos de saúde podem vir a usufruir dos serviços disponibilizados pelo SUS, em especial no atendimento em alta complexidade quando não se encontra na cobertura do plano (MEDICI, 2010; SALAZAR et al., 2003). Portanto, espera-se um aumento de demanda do sistema público considerável, para a maioria da população.

O SUS já enfrenta há alguns anos um cenário de altas taxas de ocupações de leitos de terapia intensiva, decorrente de uma capacidade inferior àquela necessitada pela população (ARAUJO et al., 2013). Em março de 2020, as UTIs de adultos do SUS já estava com uma taxa de ocupação acima de 95\% (AMIB, 2020).

Segundo os dados do Cadastro Nacional de Estabelecimentos de Saúde (CNES), no mês de fevereiro de 2020, antes do primeiro caso de COVID-19, o Estado do Rio de Janeiro comportava um total de 14.926 leitos públicos adultos (excluindo leitos obstétricos e psiquiátricos), sendo 13.505 leitos de enfermaria e 1.521 leitos de 
Unidade de Terapia Intensiva (UTI). Como mencionado anteriormente, parte desses leitos já estava comprometida com internação de pacientes com outras enfermidades.

Além do exposto acima, outra questão que ocorre é a distribuição desigual de leitos públicos no Estado do Rio de Janeiro em relação às regiões de saúde. A Figura 8 mostra o número de leitos públicos em cada região de saúde, em fevereiro de 2020, estando nítida a concentração na região de saúde Metropolitana I.

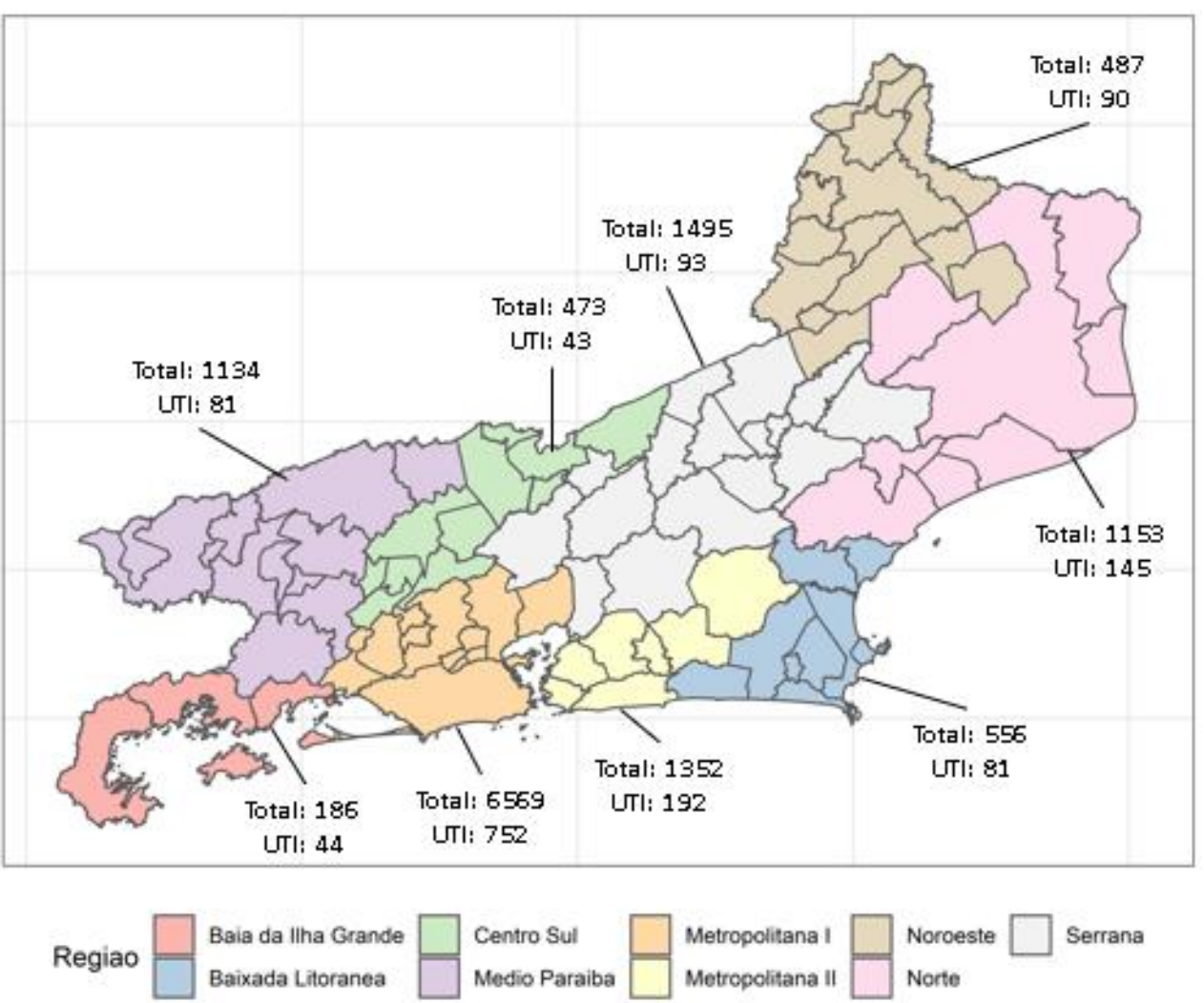

Figura 8 - Leitos SUS no Estado do Rio de Janeiro por região de saúde. Fonte: CNES - fevereiro de 2020.

Frente a esse cenário de limitação de recursos para tratar pacientes com COVID19, o Estado do RJ passou a enfrentar a disseminação da doença no início do mês de Março. Contudo, ela se apresentou de modo diferente ao longo das regiões de saúde.

Na Tabela 1 pode-se observar a taxa de incidência a cada 100 mil habitantes no final dos meses de março e abril.

Tabela 1- Taxa de incidência de COVID-19 por 100 mil habitantes no Estado do RJ

\begin{tabular}{lcc}
\hline Região de Saúde & $30 / 03 / 2020$ & $30 / 04 / 2020$ \\
\hline Baia da Ilha Grande & 0,07 & 2,09 \\
Baixada Litorânea & 0,02 & 2,48 \\
Centro-Sul & 0,03 & 2,35 \\
Médio Paraíba & 0,16 & 3,89 \\
Metropolitana I & 0,54 & 7,11
\end{tabular}




\begin{tabular}{lll} 
Metropolitana II & 0,28 & 4,31 \\
Noroeste & 0,00 & 0,63 \\
Norte & 0,01 & 1,41 \\
Serrana & 0,06 & 2,25 \\
\hline
\end{tabular}

Os primeiros casos de COVID-19 no Estado do RJ surgiram nas regiões de saúde Metropolitana I e Metropolitana II e ao final do mês de abril essas regiões foram as que apresentaram maiores taxas de incidência. Todavia, verifica-se que a doença passou a se disseminar por outras regiões, tendo casos em todas as regiões de saúde no final do mês de abril.

Ao mesmo tempo em que a doença se espalhava pelo Estado, o número de óbitos em razão dela começou a crescer. A Tabela 2 expõe esses números por meio do cálculo da taxa de mortalidade a cada 100 mil habitantes por região de saúde.

Tabela 2- Taxa de mortalidade por COVID-19 por 100 mil habitantes no Estado do RJ

\begin{tabular}{lcc}
\hline Região de Saúde & $30 / 03 / 2020$ & $30 / 04 / 2020$ \\
\hline Baia da Ilha Grande & 0,00 & 0,10 \\
Baixada Litorânea & 0,00 & 0,23 \\
Centro-Sul & 0,03 & 0,18 \\
Médio Paraíba & 0,01 & 0,21 \\
Metropolitana I & 0,01 & 0,67 \\
Metropolitana II & 0,01 & 0,35 \\
Noroeste & 0,00 & 0,03 \\
Norte & 0,00 & 0,13 \\
Serrana & 0,01 & 0,19 \\
\hline
\end{tabular}

Embora a doença já estivesse presente em todas as regiões de saúde do Estado, constata-se que ao final do mês de Março ela não havia provocado óbitos em todas as localidades. No entanto, tal situação não se manteve por muito tempo, dado que é possível perceber que ao final de abril a COVID-19 já havia originado óbitos em todas as regiões de saúde. Porém, ainda apresentava um maior número de falecimentos nas regiões Metropolitana I e Metropolitana II, semelhante ao observado para número de casos confirmados.

Destaca-se ainda a contrariedade existente em relação às recomendações do MS e às afirmações de estudos sobre o tratamento de pacientes com casos leves da doença. Segundo recomendações do MS, no início da pandemia, esse perfil de paciente deveria procurar a rede de Atenção Primária de Saúde onde seria instruído a ficar em isolamento domiciliar, sendo encaminhado para a rede hospitalar apenas em caso de 
agravamento (MS, 2020d, 2020e). Contudo, Zhang et al. (2020) afirmam que essa enfermidade apresenta um histórico de complicações ocorrendo de modo repentino, portanto mesmo os casos leves precisam de constante monitoramento. Ademais, tal prática foi abortada a partir do mês de Junho, sendo recomendada à Atenção Primária o monitoramento da evolução clínica do quadro de todos os pacientes com casos leves (MS, 2020f).

Desse modo, fez-se necessário um planejamento adequado de recursos hospitalares para o combate à doença em cada região de saúde do Estado. Tal planejamento requer a definição da quantidade e do porte dos hospitais necessários para atender demanda do local e o total de recursos - leitos de UTI, leitos de enfermaria e respiradores - a serem alocados nas unidades de saúde.

\subsection{Projeção dos novos casos de COVID-19}

No primeiro momento, foi feita uma previsão dos casos confirmados da COVID19 para o Estado do Rio de Janeiro para o período de 02/05/2020 até 31/05/2020, a partir dos dados históricos disponibilizados em Cota (2020).

Conforme apresentado na seção 3.2.4 do capítulo de procedimentos metodológicos, foram testados dois modelos de séries temporais para prever os novos casos de COVID-19: o modelo de suavização exponencial (do inglês, ETS) e o modelo ARIMA.

O modelo de suavização escolhido foi o ETS(A,A,N). Ele apresenta os seguintes componentes: erro aditivo, tendência aditiva e sem sazonalidade. Já o modelo ARIMA selecionado, segundo a métrica $\operatorname{AIC}$, foi o $\operatorname{ARIMA}(0,1,1)$

A previsão elaborada utilizando os dois modelos para os dias do subconjunto de dados teste pode ser observada a seguir na Figura 9. 


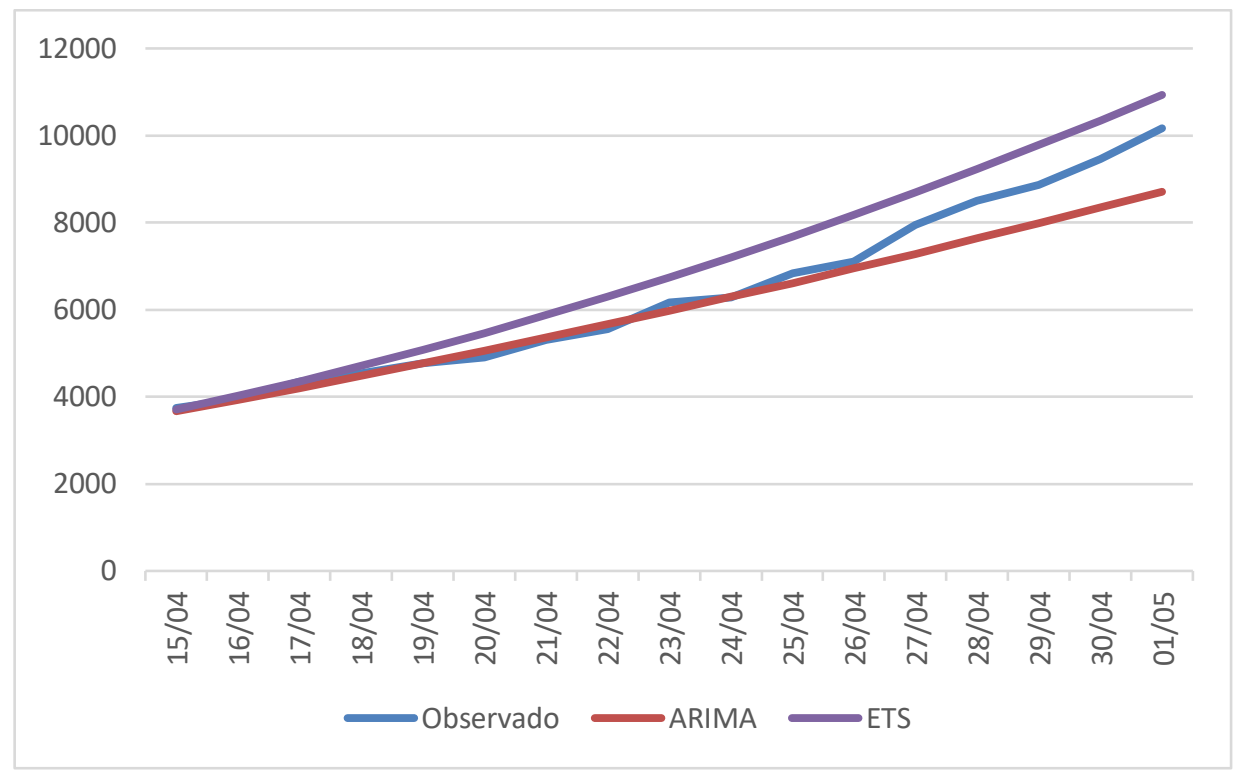

Figura 9 - Comparação dos modelos ARIMA e ETS para o período teste

Fonte: Elaboração própria

Nota-se que o modelo ARIMA obteve melhor performance frente ao modelo encontrado para o modelo ARIMA foi de 4,5\%, enquanto para o modelo ETS o valor da métrica foi de $8,6 \%$.

Portanto, escolheu-se o modelo ARIMA $(0,1,1)$ para realizar a previsão 30 dias à frente (Figura 10). 


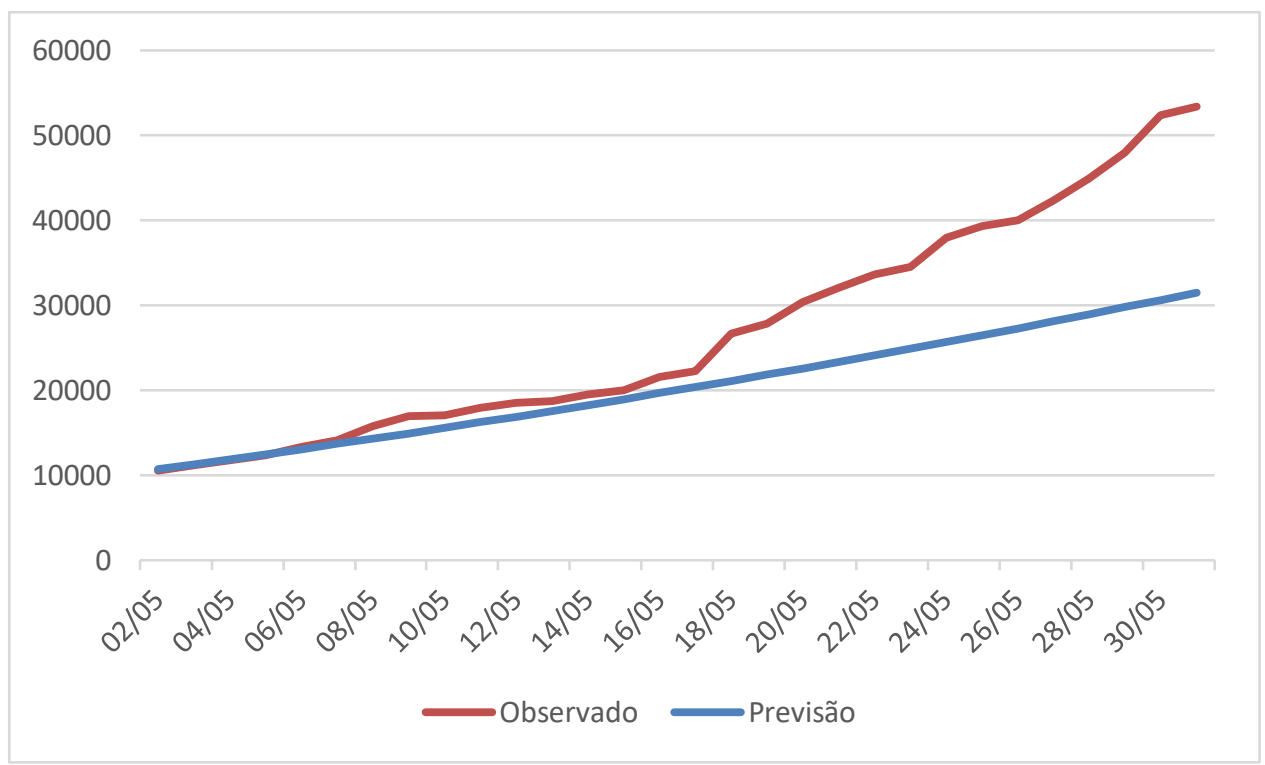

Figura 10 - Previsão de casos cumulados de COVID-19 no Estado do Rio de Janeiro em maio Fonte: Elaboração própria

O MAPE encontrado foi de 18\%. Destaca-se que o aumento do erro percentual no final do horizonte de previsão é explicado em razão do aumento da incerteza presente no longo período analisado e da própria dinâmica da doença.

Em razão da dificuldade de compreensão do comportamento da doença em cada município, causado pela ausência de histórico na maioria das localidades - o Estado possui 92 municípios, 82 desses já haviam reportado casos, porém somente 17 deles já apresentavam mais de 50 casos acumulados em 01/05/2020 - e inexistência de casos confirmados de COVID-19 em nove deles, optou-se por projetar o número de casos para o Estado.

Dessa forma, para os novos casos por município considerou-se a proporção da projeção encontrada para o Estado (Apêndice II). Para aqueles municípios que ainda não haviam notificado casos confirmados de COVID-19, considerou-se o menor valor reportado entre os municípios de sua região de saúde.

\section{3}

\section{Estimativa da necessidade de recursos}

De acordo com o painel de leitos do MS (2020g), o qual foi divulgado apenas no mês de julho, em abril havia 72 UTIs públicas com leitos adultos habilitados para 
COVID-19, sendo 30 leitos na região de saúde Médio Paraíba e 10 leitos na Metropolitana II.

A Figura 11 exibe as etapas percorridas para estimar o total de internações em hospitais públicos, sejam em leitos de UTI ou de enfermaria, e uso de VMI no Estado do RJ.

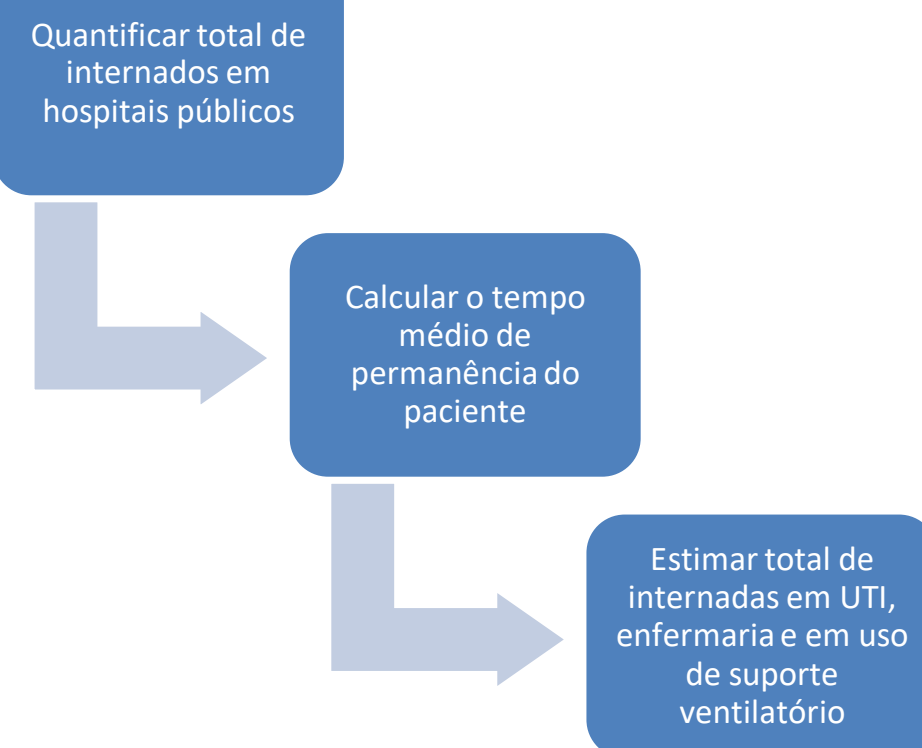

Figura 11 - Etapas da estimação de recursos Fonte: Elaboração própria.

\subsection{1 \\ Total de internados em hospitais públicos}

A estimativa dos recursos iniciou-se pela seleção das notificações SRAG em hospitais públicos, entendidos aqui como hospitais de administração pública abertos para atendimento pelo SUS conforme registro no CNES.

Os critérios de classificação adotados foram validados por especialistas na área e podem ser consultados no Apêndice III do documento.

\subsection{2 \\ Tempo médio de permanência}

Com base nas 4543 internações com notificações SRAG realizadas no ano de 2020 e com data de entrada até o dia 30/04/2020, elaborou-se a separação dessas hospitalizações segundo o tipo de leito. A Figura 12 mostra os filtros realizados na 
base de dados para identificar o volume de pacientes internados em UTI e em enfermaria até 30/04/2020.

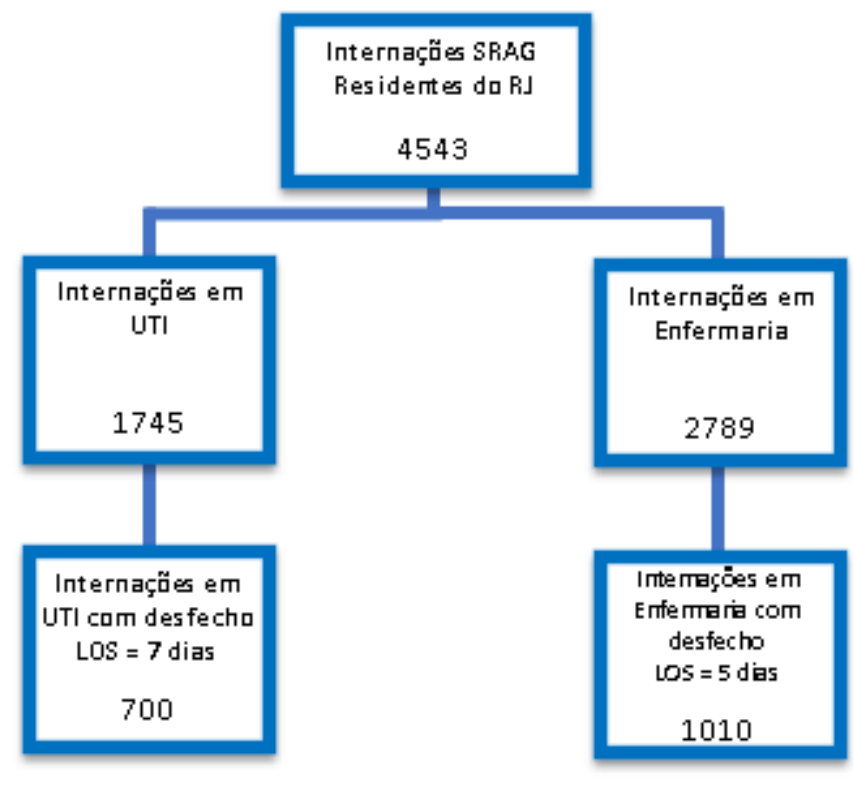

Figura 12 - Internações SRAG até 30/04/2020 Fonte: Elaboração própria.

Percebe-se que 700 internações em UTI tiveram desfecho durante o período analisado e essas apresentaram um tempo médio de permanência de sete dias. Da mesma forma, para as internações em leitos de enfermaria descobriu-se que 1010 tiveram desfecho no intervalo de tempo estudado com uma média de permanência no leito de cinco dias.

De forma análoga, separou-se as hospitalizações que realizaram uso de suporte ventilatório invasivo. A Figura 13 exibe o total de pacientes em VMI que se encontravam na UTI ou fora dela que utilizaram o dispositivo respiratório. 


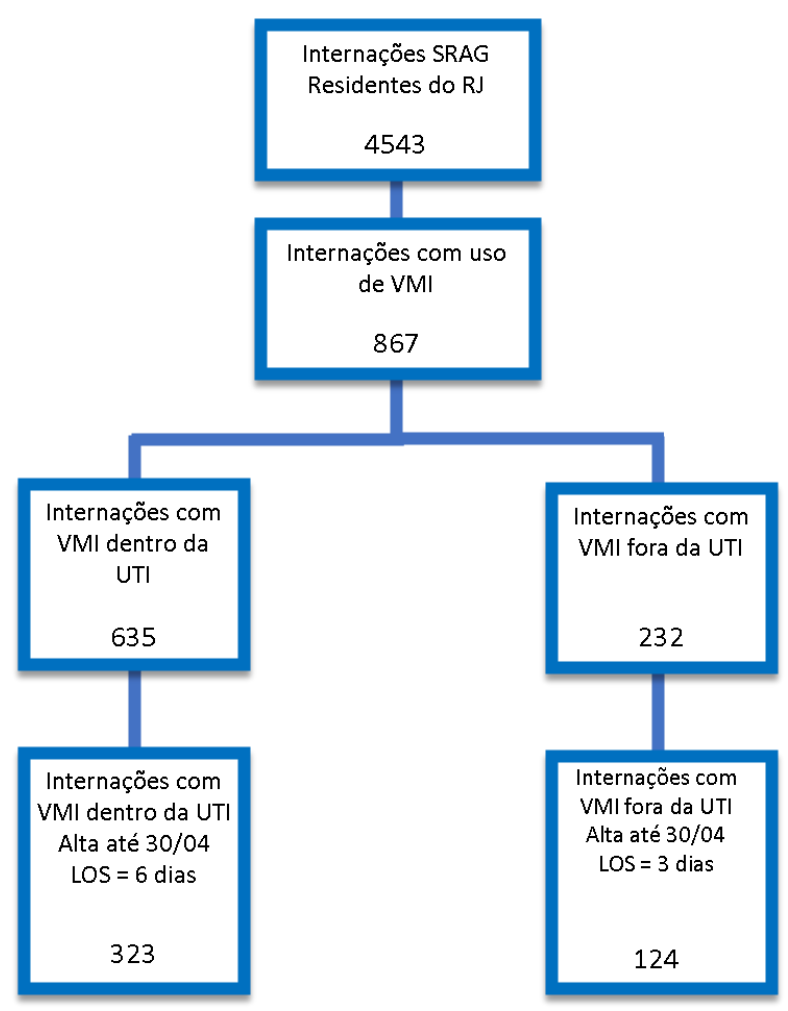

Figura 13 - Internações SRAG até 30/04/2020 Fonte: Elaboração própria.

Identifica-se que das internações com desfecho até 30/04/2020, 323 dos pacientes utilizaram VMI durante a sua internação na UTI e 124 fizeram uso do recurso fora da terapia intensiva. Os tempos médios de internações encontrados foram de seis e três dias, respectivamente.

\subsection{3}

Estimativa do total de internados em UTI, em enfermaria e em uso de suporte ventilatório

A partir dos tempos médios de permanência obtidos pelo histórico de internações notificadas como SRAG, foi possível estimar o total de pacientes utilizando cada um dos recursos analisados por dia.

A estimativa de casos de internação por dia é resultado das informações de tempo de permanência esperado, da projeção de novos casos diários confirmados da doença e do número de hospitalizados em terapia intensiva, enfermaria ou em uso de suporte ventilatório. A Figura 14 apresenta um exemplo numérico dos resultados da estimação, que apresenta a quantidade de internações esperadas entre os dias 06/março e 15/março. 


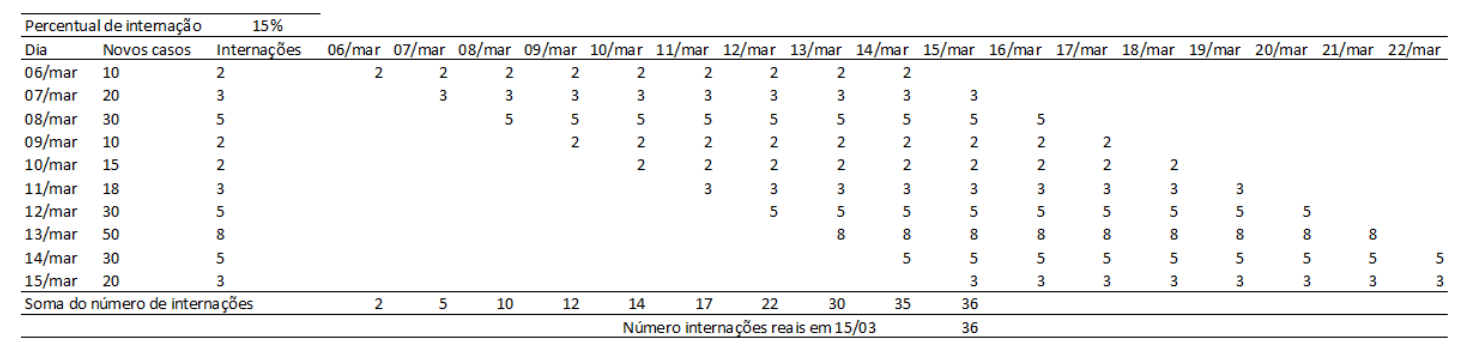

Figura 14 - Exemplo numérico da estimativa de internação em UTI Fonte: Elaboração própria.

No exemplo, observa-se os novos casos a partir do dia 06/março e sabe-se que no dia 15/março o número real de internações em UTI é 36. Além disso, sabe-se que o tempo médio de internação de 9 dias (a partir dos dados de notificação SRAG). Com isso, é possível calcular qual seria o percentual de internações para que seja atingido um número similar a 36, que, no exemplo, foi de $15 \%$.

Portanto, interpreta-se: para que se tenha 36 internações no dia 15/março, a taxa de internação média dos novos casos diários deveria ser de 15\%, a partir de um tempo médio de internação de 9 dias.

Repete-se a estimativa de modo similar para cada um dos recursos, considerando os valores de tempo de permanência encontrados na etapa anterior.

Para a estimativa de leitos de UTI considerou-se além dos pacientes internados em UTI, aqueles que utilizaram de suporte ventilatório invasivo fora da terapia intensiva, já que não houve leitos suficientes para atender toda a demanda por internações em UTI (GOULART, 2020). De modo semelhante as internações em UTI, o total de demanda de VMI estimada é resultado da estimação de paciente em suporte ventilatório dentro da UTI acrescida da estimação de pacientes que utilizaram VMI fora da UTI.

Os resultados encontrados para a estimativa de leitos de UTI, uso VMI (dentro e fora da UTI) e leitos de enfermaria encontram-se nos Apêndices IV, V, VI e VII, respectivamente.

\section{4}

\section{Resultados da estimativa de recursos}

A partir da projeção de novos casos confirmados de COVID-19 para o Estado do RJ, calculou-se a demanda por leitos de UTI, leitos de enfermaria e ventiladores mecânicos a cada dia no Estado. 


\subsection{1}

Internações em UTI no Estado do Rio de Janeiro

A Figura 15 apresenta o total de internações em UTI estimada para o período de 02/05/2020 até 31/05/2020 no Estado do Rio de Janeiro.

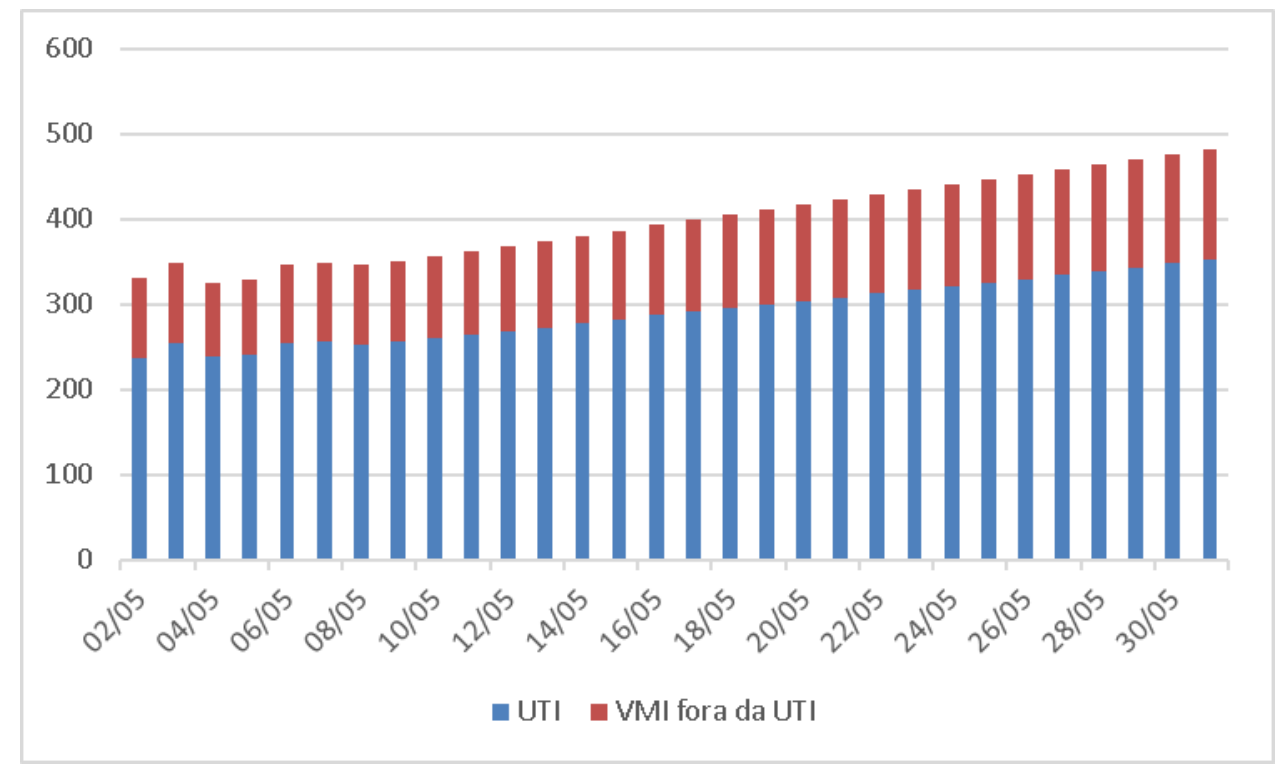

Figura 15 - Demanda estimada de internações em UTI Fonte: Elaboração própria.

A Figura 16 compara o que foi estimado de internações em UTI no Estado do Rio de Janeiro para o período de 02/05/2020 até 31/05/2020.

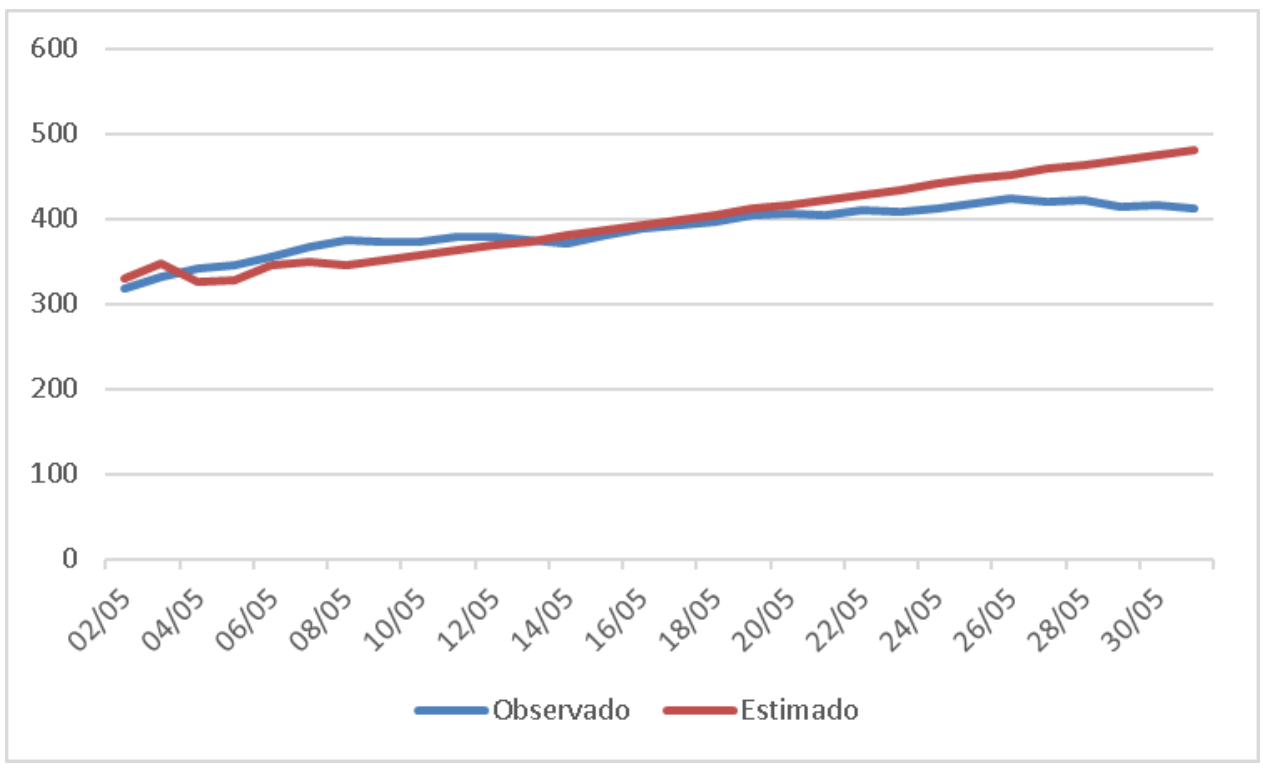


Figura 16 - Comparação entre os resultados estimados e observados para Internações em leitos de UTI no mês de maio

Fonte: Elaboração própria.

O MAPE encontrado foi de 5,5\%, com uma estimação máxima de 482 pacientes internados em UTI simultaneamente. Ademais, a demanda de leitos de UTI distribuída por município pode ser encontrada no Apêndice VIII.

\subsection{2}

Uso de Ventilação Mecânica Invasiva no Estado do RJ

A demanda estimada de VMI para o período de 02/05 até 31/05 pode ser observada na Figura 17.

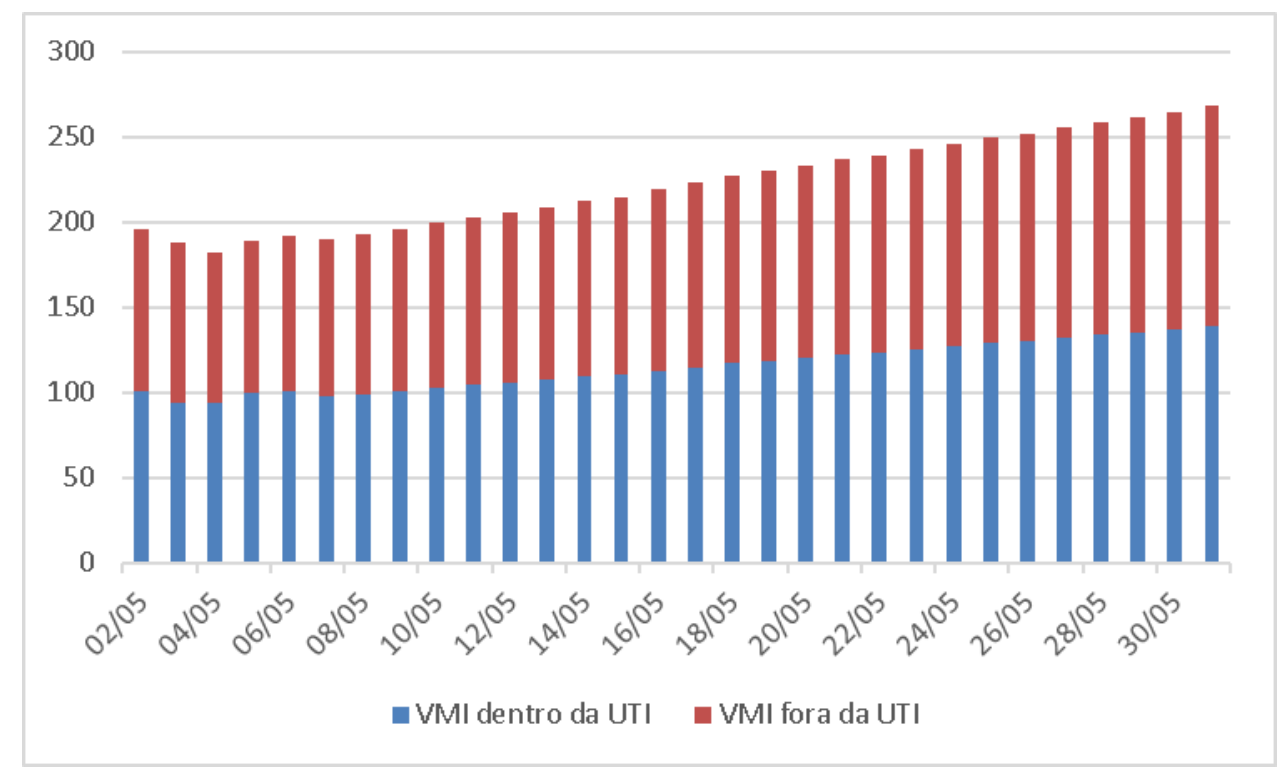

Figura 17 - Demanda estimada de uso de VMI Fonte: Elaboração própria.

A Figura 18 exibe os valores observados e estimados de pacientes em uso de VMI independentemente do tipo de leito de internação. 


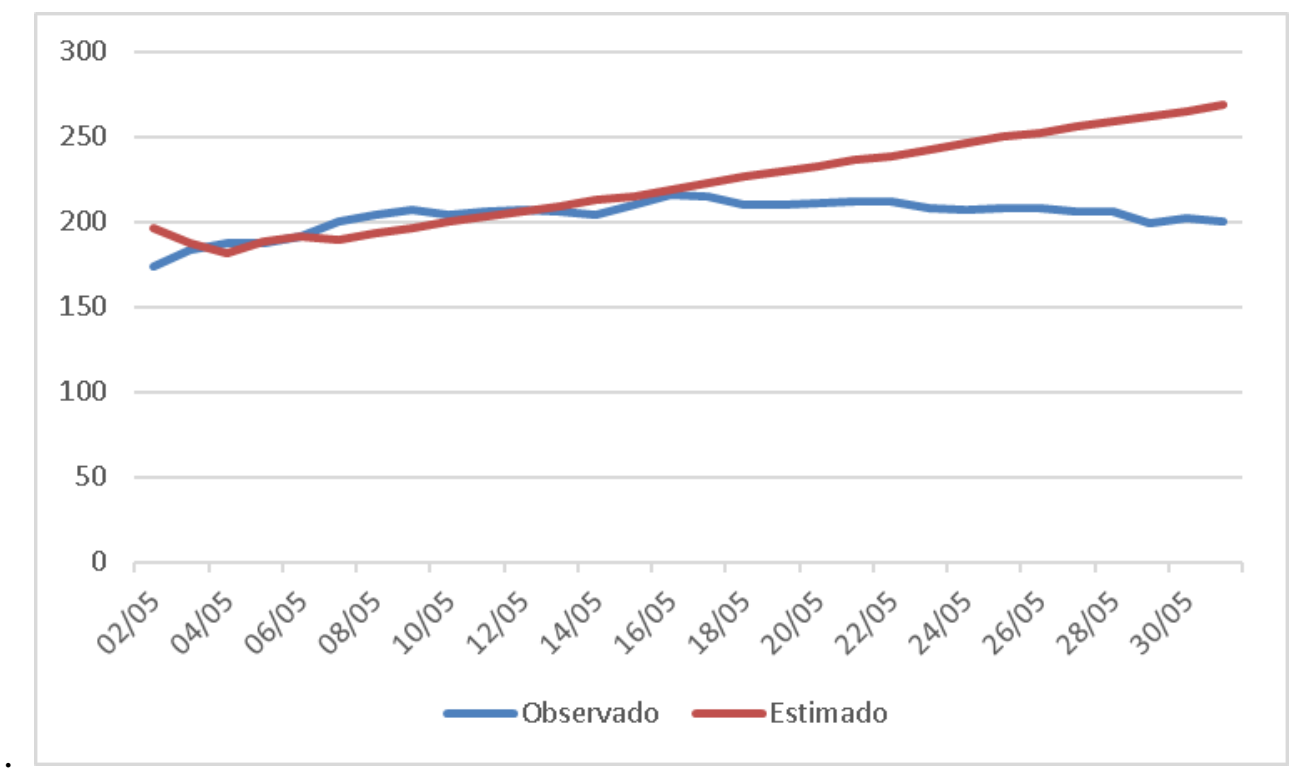

Figura 18 - Comparação entre os resultados estimados e observados para uso de VMI em maio Fonte: Elaboração própria.

O MAPE encontrado foi de 10,9\% com um valor máximo estimado de 269 pacientes em VMI conjuntamente. A demanda por uso de VMI distribuída por municípios do Estado do RJ está localizada no Apêndice IX deste documento.

\subsection{3 \\ Internações em enfermaria no Estado do RJ}

A estimativa de demanda de internações em leitos de enfermaria pode ser observada a seguir na Figura 19. 


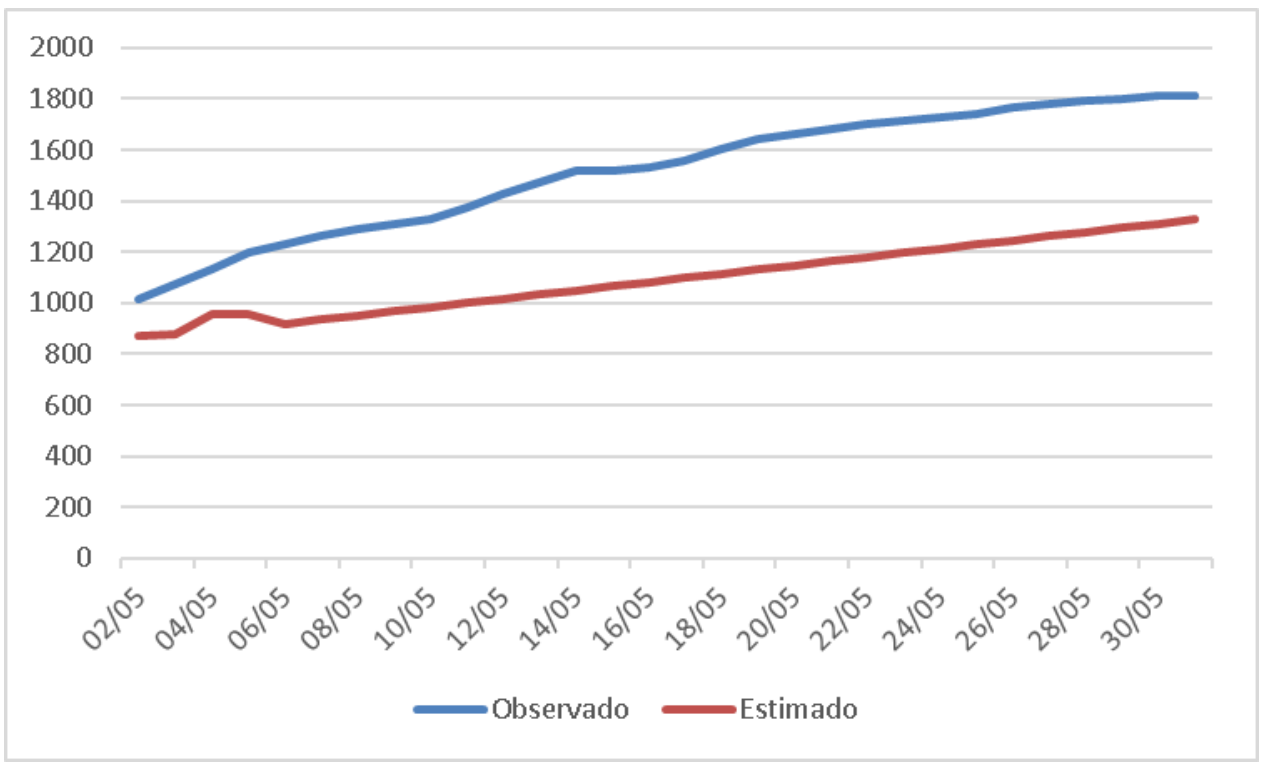

Figura 19 - Comparação entre os resultados estimados e observados para internações em leitos de enfermaria no mês de maio Fonte: Elaboração própria.

O MAPE encontrado foi de 20,1\%, com um total máximo de 1425 pacientes internados em enfermaria. A demanda de leitos de enfermaria disposta por município pode ser encontrada no Apêndice X.

Sendo assim, conclui-se que de acordo com a estimativa proposta serão necessários um total de 482 leitos de UTI, 1328 leitos de enfermaria e 269 ventiladores mecânicos invasivos. A partir dessa projeção, calculou-se a distribuição proporcional pelos municípios chegando a uma estimação da necessidade de recursos - leitos de UTI, de enfermaria e VMI - para cada localidade (Apêndices VIII, IX, e X, respectivamente), os quais serão considerados como a demanda do modelo de otimização.

\section{5}

\section{Comparação da estimativa com a real utilização dos recursos}

A partir dos resultados uso de recursos estimados, elaborou-se a comparação entre eles e a efetiva utilização dos mesmos durante o período. Para isso, consultou-se o histórico de hospitalizações notificadas como SRAG. 


\subsection{1}

\section{Internações em UTI no Estado do RJ}

A Tabela 3 apresenta o máximo de internações de SRAG observadas segundo o local de residência do paciente e a ocupação máxima estimada, sendo todos categorizados por região de saúde.

Tabela 3 - Comparação das internações de SRAG em UTI por região de saúde

\begin{tabular}{lcc} 
Região de Saúde & $\begin{array}{c}\text { Máximo de } \\
\text { internações SRAG } \\
\text { em UTI }\end{array}$ & $\begin{array}{c}\text { Máxima ocupação } \\
\text { estimada } \\
\text { em UTI }\end{array}$ \\
\hline Baia da Ilha Grande & 1 & 2 \\
Baixada Litorânea & 33 & 12 \\
Centro-Sul & 8 & 3 \\
Médio Paraíba & 11 & 17 \\
Metropolitana I & 254 & 376 \\
Metropolitana II & 67 & 48 \\
Noroeste & 3 & 1 \\
Norte & 21 & 7 \\
Serrana & 26 & 11 \\
\hline Total & 424 & 477 \\
\hline
\end{tabular}

Constata-se que a demanda total máxima estimada de ocupação de leitos de UTI, foi de 403 , indicando um erro percentual de 5\% frente ao máximo de internações ocorridas no mês de maio.

\subsection{2}

\section{Demanda de uso de VMI no Estado do RJ}

Em seguida, confrontou-se a máxima utilização ocorrida de ventiladores mecânicos de pacientes com SRAG com a estimativa máxima elaborada para o mês de maio, agregando-as por região de saúde (Tabela 4).

\begin{tabular}{lcc}
\multicolumn{2}{c}{ Tabela 4 - Comparação do uso de VMIs por pacientes com SRAG por região de saúde } \\
Máximo de \\
Região de Saúde & $\begin{array}{c}\text { Macientes com } \\
\text { SRAG em VMI }\end{array}$ & $\begin{array}{c}\text { Máxima utilização } \\
\text { estimada de VMI }\end{array}$ \\
\hline Baia da Ilha Grande & 1 & 1 \\
Baixada Litorânea & 13 & 6 \\
Centro-Sul & 2 & 3 \\
Médio Paraíba & 4 & 10 \\
Metropolitana I & 134 & 208 \\
Metropolitana II & 37 & 27 \\
Noroeste & 0 & 0
\end{tabular}




\begin{tabular}{lcc} 
Norte & 8 & 3 \\
Serrana & 17 & 5 \\
\hline Total & 216 & 263 \\
\hline
\end{tabular}

Observa-se que foi proposta uma necessidade máxima de 214 VMIs para todo o Estado do RJ, representando um erro percentual de $1 \%$.

\subsection{3 \\ Internações em enfermaria no Estado do RJ}

De forma análoga à seção anterior, elaborou-se a análise das internações em leitos de enfermaria. A Tabela 5 retrata o valor máximo de internações para o SRAG em leitos de enfermaria observadas e esperadas por região de saúde no mês de maio.

Tabela 5 - Comparação das internações de SRAG em leitos de enfermaria por região de saúde

\begin{tabular}{cc}
$\begin{array}{c}\text { Máximo de } \\
\text { internações SRAG } \\
\text { em enfermaria }\end{array}$ & $\begin{array}{c}\text { Máxima ocupação } \\
\text { estimada em } \\
\text { enfermaria }\end{array}$ \\
\hline 10 & 8 \\
100 & 31 \\
16 & 13 \\
46 & 47 \\
1315 & 1031 \\
262 & 135 \\
18 & 2 \\
92 & 20 \\
56 & 29 \\
\hline 1915 & 1316 \\
\hline
\end{tabular}




\section{Modelo Matemático}

Esta seção apresenta o modelo matemático desenvolvido para localizar os hospitais de campanha no Estado do Rio de Janeiro e alocar os seguintes recursos: leitos de UTI, leitos de enfermaria e Ventiladores Mecânicos Invasivos (VMIs). Posteriormente, é exposta a aplicação do modelo, com os resultados encontrados para solucionar o problema. Por fim, mostra-se a comparação dos resultados encontrados com o que de fato ocorreu.

\section{1}

\section{Equacionamento}

O objetivo do modelo matemático é minimizar a distância percorrida pelos pacientes e o custo de instalação do hospital de campanha. As decisões estão sujeitas a restrições relacionadas ao atendimento da demanda e à capacidade ofertada. A Tabela 6 apresenta os domínios associados aos atributos definidos no modelo, enquanto as Tabelas 7 e 8 exibem as definições de parâmetros e variáveis, respectivamente.

Tabela 6 - Conjuntos e seus domínios correspondentes

\begin{tabular}{|l|l|c|l|}
\hline \multicolumn{1}{|c|}{ Conjuntos } & Índices & \multicolumn{1}{c|}{ Domínios } & \multicolumn{1}{c|}{ Descrição } \\
\hline Município (L) & $1,1 \mathrm{l}$ & $\{1, \ldots,|\mathrm{L}|\}$ & Município do estado do Rio de Janeiro \\
\hline Tempo (T) & t & $\{1, \ldots,|\mathrm{T}|\}$ & Momento do planejamento \\
\hline Hospital (H) & h & $\{1, \ldots,|\mathrm{H}|\}$ & $\begin{array}{l}\text { Tipo de hospital de acordo com o seu } \\
\text { porte }\end{array}$ \\
\hline Recurso (R) & r & $\{1, \ldots,|\mathrm{R}|\}$ & $\begin{array}{l}\text { Tipo de recurso demandado pelo } \\
\text { paciente }\end{array}$ \\
\hline
\end{tabular}

Tabela 7 - Parâmetros do modelo

\begin{tabular}{|c|c|c|}
\hline Parâmetros & Descrição & Unidade \\
\hline
\end{tabular}




\begin{tabular}{|c|c|c|}
\hline Demanda $_{1, t, r}$ & $\begin{array}{l}\text { Pacientes com SRAG no município de origem } 1 \\
\text { que no período } t \text { demanda o recurso } r\end{array}$ & - \\
\hline Distancia $_{1,11}$ & Distância entre os municípios 1 e 11 & $\mathrm{~km}$ \\
\hline Capac_Adicional $_{\mathrm{h}, \mathrm{r}}$ & $\begin{array}{l}\text { Quantidade de recurso } \mathrm{r} \text { presente no hospital do } \\
\text { porte } \mathrm{h}\end{array}$ & - \\
\hline Custo_Hospital $_{\mathrm{h}}$ & Custo de instalação do hospital do porte $\mathrm{h}$ & $\mathrm{R} \$$ \\
\hline $\mathrm{W}$ & Parâmetro de ajuste da função objetivo & - \\
\hline
\end{tabular}

Tabela 8 - Variáveis do modelo

\begin{tabular}{|l|l|l|}
\hline Variáveis & \multicolumn{1}{|c|}{ Descrição } & Domínio \\
\hline $\mathrm{X}_{\mathrm{l}, \mathrm{ll}, \mathrm{t}, \mathrm{r}}$ & $\begin{array}{l}\text { Quantidade de pacientes com SRAG residentes do } \\
\text { município de origem l que são internados no município de } \\
\text { destino ll no período t e que demandam o recurso r }\end{array}$ & $\mathbb{Z}_{+}$ \\
\hline $\mathrm{Y}_{\mathrm{ll}, \mathrm{t}, \mathrm{h}}$ & $\begin{array}{l}\text { Decisão se o hospital de porte h é instalado no município ll } \\
\text { no período t }\end{array}$ & $\{0,1\}$ \\
\hline Yacum $_{\mathrm{ll}, \mathrm{t}, \mathrm{h}}$ & $\begin{array}{l}\text { Quantidade de hospitais de porte h instalados no município } \\
\text { ll no período t }\end{array}$ & $\mathbb{Z}_{+}$ \\
\hline
\end{tabular}

O modelo foi desenvolvido para avaliar a necessidade dos seguintes recursos: leitos de UTI, leitos de enfermaria e ventilador mecânico invasivo, dentre os dias 02/05/2020 e 31/05/2020. A escolha pelo período apontado deve-se pela estimativa de se atingir o maior número de casos acumulados de COVID-19 nesse mês (CRODA et al., 2020). Para o conjunto Hospital (H) foram considerados os diferentes tipos de hospitais planejados para o estado conforme contrato da SESRJ, com seus respectivos custos e quantidades de leitos (Tabela 9).

Tabela 9 - Perfil dos hospitais de campanha

\begin{tabular}{lcccc}
\multicolumn{1}{c}{ Hospital } & $\begin{array}{c}\text { Leitos } \\
\text { de } \\
\text { UTI }\end{array}$ & $\begin{array}{c}\text { Leitos de } \\
\text { Enfermaria }\end{array}$ & $\begin{array}{c}\text { Ventilador } \\
\text { Mecânico } \\
\text { Invasivo }\end{array}$ & Custo \\
\hline A - Duque de Caxias & 40 & 160 & 40 & $\mathrm{R} \$ 119.396 .058,54$ \\
B - Parque dos Atletas & 50 & 150 & 50 & $\mathrm{R} \$ 119.396 .058,54$ \\
C - Leblon & 100 & 100 & 100 & $\mathrm{R} \$ 119.396 .058,54$ \\
D - Nova Iguaçu & 120 & 180 & 120 & $\mathrm{R} \$ 179.094 .087,81$ \\
E - Maracanã & 160 & 240 & 160 & $\mathrm{R} \$ 238.792 .117,08$ \\
\hline
\end{tabular}


A demanda diária de internação e de uso de VMI foi calculada a partir do produto entre a estimativa de cada recurso e a taxa de representatividade proporcional de cada município, comentada no tópico 4.2 deste documento. $\mathrm{O}$ parâmetro Capac_Adicional $_{\mathbf{h}, \mathbf{r}}$ retrata o número de hospitais de determinado porte com leitos de UTI, de enfermaria e ventiladores mecânicos que serão implementados com base na decisão de instalação.

Ressalta-se que o contrato firmado pela SESRJ não menciona o total de ventiladores exigidos. Deste modo considerou-se que estará disponível um ventilador por leito de UTI.

Destaca-se que em razão da alta taxa de ocupação de leitos antes do início da pandemia, preferiu-se desconsiderar a capacidade existente.

A formulação matemática proposta é a seguinte:

\section{Função objetivo}

$$
\begin{aligned}
\text { Minimizar } & \left(\sum_{c} \sum_{t} \sum_{l l} \sum_{l} X_{l, l l, t, r} \text { Distancia }_{l, l l}\right) \\
+ & W \cdot \sum_{h} \sum_{t} \sum_{l} \text { Custo_Hospital }_{h} Y_{l, t, h}
\end{aligned}
$$

\section{Sujeito a}

$$
\begin{array}{ll}
\sum_{l l} X_{l, l l, t, r} \geq \text { Demanda }_{l, t, r} & \forall l \in \mathrm{L}, \forall \mathrm{t} \in \mathrm{T}, \forall \mathrm{r} \in \mathrm{R} \\
\sum_{l} X_{l, l l, t, r} \leq \sum_{h} \text { Capac }_{\text {Adicional }_{h, r} \text { Yacum }_{l l \mid} \mid l l \text { in Municipios }, t, h} & \forall l l \in \mathrm{L}, \forall \mathrm{t} \in \mathrm{T}, \forall \mathrm{r} \in \mathrm{R} \\
\text { Yacum }_{l l, t, h}=\sum_{t t \mid t t \leq t} Y_{l l \mid l l \text { in Municipios }, t, h} & \forall l l \in \mathrm{L}, \forall \mathrm{t} \in \mathrm{T}, \forall \mathrm{r} \in \mathrm{R}
\end{array}
$$

A função objetivo em (5.1) minimiza a distância percorrida pelos pacientes até o hospital e o custo de instalação do hospital de campanha. A restrição (5.2) define 
que a demanda de pacientes seja completamente atendida e em (5.3) temos a garantia de que a quantidade de recursos ofertada possibilite tal atendimento. A restrição (5.4) estabelece a quantidade total de hospitais instalados a cada tempo.

$\mathrm{Na}$ formulação matemática considerou-se as seguintes premissas: há a possibilidade de pacientes oriundos do mesmo município receberem tratamento em locais diferentes, a depender da disponibilidade dos recursos no momento considerado; e somente $20 \%$ dos municípios com o maior número de casos novos seriam opções de localização dos hospitais de campanha (Apêndice XI). Ademais, foi acrescentado à função objetivo o parâmetro $W$ a fim de avaliar o trade-off a distância percorrida pelos pacientes e o custo de instalação do hospital.

O modelo matemático foi implementado usando o software AIMMS 3.14 e o solver CPLEX 12.6. As análises estatísticas foram processadas no software R versão 4.0.1. As informações referentes à execução do modelo encontram-se no Apêndice XII.

\section{2 \\ Resultados do modelo}

A primeira solução encontrada apresenta uma solução com equivalência entre a distância percorrida e o custo de instalação (Caso Base). A partir dela definiu-se mais três casos para avaliar o melhor cenário de planejamento que seja compatível com possíveis limitações e restrições deparadas pelo tomador de decisão.

\subsection{1}

\section{Caso Base}

A solução ótima encontrada para o modelo proposto tem como resposta a instalação de 18 hospitais de campanha no mês de maio, estando presente em 14 dos 92 municípios existentes no estado. O resultado disposto por município é descrito na Tabela 10.

Tabela 10 - Localização dos Hospitais de Campanha para o caso base

\begin{tabular}{lcccccc} 
Localização do Hospital & $\begin{array}{c}\text { Hospital } \\
\text { A }\end{array}$ & $\begin{array}{c}\text { Hospital } \\
\text { B }\end{array}$ & $\begin{array}{c}\text { Hospital } \\
\text { C }\end{array}$ & $\begin{array}{c}\text { Hospital } \\
\text { D }\end{array}$ & $\begin{array}{c}\text { Hospital } \\
\text { E }\end{array}$ & $\begin{array}{c}\text { Total de } \\
\text { Hospitais }\end{array}$ \\
\hline Belford Roxo & 0 & 1 & 0 & 0 & 0 & 1 \\
Cabo Frio & 1 & 0 & 0 & 0 & 0 & 1 \\
Campos dos Goytacazes & 1 & 0 & 0 & 0 & 0 & 1 \\
Duque de Caxias & 0 & 0 & 1 & 0 & 0 & 1 \\
Itaboraí & 1 & 0 & 0 & 0 & 0 & 1
\end{tabular}




\begin{tabular}{|c|c|c|c|c|c|c|}
\hline Magé & 1 & 0 & 0 & 0 & 0 & 1 \\
\hline Maricá & 0 & 0 & 1 & 0 & 0 & 1 \\
\hline Niterói & 1 & 0 & 0 & 0 & 0 & 1 \\
\hline Nova Friburgo & 1 & 0 & 0 & 0 & 0 & 1 \\
\hline Nova Iguaçu & 0 & 1 & 0 & 0 & 0 & 1 \\
\hline Petrópolis & 1 & 0 & 0 & 0 & 0 & 1 \\
\hline Rio de Janeiro & 3 & 1 & 0 & 0 & 1 & 5 \\
\hline São Gonçalo & 1 & 0 & 0 & 0 & 0 & 1 \\
\hline Volta Redonda & 1 & 0 & 0 & 0 & 0 & 1 \\
\hline Total & 12 & 3 & 2 & 0 & 1 & 18 \\
\hline
\end{tabular}

É possível notar que nem todos os tipos de hospitais propostos foram selecionados pelo modelo, sendo necessários 12 do tipo $\mathrm{A}, 3$ do tipo $\mathrm{B}, 2$ do tipo $\mathrm{C}$ e 1 do tipo E. Percebe-se que a maior parte dos hospitais serão de menor porte (Hospitais A e B), porém a cidade do Rio de Janeiro necessitará do maior hospital possível.

A Figura 20 exibe a distribuição dos hospitais de campanha pelo Estado com base nas regiões de saúde. Nela é possível perceber que seis das nove regiões de saúde devem instalar pelo menos um hospital.
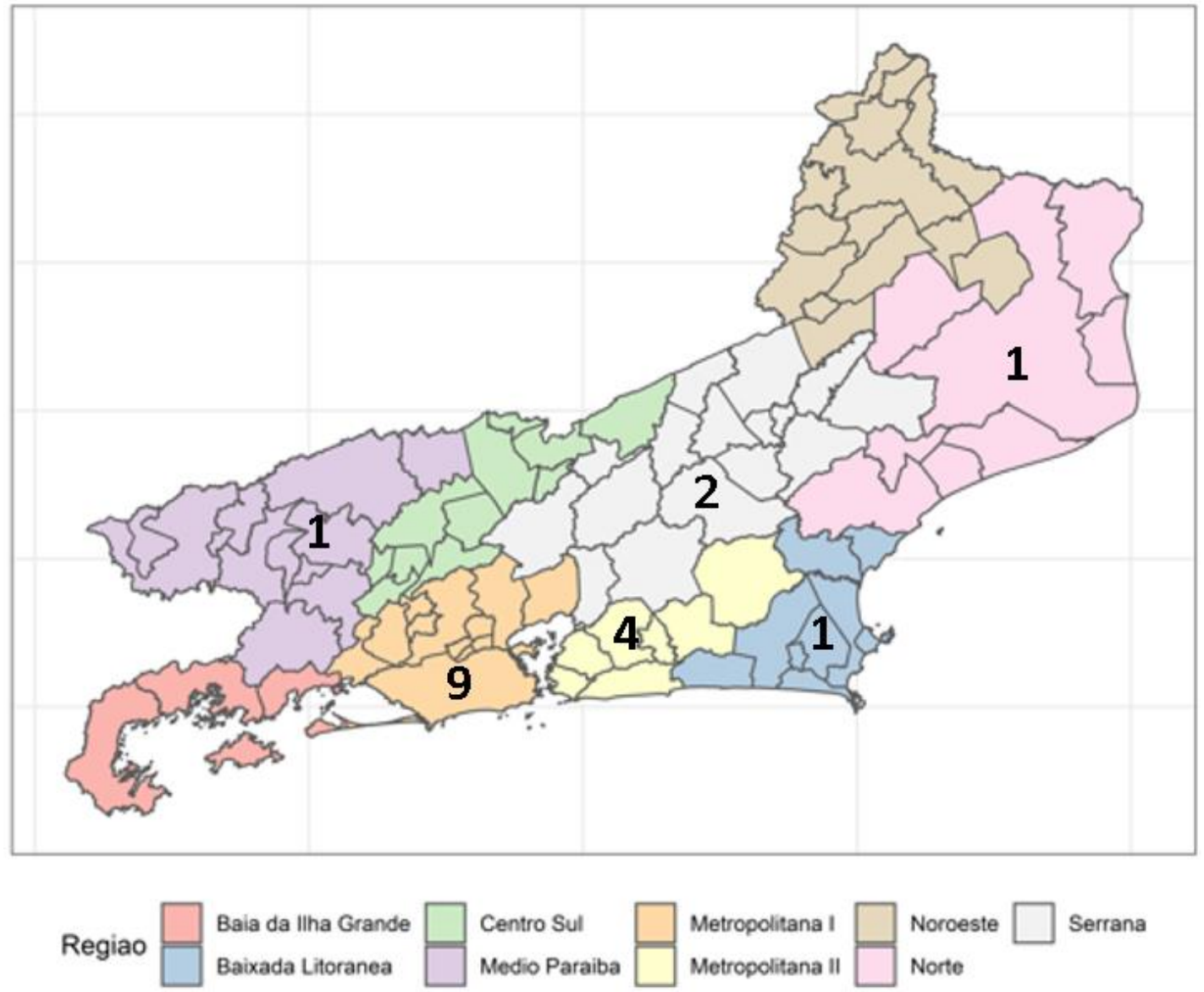

Figura 20 - Distribuição dos Hospitais de Campanha por Região de Saúde para o caso base

Pode-se observar que a região de saúde Metropolitana I apresenta uma maior concentração de hospitais, seguida da região Metropolitana II. Este fato pode ser 
explicado pela ocorrência de número de casos nas regiões mencionadas, os quais espera-se que ocasione um maior estresse do sistema de saúde em comparação com aqueles municípios onde a doença ainda não atingiu altos níveis de transmissibilidade.

A Tabela 11 apresenta a alocação dos recursos para cada um dos municípios que apresentarão hospitais de campanha. 
Tabela 11 - Utilização e capacidade de recursos para o caso base

\begin{abstract}
UTI
\end{abstract}
Localização do Hospital

Belford Roxo
Cabo Frio
Campos dos Goytacazes
Duque de Caxias
Itaboraí
Magé
Maricá
Niterói
Nova Friburgo
Nova Iguaçu
Petrópolis
Rio de Janeiro
São Gonçalo
Volta Redonda

Volta Redonda

Total

VMI

Capacidade

$50 \quad$ Utilizaçã

Enfermaria

$22 \quad 50 \quad 12$

1140

$6 \quad 40$

$21 \quad 100$

$13 \quad 40$

$8 \quad 40$

$5 \quad 100$

$22 \quad 40$

$5 \quad 40$

$36 \quad 50$

$6 \quad 40$

$\begin{array}{cc}6 & 40 \\ 13 & 330\end{array}$

$13 \quad 40$

$\begin{array}{ccc}290 & 330 & 7 \\ 13 & 40 & 11 \\ 19 & 40 & 263\end{array}$

$477 \quad 990 \quad 263$

\begin{tabular}{l} 
zação \\
12 \\
5 \\
2 \\
12 \\
7 \\
4 \\
3 \\
11 \\
3 \\
19 \\
4 \\
163 \\
7 \\
11 \\
263 \\
\hline
\end{tabular}

$40-60$

$\begin{array}{ll}40 & 29 \\ 40 & 16\end{array}$

$\begin{array}{cc}40 & 16 \\ 100 & 57\end{array}$

$\begin{array}{cc}100 & 57 \\ 40 & 36\end{array}$

$\begin{array}{ll}40 & 36 \\ 40 & 22\end{array}$

$\begin{array}{ll}400 & 15\end{array}$

$\begin{array}{cc}100 & 15 \\ 40 & 53 \\ 40 & 13\end{array}$

$\begin{array}{ll}40 & 13 \\ 50 & 96\end{array}$

$\begin{array}{ll}50 & 96 \\ 40 & 20\end{array}$

$\begin{array}{ll}40 & 20 \\ 330 & 807\end{array}$

40

40
40

40

\begin{tabular}{lc} 
ização & Capacidade \\
\hline 60 & 150 \\
29 & 160 \\
16 & 160 \\
57 & 100 \\
36 & 160 \\
22 & 160 \\
15 & 100 \\
53 & 160 \\
13 & 160 \\
96 & 150 \\
20 & 160 \\
807 & 870 \\
36 & 160 \\
56 & 160 \\
\hline 316 & 2810 \\
\hline
\end{tabular}


A capacidade total instalada proposta pelo modelo matemático foi de 990 leitos de UTI, 990 VMIs e 2810 leitos de enfermaria. Todavia, a utilização máxima estimada é de 477 leitos de UTI, 263 VMIs e 1316 leitos de enfermaria. A alocação dos recursos diária por município pode ser consultada nos Apêndices XIII, XIV e XV.

Observa-se que a utilização estimada dos leitos foi bem inferior à capacidade alocada em cada hospital. Isso se deve a dois fatos: os modelos de hospitais estabelecidos pela SESRJ têm portes excessivamente grandes e para o modelo matemático não há diferença de escolha entre os modelos $\mathrm{A}, \mathrm{B}$ e C, pois esses possuem o mesmo custo de instalação.

Dessa forma, identifica-se que para Campos dos Goytacazes foi localizado um hospital com a menor capacidade possível (40 leitos), porém essa capacidade é muito superior à demanda esperada a ser atendido por esse município ( 6 pacientes).

Ademais, pode-se exemplificar a segunda situação com o município Maricá, propõe-se alocar 100 leitos para atender uma demanda estimada de 5 pacientes, já que não há diferença no custo de instalação na escolha entre o porte $\mathrm{C}$ (modelo de hospital escolhido) e os outros dois portes menores: A com 40 leitos e B com 50 leitos.

Portanto, de modo a evitar uma implementação que ocasionaria em uma grande quantidade de recursos ociosos, sugere-se instalar as quantidades apresentadas na coluna "Utilização" para cada tipo de recurso presente na Tabela 10.

\section{2 .2 \\ Caso 1}

A primeira variação de caso buscou dar maior importância na minimização o deslocamento realizado pelo paciente, isto é, evitar que o paciente percorra longas distâncias mesmo que seja necessário abrir mais hospitais. Para tal, considerou-se que a parcela da distância tem uma ordem de grandeza 10 vezes maior que a parcela do custo.

Encontrou-se como resultado uma solução com 22 hospitais de campanha instalados em 18 municípios do Estado, os quais estão representados na Tabela 12.

Tabela 12 - Localização dos Hospitais de Campanha para o caso 1

\begin{tabular}{cccccccc}
$\begin{array}{c}\text { Localização do } \\
\text { Hospital }\end{array}$ & $\begin{array}{c}\text { Hospital } \\
\text { A }\end{array}$ & $\begin{array}{c}\text { Hospital } \\
\text { B }\end{array}$ & $\begin{array}{c}\text { Hospital } \\
\text { C }\end{array}$ & $\begin{array}{c}\text { Hospital } \\
\text { Dospital }\end{array}$ & $\begin{array}{c}\text { Total de } \\
\text { Hospitais }\end{array}$ \\
\hline Belford Roxo & 1 & 0 & 0 & 0 & 0 & 1
\end{tabular}




\begin{tabular}{lcccccc} 
Cabo Frio & 1 & 0 & 0 & 0 & 0 & 1 \\
Campos dos Goytacazes & 1 & 0 & 0 & 0 & 0 & 1 \\
Duque de Caxias & 1 & 0 & 0 & 0 & 0 & 1 \\
Itaboraí & 1 & 0 & 0 & 0 & 0 & 1 \\
Magé & 1 & 0 & 0 & 0 & 0 & 1 \\
Maricá & 1 & 0 & 0 & 0 & 0 & 1 \\
Mesquita & 1 & 0 & 0 & 0 & 0 & 1 \\
Nilópolis & 0 & 0 & 1 & 0 & 0 & 1 \\
Niterói & 0 & 0 & 1 & 0 & 0 & 1 \\
Nova Friburgo & 1 & 0 & 0 & 0 & 0 & 1 \\
Nova Iguaçu & 0 & 1 & 0 & 0 & 0 & 1 \\
Petrópolis & 1 & 0 & 0 & 0 & 0 & 1 \\
Queimados & 0 & 0 & 1 & 0 & 0 & 1 \\
Rio de Janeiro & 3 & 1 & 0 & 0 & 1 & 5 \\
São Gonçalo & 1 & 0 & 0 & 0 & 0 & 1 \\
São João de Meriti & 1 & 0 & 0 & 0 & 0 & 1 \\
Volta Redonda & 1 & 0 & 0 & 0 & 0 & 1 \\
\hline Total & 16 & 2 & 3 & 0 & 1 & 22
\end{tabular}

Nesse cenário não foram abertos hospitais do porte $\mathrm{D}$ e manteve-se o hospital de maior porte localizado no Rio de Janeiro. Em relação ao cenário base, a solução atual apresenta quatro hospitais de menor porte a mais (tipo A), instalando hospitais em mais municípios e, consequentemente, reduzindo os deslocamentos dos pacientes. A alocação diária dos recursos por município pode ser consultada nos Apêndices XVI, XVII e XVIII.

A Figura 21 mostra a distribuição dos hospitais propostos nesse cenário pelas regiões de saúde do Estado. 

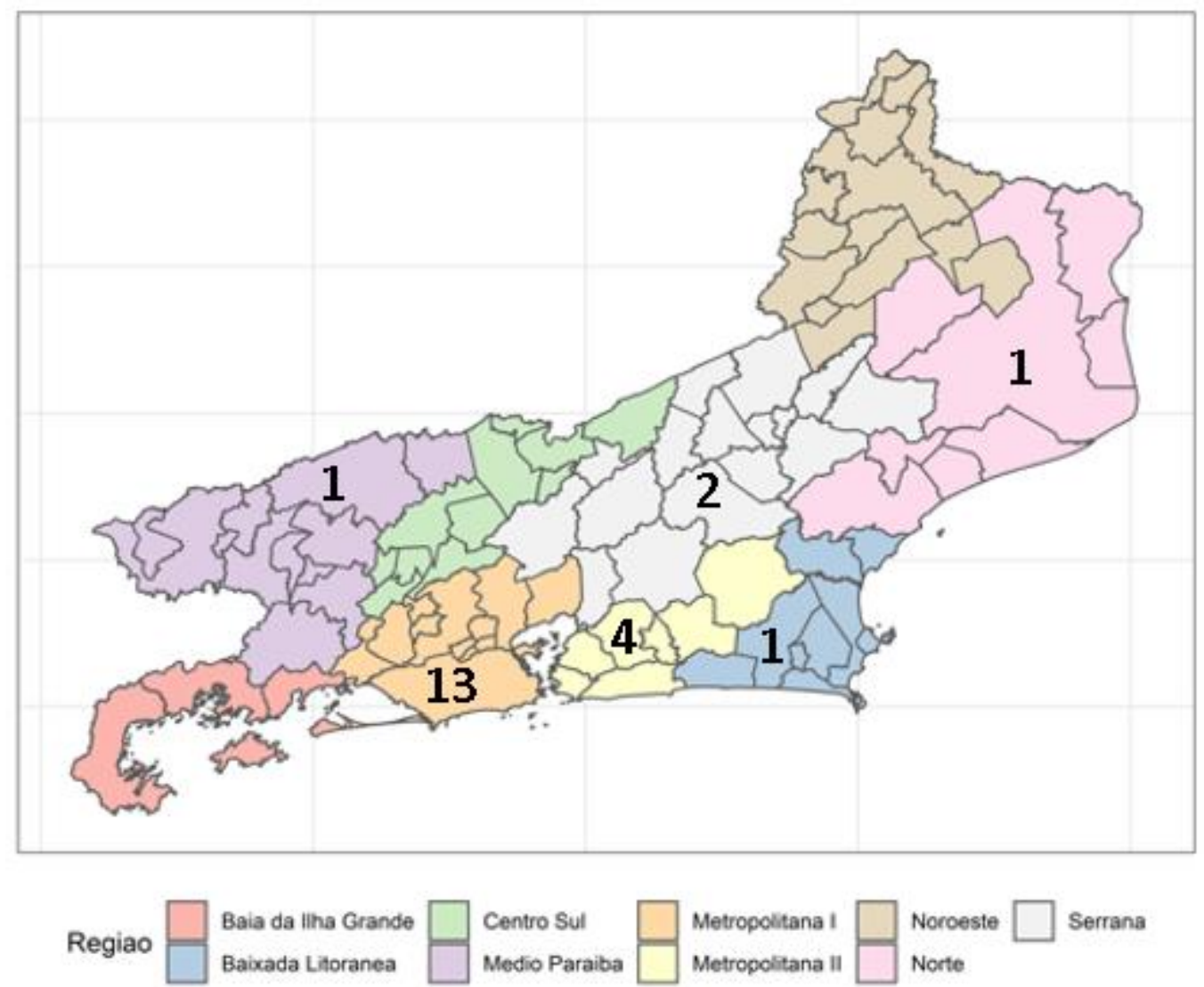

Figura 21 - Distribuição dos Hospitais de Campanha por Região de Saúde para o caso 1

Embora mais municípios tenham recebido hospitais, a nova solução manteve uma cobertura de seis regiões de saúde. Percebe-se o aumento da oferta de hospitais concentrado na região de saúde Metropolitana I, constatando-se que a região de maior número de casos de COVID-19 irá dispor de mais recursos para conseguir atender os residentes dessa localidade.

A Tabela 13 expõe a alocação dos recursos proposta pelo modelo matemático e a demanda estimada para cada município que hospedará os hospitais. 
Tabela 13 - Utilização e capacidade de recursos para o caso 1

\begin{tabular}{lcccccc} 
Localização do Hospital & \multicolumn{2}{c}{ UTI } & \multicolumn{2}{c}{ VMI } & \multicolumn{2}{c}{ Enfermaria } \\
& Utilização & Capacidade & Utilização & Capacidade & Utilização & Capacidade \\
\hline Belford Roxo & 8 & 40 & 5 & 40 & 23 & 160 \\
Cabo Frio & 11 & 40 & 5 & 40 & 29 & 160 \\
Campos dos Goytacazes & 6 & 40 & 2 & 40 & 16 & 160 \\
Duque de Caxias & 21 & 40 & 12 & 40 & 57 & 160 \\
Itaboraí & 13 & 40 & 7 & 40 & 36 & 160 \\
Magé & 8 & 40 & 4 & 40 & 22 & 160 \\
Maricá & 5 & 40 & 3 & 40 & 15 & 160 \\
Mesquita & 8 & 40 & 4 & 40 & 21 & 160 \\
Nilópolis & 4 & 100 & 2 & 100 & 11 & 100 \\
Niterói & 19 & 100 & 11 & 100 & 53 & 100 \\
Nova Friburgo & 5 & 40 & 3 & 40 & 13 & 160 \\
Nova Iguaçu & 19 & 50 & 11 & 50 & 53 & 150 \\
Petrópolis & 6 & 40 & 4 & 40 & 18 & 160 \\
Queimados & 9 & 100 & 4 & 100 & 25 & 100 \\
Rio de Janeiro & 293 & 330 & 163 & 330 & 807 & 870 \\
São Gonçalo & 13 & 40 & 7 & 40 & 36 & 160 \\
São João de Meriti & 10 & 40 & 5 & 40 & 26 & 160 \\
Volta Redonda & 19 & 40 & 11 & 40 & 55 & 160 \\
\hline Total & 477 & 1200 & 263 & 1200 & 1316 & 3400 \\
\hline
\end{tabular}


Ainda que não haja diferença de custo entre os hospitais $\mathrm{A}, \mathrm{B}$ e C, nesse cenário o modelo definiu o hospital de menor porte para a maioria dos municípios, com exceção do Rio de Janeiro. Novamente nota-se que a capacidade instalada excede a utilização estimada, mas com uma diferença entre esses valores maior que o caso base, posto que uma maior quantidade de hospitais foi localizada e mais recursos foram ofertados.

\section{2 .3}

\section{Caso 2}

O segundo caso procurou limitar os gastos com a instalação dos hospitais. Para tal, incrementou-se a parcela do custo em 50 vezes de modo que os pacientes se locomovam por maiores distâncias em prol de evitar a abertura de hospitais

A solução ótima encontrada indica a implementação de 11 hospitais de campanha em 8 municípios, apresentados na Tabela 14.

Tabela 14 - Localização dos Hospitais de Campanha para o caso 2

\begin{tabular}{lcccccc} 
Localização do Hospital & $\begin{array}{c}\text { Hospital } \\
\text { A }\end{array}$ & $\begin{array}{c}\text { Hospital } \\
\text { B }\end{array}$ & $\begin{array}{c}\text { Hospital } \\
\text { C }\end{array}$ & $\begin{array}{c}\text { Hospital } \\
\text { D }\end{array}$ & $\begin{array}{c}\text { Hospita } \\
\text { I E }\end{array}$ & $\begin{array}{c}\text { Total de } \\
\text { Hospitais }\end{array}$ \\
\hline Cabo Frio & 1 & 0 & 0 & 0 & 0 & 1 \\
Campos dos Goytacazes & 0 & 0 & 1 & 0 & 0 & 1 \\
Duque de Caxias & 0 & 1 & 0 & 0 & 0 & 1 \\
Itaboraí & 0 & 1 & 0 & 0 & 0 & 1 \\
Niterói & 0 & 1 & 0 & 0 & 0 & 1 \\
Nova Iguaçu & 0 & 1 & 0 & 0 & 0 & 1 \\
Rio de Janeiro & 2 & 1 & 0 & 1 & 0 & 4 \\
Volta Redonda & 1 & 0 & 0 & 0 & 0 & 1 \\
\hline Total & 4 & 5 & 1 & 1 & 0 & 11
\end{tabular}

Uma vez que se objetivou reduzir os custos de instalação, foram selecionados menos hospitais e com menor porte. Repara-se que o hospital E não se encontra mais na solução, optando-se pelo hospital D. Em comparação com o cenário base, temos menos sete hospitais de menor porte (tipos A, B e C), diminuindo o quantitativo de pacientes atendidos no próprio município.

A disposição dos hospitais proposto por região de saúde pode ser observada na Figura 22. 

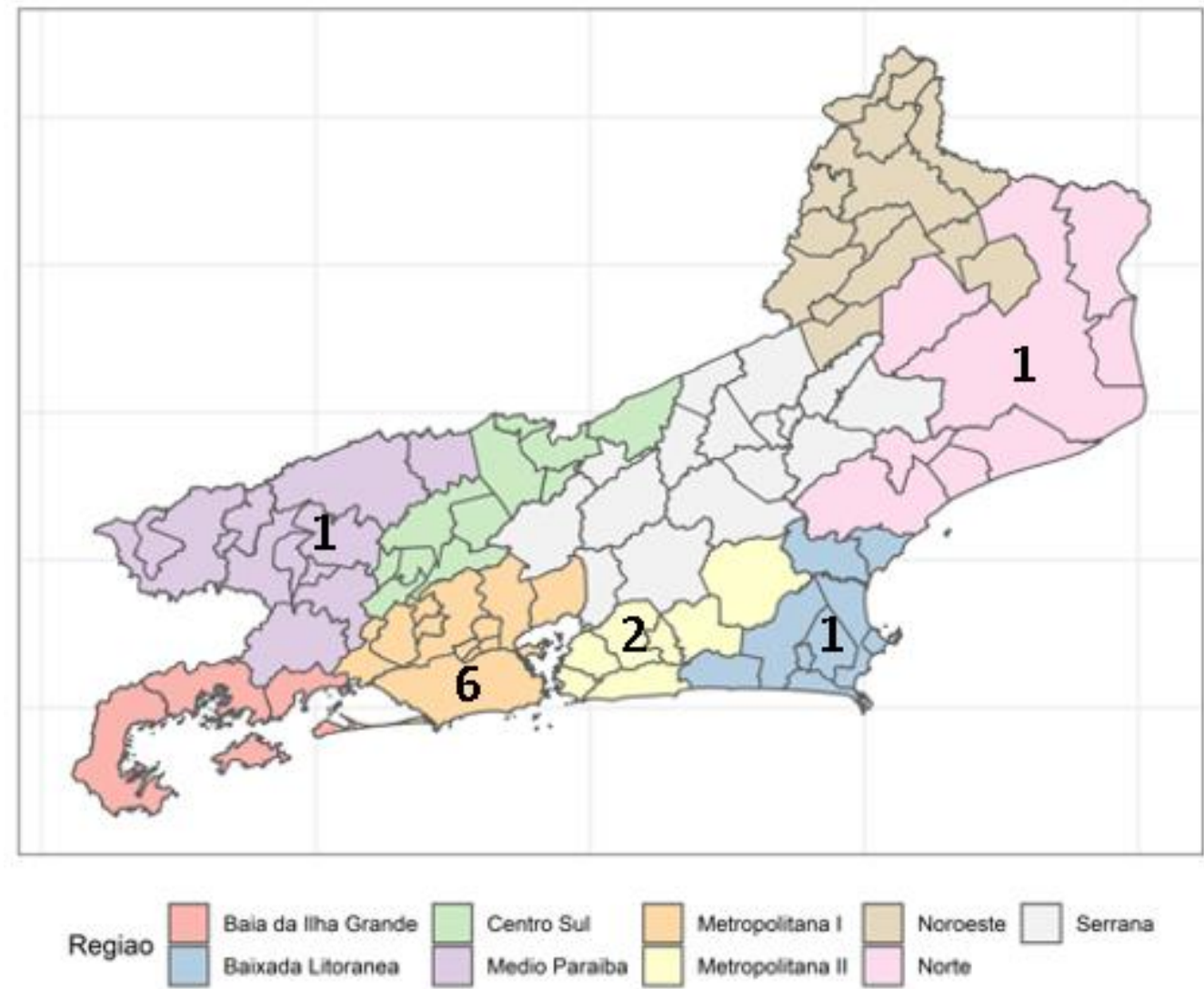

Figura 22 - Distribuição dos Hospitais de Campanha por Região de Saúde para o caso 2

Nota-se que apenas cinco regiões de saúde irão dispor de hospitais de campanha, permanecendo sua maioria concentrada na região Metropolitana I.

A Tabela 15 mostra a capacidade oferecida por cada município em relação a demanda esperada para ele. 
Tabela 15 - Utilização e capacidade de recursos para o caso 2

\begin{tabular}{lcccccc} 
& \multicolumn{2}{c}{ UTI } & \multicolumn{2}{c}{ VMI } & \multicolumn{2}{c}{ Enfermaria } \\
& Utilização & Capacidade & Utilização & Capacidade & Utilização & Capacidade \\
\hline Cabo Frio & 12 & 40 & 6 & 40 & 32 & 160 \\
Campos dos Goytacazes & 6 & 100 & 2 & 100 & 16 & 100 \\
Duque de Caxias & 47 & 50 & 16 & 50 & 142 & 150 \\
Itaboraí & 43 & 50 & 23 & 50 & 119 & 150 \\
Niterói & 50 & 50 & 11 & 50 & 150 & 150 \\
Nova Iguaçu & 50 & 50 & 31 & 50 & 150 & 150 \\
Rio de Janeiro & 250 & 250 & 163 & 250 & 650 & 650 \\
Volta Redonda & 19 & 40 & 11 & 40 & 57 & 160 \\
\hline Total & 477 & 630 & 263 & 630 & 1316 & 1670 \\
\hline
\end{tabular}


Ao reduzir o custo de instalação, houve uma diminuição não só na quantidade de hospitais ofertados e no total de municípios que receberão esses estabelecimentos. A solução encontrada agora concentra os 12 hospitais de campanha em 8 municípios. A alocação diária dos recursos por município pode ser consultada nos Apêndices XIX, XX e XXI.

Ainda ocorrem os problemas de excesso de capacidade relatados nos cenários anteriores, porém a discrepância entre os valores de leitos ofertados e de demanda estimada são menores.

\section{2 .4}

\section{Caso 3}

Buscando reduzir ainda mais os custos de instalação, elaborou-se o terceiro caso aumentando o peso da parcela do custo de instalação em 100 vezes. Com isso, o modelo propõe instalar o menor número de hospitais possíveis ainda que a distância percorrida pelos pacientes continue a aumentar.

A solução ótima encontrada para esse cenário dispõe de 9 hospitais localizados em 6 municípios do Estado, exibidos na Tabela 16.

Tabela 16 - Localização dos Hospitais de Campanha para o caso 3

\begin{tabular}{lcccccc} 
Localização do Hospital & $\begin{array}{c}\text { Hospital } \\
\text { A }\end{array}$ & $\begin{array}{c}\text { Hospital } \\
\text { B }\end{array}$ & $\begin{array}{c}\text { Hospital } \\
\text { C }\end{array}$ & $\begin{array}{c}\text { Hospital } \\
\text { D }\end{array}$ & $\begin{array}{c}\text { Hospita } \\
\text { I E }\end{array}$ & $\begin{array}{c}\text { Total de } \\
\text { Hospitais }\end{array}$ \\
\hline Campos dos Goytacazes & 1 & 0 & 0 & 0 & 0 & 1 \\
Duque de Caxias & 1 & 0 & 0 & 0 & 0 & 1 \\
Itaboraí & 0 & 1 & 0 & 0 & 0 & 1 \\
Nova Iguaçu & 0 & 1 & 0 & 0 & 0 & 1 \\
Rio de Janeiro & 2 & 1 & 0 & 0 & 1 & 4 \\
Volta Redonda & 1 & 0 & 0 & 0 & 0 & 1 \\
\hline Total & 5 & 3 & 0 & 0 & 1 & 9
\end{tabular}

O cenário apresentado retrata uma redução ainda maior no total de hospitais estabelecidos, tem-se a recomendação de instalação de 9 hospitais dos quais 8 possuem um pequeno porte. Porém manteve-se a escolha do hospital E mesmo possuindo um custo maior.

A Figura 23 exibe a proposição encontrada ao longo das regiões de saúde do Estado. 

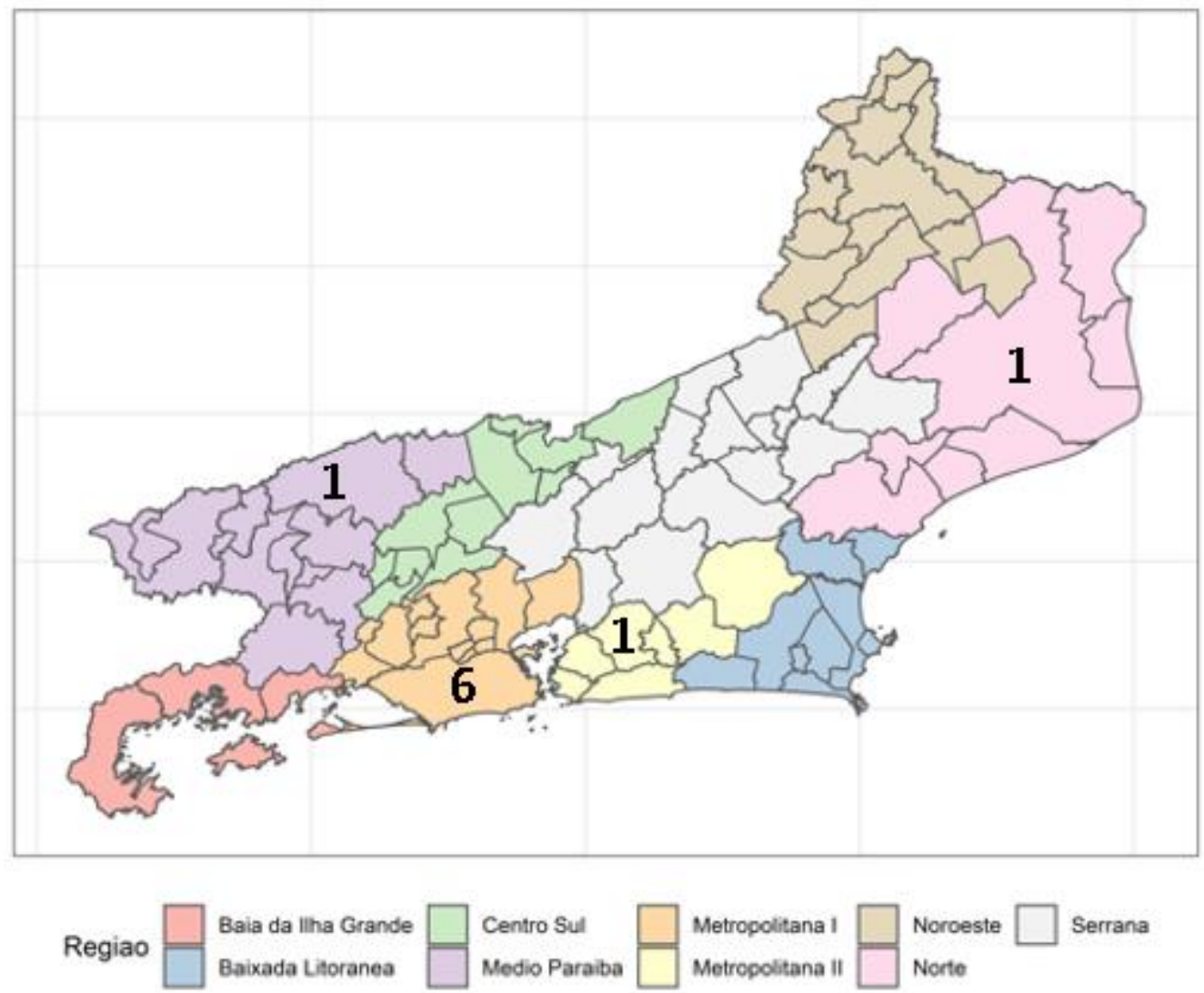

Figura 23 - Distribuição dos Hospitais de Campanha por Região de Saúde para o caso 3

É possível perceber que apenas quatro das nove regiões de saúde devem instalar hospitais de campanha, mantendo-se o maior volume na região Metropolitana I.

A Tabela 17 mostra a alocação dos recursos para cada município com hospitais de campanha e a demanda esperada para ele. 
Tabela 17 - Utilização e capacidade de recursos para o caso 3

\begin{tabular}{|c|c|c|c|c|c|c|}
\hline \multirow{2}{*}{ Localização do Hospital } & \multicolumn{2}{|c|}{ UTI } & \multicolumn{2}{|c|}{ VMI } & \multicolumn{2}{|c|}{ Enfermaria } \\
\hline & Utilização & Capacidade & Utilização & Capacidade & Utilização & Capacidade \\
\hline Campos dos Goytacazes & 15 & 40 & 3 & 40 & 43 & 160 \\
\hline Duque de Caxias & 40 & 40 & 16 & 40 & 160 & 160 \\
\hline Itaboraí & 50 & 50 & 28 & 50 & 150 & 150 \\
\hline Nova Iguaçu & 50 & 50 & 31 & 50 & 150 & 150 \\
\hline Rio de Janeiro & 290 & 290 & 174 & 290 & 710 & 710 \\
\hline Volta Redonda & 32 & 40 & 11 & 40 & 103 & 160 \\
\hline Total & 477 & 510 & 263 & 510 & 1316 & 1490 \\
\hline
\end{tabular}


A alocação diária dos recursos por município pode ser consultada nos Apêndices XXII, XXIII e XXIV.

Constata-se que ainda existe excesso de capacidade, igualmente relatado nos outros cenários. Porém, a diferença entre os valores de capacidade ofertada e de demanda estimada foi a menor encontrada entre todos os cenários.

\section{2 .5 \\ Comparação entre os cenários propostos}

A Tabela 18 apresenta uma síntese dos resultados obtidos para os quatro casos abordados.

\begin{tabular}{lccccc} 
Caso & $\begin{array}{c}\text { Tabela } 18-\text { Síntese dos resultados } \\
\text { Total de } \\
\text { Hospitais }\end{array}$ & $\begin{array}{c}\text { Total de } \\
\text { Regiões de } \\
\text { Saúde }\end{array}$ & $\begin{array}{c}\text { Total de } \\
\text { Municípios }\end{array}$ & $\begin{array}{c}\text { Distância Total } \\
(\mathrm{Km})\end{array}$ & $\begin{array}{c}\text { Custo de Instalação } \\
\text { Total }(\mathrm{R} \$ 1.000,00)\end{array}$ \\
\hline Base & 18 & 6 & 15 & 210.910 & $22.088,30$ \\
$\# 1$ & 22 & 6 & 18 & 184.951 & $27.461,00$ \\
$\# 2$ & 11 & 5 & 8 & 395.082 & $13.730,54$ \\
$\# 3$ & 9 & 4 & 6 & 515.063 & $11.939,61$ \\
\hline
\end{tabular}

É possível perceber que em comparação com o caso, o caso 1 apresenta a menor distância total. Os casos 2 e 3 objetivaram reduzir o custo de implantação dos hospitais, constatando-se que quanto menor o custo, maior será o deslocamento dos pacientes e menos regiões de saúde hospedarão hospitais.

Essa tabela auxilia o tomador de decisão na escolha do melhor cenário de planejamento, para atender a demanda de pacientes com SRAG no Estado do Rio de Janeiro. A partir dela, é possível ponderar restrições de orçamento e condições de atendimento para oferecer acesso aos serviços públicos de saúde no tratamento da COVID-19 e da SRAG.

\section{3}

\section{Análise da solução proposta}

Devido ao período estudado já ter ocorrido, é possível contrapor a proposta de solução com o que de fato ocorreu. A seguir é apresentado o total de leitos alocados nos hospitais de campanha implantados no Estado do Rio de Janeiro e, em seguida, comparado com a oferta de leitos proposta pela modelagem matemática desenvolvida nesta pesquisa. 
Salienta-se que não foi possível realizar a comparação entre a distribuição do equipamento pelas regiões de saúde do Estado e sua real necessidade, visto que não há informação sobre a quantidade de respiradores destinados ao tratamento de pacientes confirmados ou com suspeita de COVID-19.

\section{3 .1 \\ Hospitais de campanha instalados no Estado do Rio de Janeiro}

Em razão do planejamento de leitos realizado pela SESRJ ter considerado apenas hospitais localizados na cidade do Rio de Janeiro, elaborou-se a comparação dos leitos propostos com a informação de leitos em hospitais de campanha presentes no CNES.

A Tabela 19 expõe a localização dos hospitais de campanha abertos no Estado até o final do mês de maio, independente da esfera administrativa, com seus respectivos leitos de UTI e de enfermaria. 
Tabela 19 - Hospitais de campanha implementados no Estado do Rio de Janeiro

\begin{tabular}{|c|c|c|c|c|}
\hline Região de Saúde & Município & Hospital de Campanha & $\begin{array}{l}\text { Leitos } \\
\text { de UTI }\end{array}$ & $\begin{array}{c}\text { Leitos de } \\
\text { Enfermaria }\end{array}$ \\
\hline Baia da Ilha Grande & Angra dos Reis & HOSPITAL DE CAMPANHA CENTRO DE REFERÊNCIA COVID 19 & 40 & 80 \\
\hline Médio Paraíba & Barra Mansa & HOSPITAL DE CAMPANHA COVID 19 UPA LESTE & 4 & 12 \\
\hline Médio Paraíba & Volta Redonda & HOSPITAL DE CAMPANHA COVID 19SMS VR & 0 & 114 \\
\hline Metropolitana I & Rio de Janeiro & HOSPITAL DE CAMPANHA COVID 19 LEBLON & 100 & 100 \\
\hline Metropolitana I & Rio de Janeiro & SMS HOSPITAL MUNICIPAL DE CAMPANHA DO RIOCENTRO COVID 19 & 100 & 400 \\
\hline Metropolitana I & Rio de Janeiro & HOSPITAL DE CAMPANHA COVID 19 MARACANA & 22 & 40 \\
\hline Metropolitana I & Rio de Janeiro & HOSPITAL DE CAMPANHA COVID 19 PARQUE DOS ATLETAS & 100 & 100 \\
\hline Metropolitana I & Queimados & HOSPITAL DE CAMPANHA COVID 19 QUEIMADOS RJ & 10 & 10 \\
\hline Metropolitana II & São Gonçalo & HOSPITAL DE CAMPANHA COVID 19 SAO GONCALO & 40 & 60 \\
\hline Norte & Carapebus & HOSPITAL DE CAMPANHA DO MUNICIPIO DE CARAPEBUS & 0 & 20 \\
\hline Norte & Quissamã & HOSPITAL DE CAMPANHA DO MUNICIPIO DE QUISSAMA & 10 & 1 \\
\hline
\end{tabular}


Sabe-se que 11 hospitais de campanha foram instalados no Estado até o final do mês de maio, localizados nas seguintes regiões de saúde: Baia da Ilha Grande, Metropolitana I, Metropolitana II, Médio Paraíba e Serrana. Ao todo foram disponibilizados um total de 1363 leitos, sendo 426 de UTI e 937 de enfermaria.

\section{3 .2 \\ Internações em UTI no Estado do RJ}

A Tabela 20 apresenta o total de leitos de UTI ofertados pelos hospitais de campanha instalados no Estado, a alocação da oferta de leitos de UTI encontrada em cada caso criado e o máximo de internações de SRAG observadas segundo o local de residência do paciente, sendo todos categorizados por região de saúde. 
Tabela 20 - Comparação das internações de SRAG em UTI por região de saúde

Leitos em

Hospitais de

Campanha

Oferta de leitos de UTI proposta

\begin{tabular}{lcccccc} 
Região de Saúde & $\begin{array}{c}\text { Hospitais de } \\
\text { Campanha }\end{array}$ & $\begin{array}{c}\text { Caso Base } \\
(\mathbf{1 8} \text { Hosp.) }\end{array}$ & $\begin{array}{c}\text { Caso 1 } \\
(\mathbf{2 2} \text { Hosp. })\end{array}$ & $\begin{array}{c}\text { Caso 2 } \\
(\mathbf{1 1} \text { Hosp.) }\end{array}$ & $\begin{array}{c}\text { Caso 3 } \\
\text { (9 Hosp.) }\end{array}$ & $\begin{array}{c}\text { Máximo de } \\
\text { internações SRAG } \\
\text { em UTI }\end{array}$ \\
\hline Baia da Ilha Grande & 40 & 0 & 0 & 0 & 0 & 1 \\
Baixada Litorânea & 0 & 11 & 11 & 12 & 0 & 33 \\
Centro-Sul & 0 & 0 & 0 & 0 & 0 & 8 \\
Médio Paraíba & 4 & 19 & 19 & 19 & 32 & 11 \\
Metropolitana I & 332 & 377 & 380 & 347 & 380 & 254 \\
Metropolitana II & 40 & 53 & 50 & 93 & 50 & 67 \\
Noroeste & 0 & 0 & 0 & 6 & 15 & 3 \\
Norte & 10 & 6 & 6 & 0 & 0 & 21 \\
Serrana & 0 & 11 & 11 & 477 & 477 & 26 \\
\hline Total & 426 & 477 & 477 & & 424 \\
\hline
\end{tabular}


Constata-se que embora o total de leitos disponibilizados em hospitais de campanha tenham sido suficientes para atender a demanda, houve uma má distribuição deles pelo Estado. Sete das nove regiões de saúde não apresentavam leitos suficientes para atender a demanda local e para aquelas regiões que a demanda foi atendida ocorreu um excesso de capacidade ofertada.

A mesma má distribuição entre as regiões de saúde se apresenta para os cenários propostos, em razão da dificuldade de se estimar os recursos nesse nível de granularidade. Sendo apenas a região Metropolitana I aquela que atenderia por completo sua demanda, em todos os casos propostos

Para mais, avaliou-se a distância real percorrida pelos pacientes com SRAG e aquela proposta para cada cenário elaborado (Tabela 21).

Tabela 21 - Comparação das distâncias percorridas por pacientes com demanda de internações em UTI

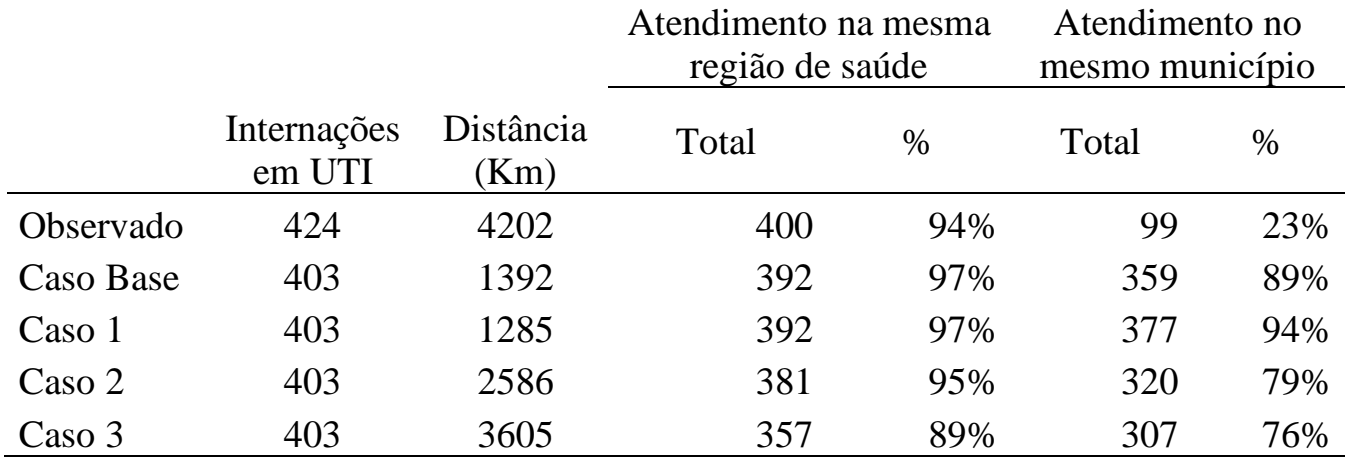

É possível perceber que a solução encontrada no modelo matemático apresentou uma menor distância total de deslocamento dos pacientes em ambos os cenários. Uma vez que a quantidade de pacientes estimados é superior à quantidade real atendida no período estudado, comparou-se a proporção de pacientes que foram atendidos na região de saúde e no município em que residem.

Nota-se que 94\% dos internados em UTI não precisaram se locomover além da sua região de saúde, enquanto na solução encontrada no modelo matemático seriam 97\% dos pacientes estimados, para os dois cenários com a menor distância total percorrida desenvolvidos (Caso Base e Caso 1).

Por outro lado, ao contrapor o total de pacientes atendidos no próprio município de residência observa-se que somente $23 \%$ dos casos foram atendidos no município em que moram. Já nos dois primeiros cenários propostos, a solução matemática oferece uma melhor performance, sendo $89 \%$ deles para o caso base e $94 \%$ para o caso 1 . 
Destaca-se que o aumento da quantidade de pacientes atendidos no próprio município de residência deve-se ao maior número de hospitais propostos nesse cenário, evitando a locomoção dos pacientes para os municípios vizinhos pertencentes a sua região de saúde.

Ademais, ao comparar os casos 2 e 3, cenários os quais visam minimizar os custos de instalação, percebe-se que distância total percorrida ainda é inferior ao que de fato ocorreu.

Desse modo, ao compará-los entre si observa-se que no Caso 3, cenário com menor custo de instalação, temos a maior distância total percorrida com as menores taxas de atendimento no local de residência: $89 \%$ dos pacientes atendidos na mesma região (percentual inferior ao cenário real) e $76 \%$ atendidos no próprio município de residência. Já no Caso 2, constata-se uma melhor performance que a situação real em ambos os atendimentos.

\section{3 .3 \\ Internações em enfermaria no Estado do RJ}

De forma análoga à seção anterior, elaborou-se a análise das internações em leitos de enfermaria. A Tabela 22 retrata o total de leitos de enfermaria alocados nos hospitais de campanha do Estado, a oferta de leitos de enfermaria proposta por cada cenário desenvolvido e o valor máximo de internações em leitos de enfermaria observadas no mês de maio, sendo todas agregadas por região de saúde. 
Tabela 22 - Comparação das internações de SRAG em leitos de enfermaria por região de saúde

\begin{tabular}{|c|c|c|c|c|c|c|}
\hline \multirow[b]{2}{*}{ Região de Saúde } & \multirow{2}{*}{$\begin{array}{l}\text { Leitos em } \\
\text { Hospitais de } \\
\text { Campanha }\end{array}$} & \multicolumn{4}{|c|}{ Oferta de leitos de enfermaria proposta } & \multirow{2}{*}{$\begin{array}{c}\text { Máximo de } \\
\text { internações } \\
\text { SRAG em } \\
\text { enfermaria }\end{array}$} \\
\hline & & $\begin{array}{l}\text { Caso Base } \\
\text { (18 Hosp.) }\end{array}$ & $\begin{array}{c}\text { Caso } 1 \\
(22 \text { Hosp.) }\end{array}$ & $\begin{array}{c}\text { Caso } 2 \\
\text { (11 Hosp.) }\end{array}$ & $\begin{array}{c}\text { Caso } 3 \\
(9 \text { Hosp.) }\end{array}$ & \\
\hline Baia da Ilha Grande & 80 & 0 & 0 & 0 & 0 & 10 \\
\hline Baixada Litorânea & 0 & 29 & 29 & 32 & 0 & 93 \\
\hline Centro-Sul & 0 & 0 & 0 & 0 & 0 & 16 \\
\hline Médio Paraíba & 126 & 56 & 55 & 57 & 103 & 46 \\
\hline Metropolitana I & 650 & 1042 & 1045 & 942 & 1020 & 1248 \\
\hline Metropolitana II & 60 & 140 & 140 & 269 & 150 & 249 \\
\hline Noroeste & 0 & 0 & 0 & 0 & 0 & 17 \\
\hline Norte & 21 & 16 & 16 & 16 & 43 & 91 \\
\hline Serrana & 0 & 33 & 31 & 0 & 0 & 46 \\
\hline Total & 937 & 1316 & 1316 & 1316 & 1316 & 1816 \\
\hline
\end{tabular}


É possível perceber uma grande diferença entre o total de leitos disponibilizados em hospitais de campanha, a ocupação por pacientes internados com SRAG e a máxima ocupação estimada. Tal fato é explicado devido à mudança de recomendações do MS para os pacientes que apresentassem casos leves da doença (MS, 2020d).

Como no início da pandemia, foi recomendado a esse perfil a ficar em isolamento domiciliar, encaminhando-se para a rede hospitalar apenas em caso de agravamento (MS, 2020e), a estimativa de ocupações de leitos de enfermaria baseouse em um histórico de baixa demanda. No entanto, com a mudança do MS, a procura aumentou no mês de maio, como observado na coluna "Máximo de internações SRAG em enfermaria" da Tabela 22.

Apesar disso, a solução proposta aproxima-se mais da real necessidade de internação ocorrida quando comparada com o total de leitos alocados nos hospitais de campanha. 


\section{6 \\ Considerações Finais}

Esta dissertação teve como objetivo principal propor um modelo de localização para hospitais de campanha no Estado do Rio de Janeiro visando atender os pacientes com COVID-19. Para isso, analisou-se a evolução da doença na região e características epidemiológicas dos pacientes com o novo coronavírus, por meio do cálculo dos indicadores de incidência e de mortalidade. Assim, foi possível projetar o total de casos de COVID-19 para a região estudada.

A partir do histórico de internações até o final de abril, foi possível dimensionar a quantidade de leitos de UTI, leitos de enfermaria e respiradores a ser alocada em cada região de saúde do Estado ao longo do mês de maio.

As soluções encontradas para a estimativa de demanda e modelo matemático proposto mostraram-se eficazes no atendimento à pacientes com SRAG. Enquanto $23 \%$ dos pacientes foram atendidos no município em que residem, o cenário proposto com o intuito de minimizar o deslocamento da demanda oferecia atendimento em seu próprio município para $94 \%$ dos pacientes.

Conclui-se, portanto, que os hospitais de campanha propostos atuariam como referência para esse perfil de paciente, não sendo necessário interromper atendimentos eletivos nos hospitais públicos existentes e evitando o estresse do sistema de saúde.

Sugere-se como trabalhos futuros a expansão da pesquisa para um período temporal maior que o analisado, dado que até o momento a epidemia não foi controlada.

Além disso, indica-se variações no modelo matemático, incluindo: restrições de orçamento; outros perfis de hospitais com diferentes portes e custos; e diferentes objetivos, tal como o modelo matemático MiniMax o qual objetiva minimizar a maior distância percorrida pelos pacientes. 


\section{Referências Bibliográficas}

AHMADI-JAVID, A.; SEYEDI, P.; SYAM, S. S. A survey of healthcare facility location. Computers and Operations Research, v. 79, p. 223-263, 2017.

AMIB. COMUNICADO DA AMIB SOBRE O AVANÇO DO COVID-19 E A NECESSIDADE DE LEITOS EM UTIS NO FUTURO. Disponível em: < http://www.somiti.org.br/arquivos/site/comunicacao/noticias/2020/covid19/comunicado-da-amib-sobre-o-avanco-do-covid-19-e-a-necessidade-de-leitos-emutis-no-futuro.pdf>. Acesso em: 3 maio. 2020.

ANDERSON, R. M. et al. How will country-based mitigation measures influence the course of the COVID-19 epidemic? The Lancet, v. 395, n. 10228, p. 931-934, 2020.

ANS. Dados Gerais - ANS - Agência Nacional de Saúde Suplementar. Disponível em: <https://www.ans.gov.br/perfil-do-setor/dados-gerais>. Acesso em: 3 jul. 2020.

ANTUNES, B. B. de P., et al. Progression of confirmed COVID-19 cases after the implementation of control measures. Revista Brasileira de Terapia Intensiva, v. 32, n.2, p. 213-223, 2020.

ARAUJO, T. G. de et al. Readmissões e óbitos após a alta da UTI: um desafio da terapia intensiva. Revista Brasileira de Terapia Intensiva, v. 25, n. 1, p. 32-38, 2013.

ARVAN, M.; TAVAKKOLI-MOGHADDAM, R.; ABDOLLAHI, M. Designing a bi-objective, multi-product supply chain network for blood supply. Uncertain Supply Chain Management, v. 3, n. 1, p. 57-68, 2015.

BASTOS, L. S. et al. A modelling approach for correcting reporting delays in disease surveillance data. Statistics in Medicine, v. 38, n. 22, p. 4363-4377, 2019.

BASU, R.; JANA, A.; BARDHAN, R. A Health Care Facility Allocation Model for Expanding Cities in Developing Nations: Strategizing Urban Health Policy Implementation. Applied Spatial Analysis and Policy, v. 11, n. 1, p. 21-36, 2018.

BERTRAND, J. W. M.; FRANSOO, J. C. Operations management research 
methodologies using quantitative modeling. International Journal of Operations and Production Management, v. 22, n. 2, p. 241-264, 2002.

BOX, G. E. et al. Time series analysis: forecasting and control. New Jersey: John Wiley \& Sons, 2015. v. 369

BROWN, E. E. et al. Anticipating and Mitigating the Impact of the COVID-19 Pandemic on Alzheimer's Disease and Related Dementias. American Journal of Geriatric Psychiatry, v. 28, n. 7, p. 712-721, 2020.

BURK, T. K. Coronavirus in China. The Lancet, n. January, 2020.

CAUCHICK MIGUEL, P. A. Estudo de caso na engenharia de produção: estruturação e recomendações para sua condução. Production, v. 17, n. 1, p. 216-229, 2007.

ÇETIN, E.; KIREMITCI, S.; KIREMITCI, B. Developing optimal policies to fight pandemics and covid-19 combat in the United States. European Journal of Pure and Applied Mathematics, v. 13, n. 2, p. 369-389, 2020.

CHEN, Z. et al. Mobile field hospitals, an effective way of dealing with COVID19 in China: sharing our experience. BioScience Trends, 2020a.

CHEN, N. et al. Epidemiological and clinical characteristics of 99 cases of 2019 novel coronavirus pneumonia in Wuhan, China: a descriptive study. The Lancet, v. 395, n. 10223, p. 507-513, 2020 b.

CHURCH, R. L.; REVELLE, C. The maximal covering location problem. Papers of the Regional Science Association, v. 32, p. 101-118, 1974.

COLLETT, Dave. Ordered cathegorical data-Lecture 14, 14p. MSc generalised linear models course, 2003.

COTA, W. Monitoring the number of COVID-19 cases and deaths in brazil at municipal and federative units level. SciELOPreprints, v. 362, p. 1-7, 2020.

CRODA, J. et al. Covid-19 in Brazil: Advantages of a socialized unified health system and preparation to contain cases. Revista da Sociedade Brasileira de Medicina Tropical, v. 53, n. April, p. 2-7, 2020.

CURRIE, C. S. M. et al. How simulation modelling can help reduce the impact of COVID-19. Journal of Simulation, v. 14, n. 2, p. 83-97, 2020.

DASKIN, M. S. What You Should Know About Location Modeling. Naval Research Logistics, v. 55, n. 4, p. 283-294, 2008.

DASKIN, M. S. Network and Discrete Location Models, Algorithms, and Applications. John Wiley \& Sons, 2013. 
DASKIN, M. S.; DEAN, L. K. Handbook of OR/MS in Health Care: A Handbook of Methods and Applications, Operations Research and Health Care, 2004.

DE VRIES, H.; VAN DE KLUNDERT, J.; WAGELMANS, A. P. M. The Roadside Healthcare Facility Location Problem A Managerial Network Design Challenge. Production and Operations Management, v. 29, n. 5, p. 1165-1187, 2020.

DJENIĆ, A. et al. A variable neighbourhood search method for solving the longterm care facility location problem. IMA Journal of Management Mathematics, v. 28, n.2, p. 321-338, 2017.

FARAHANI, R. Z.; HEKMATFAR, M. Facility location: concepts, models, algorithms and case studies. Springer Science \& Business Media, 2009.

FERGUSON, N. M. et al. Impact of non-pharmaceutical interventions (NPIs) to reduce COVID-19 mortality and healthcare demand. Imperial.Ac.Uk, 2020.

GIL, A. C. Delineamento da pesquisa. _. Métodos e técnicas de pesquisa social, 2006.

GOULART, G. Coronavírus: Rio tem fila de 369 pessoas com sintomas de Covid-19 por UTI na rede de saúde - Jornal O Globo. Disponível em: <https://oglobo.globo.com/rio/coronavirus-rio-tem-fila-de-369-pessoas-comsintomas-de-covid-19-por-uti-na-rede-de-saude-24407131>. Acesso em: 2 maio. 2020.

GOVERNO DO ESTADO DO RIO DE JANEIRO. SESRJ. Contrato n⿳ 27, de 3 de abril de 2020. Rio de Janeiro, 3 abr. 2020. Disponível em: <https://sei.fazenda.rj.gov.br/sei/modulos/pesquisa/md_pesq_documento_consulta_e xterna.php?9LibXMqGnN7gSpLFOOgUQFziRouBJ5VnVL5b7UrE5T2tn9j1ZNaUhI0e9poYYJnkMDCygKyP0AMf_aSERAypfSbOAoJe3yJmaWuD1OCQ45x6KbzCTZKkg7LNJDmBXF>. Acesso em: 19 jul. 2020.

GÜNEŞ, Evrim Didem; MELO, Teresa; NICKEL, Stefan. Location problems in healthcare. In: Location science. Springer, Cham, 2019. p. 657-686.

HAASE, K.; MÜLLER, S. Insights into clients' choice in preventive health care facility location planning. OR Spectrum, v. 37, n. 1, p. 273-291, 2015.

HAASE, Knut, et al. Facility Location in the Public Sector. In: Location Science. Springer, Cham, 2019. p. 745-764.

HALPERN, S. D.; MILLER, F. G. The Urge to Build More Intensive Care Unit 
Beds and Ventilators: Intuitive but Errant. Annals of Internal Medicine, 2020.

HARAPAN, H. et al. Coronavirus disease 2019 (COVID-19): A literature review. Journal of Infection and Public Health, v. 13, n. 5, p. 667-673, 2020.

HILLIER, F. S. et al. Operations Research and Health Care a Handbook. Springer Science \& Business Media, 2004.

HOLT, Charles C. Forecasting seasonals and trends by exponentially weighted moving averages. International journal of forecasting, v. 20, n1, p. 5-10, 2004.

HONE, T. et al. Effect of economic recession and impact of health and social protection expenditures on adult mortality: a longitudinal analysis of 5565 Brazilian municipalities. The Lancet Global Health, v. 7, n. 11, p. e1575-e1583, 2019.

HUANG, C. et al. Clinical features of patients infected with 2019 novel coronavirus in Wuhan, China. The Lancet, v. 395, n. 10223, p. 497-506, 2020.

KIM, D. G.; KIM, Y. D. A Lagrangian heuristic algorithm for a public healthcare facility location problem. Annals of Operations Research, v. 206, n. 1, p. 221-240, 2013.

LASRY, A. et al. Timing of Community Mitigation and Changes in Reported COVID-19 and Community Mobility - Four U.S. Metropolitan Areas, February 26April 1, 2020. MMWR. Morbidity and mortality weekly report, v. 69, n. 15, p. 451-457, 17 abr. 2020.

LAUER, S. A. et al. The incubation period of coronavirus disease 2019 (CoVID19) from publicly reported confirmed cases: Estimation and application. Annals of Internal Medicine, v. 172, n. 9, p. 577-582, 5 maio 2020.

LIMA, C. P. Comparando a saúde no Brasil com os países da OCDE : explorando dados de saúde pública. Rio de Janeiro, 2016.149p. Dissertação - Escola de Matemática Aplicada, Fundação Getúlio Vargas.

LU, H.; STRATTON, C. W.; TANG, Y. W. Outbreak of Pneumonia of Unknown Etiology in Wuhan, China: The Mystery and the Miracle. Journal of medical virology, v. 92, n. 4, 2020.

MEDICI, A. Breves considerações sobre a relação entre direito sanitário e financiamento à saúde no Brasil. Direito da saúde no Brasil, p. 243-278, 2010.

MEHROTRA, S. et al. A Model for Supply-Chain Decisions for Resource Sharing with an Application to Ventilator Allocation to Combat COVID-19. Naval Research Logistics (NRL), 2020.

MESTRE, A. M.; OLIVEIRA, M. D.; BARBOSA-PÓVOA, A. P. Location- 
allocation approaches for hospital network planning under uncertainty. European Journal of Operational Research, v. 240, n. 3, p. 791-806, 2015.

MOTALLEBI NASRABADI, A.; NAJAFI, M.; ZOLFAGHARINIA, H. Considering short-term and long-term uncertainties in location and capacity planning of public healthcare facilities. European Journal of Operational Research, v. 281, n. 1, p. 152-173, 2020.

MS. Ministério da Saúde. Brasil confirma primeiro caso da doença. Disponível em: <https://www.saude.gov.br/noticias/agencia-saude/46435-brasilconfirma-primeiro-caso-de-novo-coronavirus>. Acesso em: 3 jul. 2020a.

MS. Ministério da Saúde. Saúde regulamenta condições de isolamento e quarentena. Disponível em: <https://www.saude.gov.br/noticias/agenciasaude/46536-saude-regulamenta-condicoes-de-isolamento-e-quarentena>. Acesso em: 5 jul. $2020 b$.

MS. Ministério da Saúde. Open Data SUS. Disponível em: <https://opendatasus.saude.gov.br/>. Acesso em: 6 jul. 2020c.

MS. Ministério da Saúde. Ministério da Saúde atualiza situação do novo coronavírus para os estados. Disponível em: $<$ https://www.saude.gov.br/noticias/agencia-saude/46230-ministerio-da-saudeatualiza-situacao-para-os-estados>. Acesso em: 5 jul. 2020d.

MS. Ministério da Saúde. Saúde anuncia orientações para evitar a disseminação do coronavírus. Disponível em: <https://www.saude.gov.br/noticias/agencia-saude/46540-saude-anuncia-orientacoespara-evitar-a-disseminacao-do-coronavirus>. Acesso em: 5 jul. 2020e.

MS. Ministério da Saúde. Orientações para manejo de pacientes com COVID-19. Disponível em: < https://www.saude.gov.br/noticias/agenciasaude/47068-ministerio-da-saude-lanca-orientacoes-para-padronizacao-doatendimento-a-covid-19>. Acesso em: 10jul. 2020f.

MS. Ministério da Saúde. Localiza-SUS. Disponível em: <https://viz.saude.gov.br/extensions/SC-GN/SC-GN.html>. Acesso em: 18 jul. $2020 \mathrm{~g}$.

MS. Ministério da Saúde. Definição de Caso e Notificação. Disponível em: $<$ https://coronavirus.saude.gov.br/definicao-de-caso-e-notificacao>. Acesso em: 9 abr. 2020h.

NASRABADI, A. M.i; NAJAFI, M.; ZOLFAGHARINIA, H. Considering 
short-term and long-term uncertainties in location and capacity planning of public healthcare facilities. European Journal of Operational Research, v. 281, n. 1, p.152-173, 2020.

NORONHA, K. V. M. DE S. et al. The COVID-19 pandemic in Brazil: analysis of supply and demand of hospital and ICU beds and mechanical ventilators under different scenarios. Cadernos de saude publica, v. 36, n. 6, p. e00115320, 17 jun. 2020.

OLIVEIRA, M. C. M. DE. Logística humanitária: apoio do Hospital de Campanha (HCAMP) ao terremoto no Haiti em 2010. Revista da UNIFA, v. 29, n. 1, p. 49-58, 2016.

OLIVEIRA, W. K. DE et al. How Brazil can hold back COVID-19. Epidemiologia e servicos de saude : revista do Sistema Unico de Saude do Brasil, v. 29, n. 2, p. e2020044, 2020.

OMS. Coronavirus disease 2019 (COVID-19) Situation Report - 66, 2020.

OUYANG, R.; FAIZ, T. I.; NOOR-E-ALAM, M. Location-allocation models for healthcare facilities with long-term demand. International Journal of Operational Research, v. 38, n. 3, p. 295-320, 2020.

OWEN, S. H.; DASKIN, M. S. Strategic facility location: A review. European Journal of Operational Research, v. 111, n. 3, p. 423-447, 1998.

PARAGUASSU, L.; MANDL, C. Brazil Health Ministry confirms first coronavirus case in Latin America. Disponível em: <https://www.reuters.com/article/us-china-health-brazil/brazil-confirms-firstcoronavirus-case-in-latin-america-source-idUSKCN20K1EU>. Acesso em: 3 jul. 2020 .

PIRES, R. R. C. Os Efeitos sobre grupos sociais e territórios vulnerabilizados das medidas de enfrentamento à crise sanitária da Covid-19: propostas para o aperfeiçoamento da ação pública. 2020.

RITCHIE, H. et al. Coronavirus (COVID-19) Deaths - Statistics and Research - Our World in Data. Disponível em: <https://ourworldindata.org/coviddeaths>. Acesso em: 24 jul. 2020.

SALAZAR, A. et al. O SUS pode ser seu melhor plano de saúde. 2003.

SESRJ. Secretaria de Estado de Saúde do RJ. Primeiro caso do Novo Coronavírus é confirmado no Estado do Rio. Disponível em: <https://www.saude.rj.gov.br/noticias/2020/03/primeiro-caso-do-novo-coronavirus- 
e-confirmado-no-estado-do-rio>. Acesso em: 5 jul. 2020a.

SESRJ. Secretaria de Estado de Saúde do RJ. Plano de resposta de emergência ao Coronavírus no estado do Rio de Janeiro TT - Coronavirus emergency response plan in the state of Rio de Janeiro. Disponível em: <https://portalarquivos2.saude.gov.br/images/pdf/2020/fevereiro/13/PLANO-DECONTINGENCIA-novo-coronavirus-RIO-DE-JANEIRO-EM-REVIS--O.pdf http://fi-admin.bvsalud.org/document/view/nag2y> Acesso em: 6 abr. 2020 b.

SESRJ. Secretaria de Estado de Saúde do RJ. Estado do Rio registra a primeira morte por coronavírus. Disponível em: <https://saude.rj.gov.br/noticias/2020/03/estado-do-rio-registra-a-primeira-mortepor-coronavirus>. Acesso em: 9 jul. 2020c.

SESRJ. Secretaria de Estado de Saúde do RJ. Painel coronavírus COVID-19. Disponível em: <http://painel.saude.rj.gov.br/monitoramento/covid19.html〉. Acesso em: 10 ago. $2020 \mathrm{~d}$.

SALMAN, F. S.; GÜL, S. Deployment of field hospitals in mass casualty incidents. Computers and Industrial Engineering, v. 74, n. 1, p. 37-51, 2014

SHAH, K. et al. Unfolding trends of covid-19 transmission in india: Critical review of available mathematical modelsIndian Journal of Community HealthIndian Association of Preventive and Social Medicine, , 20 abr. 2020.

SHARIFF, S. S. R.; MOIN, N. H.; OMAR, M. Location allocation modeling for healthcare facility planning in Malaysia. Computers and Industrial Engineering, v. 62, n. 4, p. 1000-1010, 2012.

SOHRABI, Catrin, et al. World Health Organization declares global emergency: A review of the 2019 novel coronavirus (COVID-19). International Journal of Surgery, 2020.

TANG, J. W.; TAMBYAH, P. A.; HUI, D. S. C. Emergence of a novel coronavirus causing respiratory illness from Wuhan, China. Journal of Infection, v. 80, n. 3, p. 350-371, 2020.

TAVAKKOLI-MOGHADDAM, R. et al. A Bi-objective Credibility-based Fuzzy Mathematical Programming Model for a Healthcare Facility Location-network Design Problem. IEEE International Conference on Industrial Engineering and Engineering Management, v. 2019- Decem, p. 1181-1185, 2019.

WERNECK, G. L.; CARVALHO, M. S. The COVID-19 pandemic in Brazil: chronicle of a health crisis foretold. Cadernos de saude publica, v. 36, n. 5, p. 
e00068820, 2020.

WHO (WORLD HEALTH ORGANIZATION); R\&D BLUEPRINT. COVID 19 Public Health Emergency of International Concern | Global research and innovation forum: towards a reserach roadmapWHO (World Health Organization). Disponível em: <https://covid19evidence.paho.org/handle/20.500.12663/714>. Acesso em: 29 jun. 2020.

WOOD, R. M.; TO. Modelling the impact of COVID-19 on elective waiting times. Journal of Simulation, v. 00, n. 00, p. 1-9, 2020.

XU, Z. et al. Pathological findings of COVID-19 associated with acute respiratory distress syndrome. The Lancet Respiratory Medicine, v. 8, n. 4, p. 420422, 1 abr. 2020.

YU, H. et al. Reverse Logistics Network Design for Effective Management of Medical Waste in Epidemic Outbreak: Insights from the Coronavirus Disease 2019 (COVID-19) in Wuhan. SSRN Electronic Journal, 2020.

ZHANG, J. JIN et al. Clinical characteristics of 140 patients infected with SARS-CoV-2 in Wuhan, China. Allergy: European Journal of Allergy and Clinical Immunology, n. February, p. 1-12, 2020.

ZHANG, W. et al. A multi-objective optimization approach for health-care facility location-allocation problems in highly developed cities such as Hong Kong. Computers, Environment and Urban Systems, v. 59, p. 220-230, 2016.

ZHANG, Y.; BERMAN, O.; VERTER, V. The impact of client choice on preventive healthcare facility network design. OR Spectrum, v. 34, n. 2, p. 349-370, 2012. 
APÊNDICE I - Localização de estabelecimentos de saúde

\begin{tabular}{|c|c|c|c|c|c|}
\hline Artigo & Tipo de aplicação & Objetivo & $\begin{array}{l}\text { Abordagem de } \\
\text { modelagem }\end{array}$ & Método de solução & $\begin{array}{l}\text { Perfil da } \\
\text { demanda }\end{array}$ \\
\hline Shariff et al. (2012) & $\begin{array}{l}\text { Planejamento de } \\
\text { instalações de saúde }\end{array}$ & Maximizar a cobertura & CMCLP & GA, CPLEX & Fixa \\
\hline Zhang et al. (2012) & $\begin{array}{l}\text { Localização preventiva } \\
\text { do estabelecimento de } \\
\text { saúde }\end{array}$ & $\begin{array}{l}\text { Maximizar a participação do } \\
\text { programa de saúde } \\
\text { preventiva }\end{array}$ & $\begin{array}{l}\text { Modelo de escolha } \\
\text { probabilística, } \\
\text { modelo de escolha } \\
\text { ótima baseado em } \\
\text { MNL, MIP }\end{array}$ & CPLEX & Variável \\
\hline Kim \& Kim (2013) & $\begin{array}{l}\text { Localização de } \\
\text { estabelecimento de } \\
\text { saúde pública }\end{array}$ & $\begin{array}{l}\text { Maximizar o número de } \\
\text { pacientes atendidos }\end{array}$ & IP & $\begin{array}{l}\text { Algoritmo heurístico } \\
\text { baseado em métodos } \\
\text { de otimização LR e } \\
\text { subgradiente }\end{array}$ & Variável \\
\hline Mestre et al. (2015) & $\begin{array}{l}\text { Definição de } \\
\text { localização para } \\
\text { planejamento hospitalar } \\
\text { sob incerteza }\end{array}$ & $\begin{array}{l}\text { Minimizar o tempo } \\
\text { esperado de viagem; } \\
\text { Minimizar o custo esperado } \\
\text { e os custos de capital. }\end{array}$ & $\begin{array}{l}\text { Modelo 1: } \\
\text { localização como } \\
\text { uma decisão de } \\
\text { primeira etapa, }\end{array}$ & CPLEX & Variável \\
\hline
\end{tabular}




\begin{tabular}{|c|c|c|c|c|c|}
\hline & & & $\begin{array}{l}\text { Modelo 2: } \\
\text { Localização e } \\
\text { alocação como } \\
\text { decisões de primeiro } \\
\text { estágio }\end{array}$ & & \\
\hline $\begin{array}{l}\text { Haase \& Müller } \\
(2015)\end{array}$ & $\begin{array}{l}\text { Localização de } \\
\text { estabelecimento de } \\
\text { saúde preventiva }\end{array}$ & $\begin{array}{l}\text { Maximizar a participação do } \\
\text { programa de saúde } \\
\text { preventiva }\end{array}$ & $\begin{array}{l}\text { MNL, MILP, } \\
\text { derivação do limite } \\
\text { inferior }\end{array}$ & CPLEX & Variável \\
\hline Arvan et al. (2015) & $\begin{array}{l}\text { Rede da cadeia de } \\
\text { suprimento de sangue } \\
\text { humano }\end{array}$ & $\begin{array}{l}\text { Minimizar o custo total, } \\
\text { minimizar os tempos em } \\
\text { que os produtos sanguíneos } \\
\text { permanecem na rede }\end{array}$ & $\begin{array}{l}\text { Modelo biobjetivo, } \\
\text { MILP }\end{array}$ & Método $\varepsilon$-constraint & $\begin{array}{l}\text { Determinística } \\
\text { fixada }\end{array}$ \\
\hline Zhang et al. (2016) & $\begin{array}{l}\text { Alocação e localização } \\
\text { de estabelecimento de } \\
\text { saúde }\end{array}$ & $\begin{array}{l}\text { Maximizar acessibilidade; } \\
\text { Minimizar a desigualdade } \\
\text { de acessibilidade; } \\
\text { Minimizar a população } \\
\text { descoberta; } \\
\text { Minimizar o custo de } \\
\text { construção. }\end{array}$ & $\begin{array}{l}\text { Otimização } \\
\text { multiobjetivo }\end{array}$ & GA & Fixa \\
\hline
\end{tabular}




\begin{tabular}{|c|c|c|c|c|c|}
\hline Djenic et al. (2016) & $\begin{array}{l}\text { Localização de } \\
\text { facilidade de cuidado a } \\
\text { longo prazo }\end{array}$ & $\begin{array}{l}\text { Minimizar o número } \\
\text { máximo de pacientes } \\
\text { associados a uma única } \\
\text { instalação localizada }\end{array}$ & LTCFLP LTCFLP-I & $\begin{array}{l}\text { Metaheurística } \\
\text { baseada em Variable } \\
\text { Neighborhood Search } \\
\text { (VNS) }\end{array}$ & Fixa \\
\hline Basu et al. (2018) & $\begin{array}{l}\text { Alocação de unidades } \\
\text { de saúde }\end{array}$ & - & - & - & Variável \\
\hline $\begin{array}{l}\text { Tavakkoli- } \\
\text { Moghaddam et al. } \\
\text { (2019) }\end{array}$ & $\begin{array}{l}\text { Localização de } \\
\text { estabelecimento de } \\
\text { saúde }\end{array}$ & $\begin{array}{l}\text { Minimizar o custo total de } \\
\text { transporte e construção de } \\
\text { instalações; } \\
\text { Maximizar os impactos } \\
\text { sociais do estabelecimento } \\
\text { localizado. }\end{array}$ & FLNDP & $\begin{array}{l}\text { Metaheurísticas } \\
\text { multiobjetivos, } \\
\text { conhecidas como } \\
\text { NSGA-II e MPOSO }\end{array}$ & Variável \\
\hline $\begin{array}{l}\text { Ouyang et al. } \\
(2020)\end{array}$ & $\begin{array}{l}\text { Localização de } \\
\text { estabelecimentos de } \\
\text { saúde e alocação de } \\
\text { pacientes }\end{array}$ & $\begin{array}{l}\text { Minimizar os custos totais } \\
\text { de construção e manutenção } \\
\text { das instalações }\end{array}$ & ILP & CPLEX & Fixa \\
\hline Vries et al. (2020) & $\begin{array}{l}\text { Localização de unidade } \\
\text { de saúde na estrada }\end{array}$ & $\begin{array}{l}\text { Maximizar o volume de } \\
\text { pacientes nas unidades; }\end{array}$ & MILP & CPLEX & Fixa \\
\hline
\end{tabular}




\begin{tabular}{|c|c|c|c|c|c|}
\hline & & $\begin{array}{l}\text { Maximizar a efetividade da } \\
\text { prestação de serviços de } \\
\text { saúde à população atendida. }\end{array}$ & & & \\
\hline $\begin{array}{l}\text { Nasrabadi et al. } \\
(2020)\end{array}$ & $\begin{array}{l}\text { Localização de } \\
\text { instalações de saúde, } \\
\text { alocação de unidades de } \\
\text { serviço e determinação } \\
\text { das capacidades das } \\
\text { instalações }\end{array}$ & $\begin{array}{l}\text { Minimizar o tempo total de } \\
\text { transporte; } \\
\text { Minimizar o custo fixo e } \\
\text { operacional da implantação } \\
\text { da instalação. }\end{array}$ & HiFLP & $\begin{array}{l}\text { Metaheurística } \\
\text { multiobjetivos } \\
\text { NSGA-II }\end{array}$ & Variável \\
\hline Silva (2020) & $\begin{array}{l}\text { Localização de } \\
\text { hospitais de campanha } \\
\text { e alocação de leitos e } \\
\text { respiradores }\end{array}$ & $\begin{array}{l}\text { Minimizar a distância } \\
\text { percorrida e o custo de } \\
\text { instalação }\end{array}$ & $\begin{array}{l}\text { ILP para problemas } \\
\text { de cobertura }\end{array}$ & CPLEX & Fixa \\
\hline
\end{tabular}


APÊNDICE II - Proporção do total de casos por município do estado do RJ

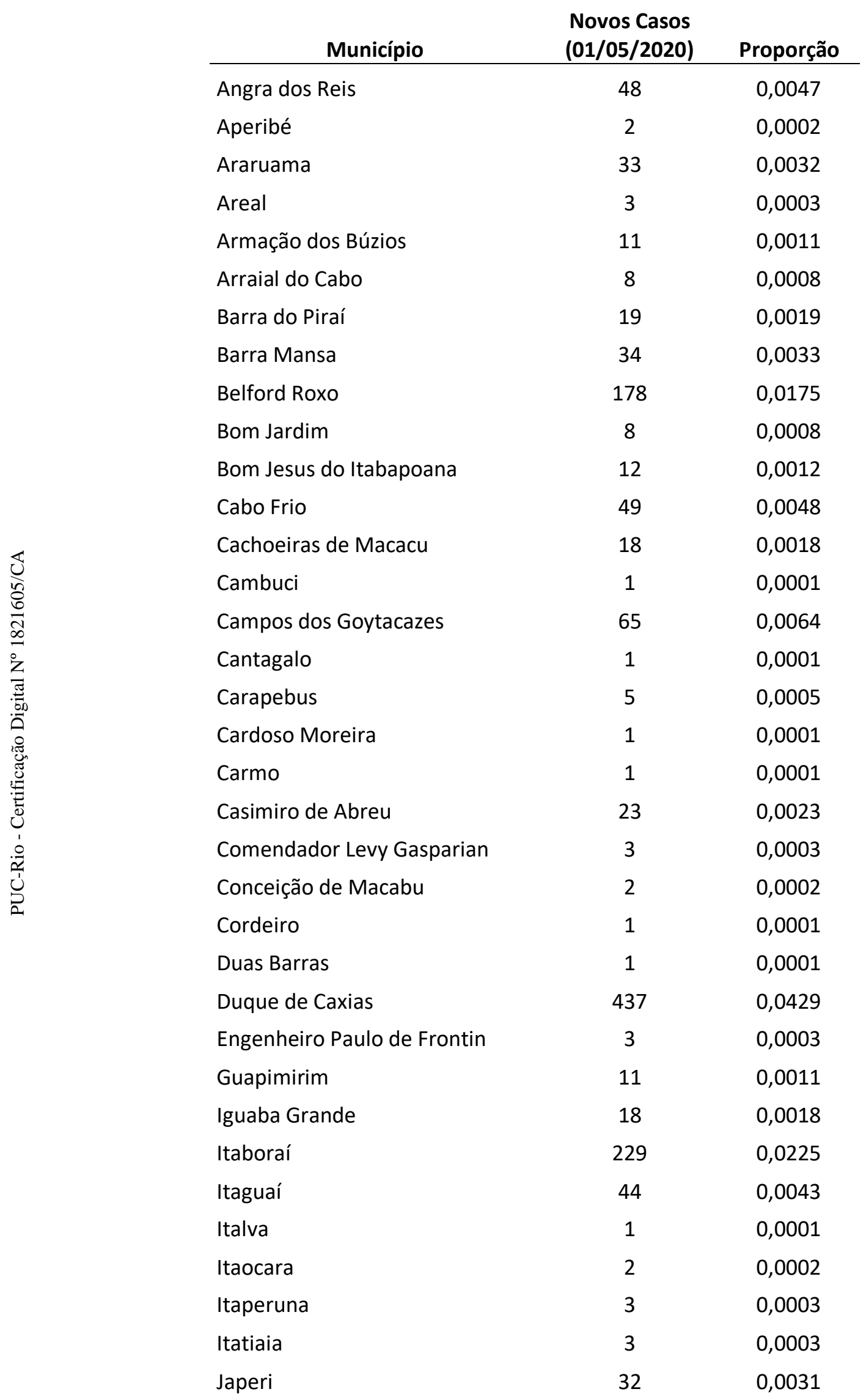




\begin{tabular}{|c|c|c|}
\hline Laje do Muriaé & 1 & 0,0001 \\
\hline Macaé & 47 & 0,0046 \\
\hline Macuco & 1 & 0,0001 \\
\hline Magé & 113 & 0,0111 \\
\hline Mangaratiba & 7 & 0,0007 \\
\hline Maricá & 73 & 0,0072 \\
\hline Mendes & 3 & 0,0003 \\
\hline Mesquita & 164 & 0,0161 \\
\hline Miguel Pereira & 8 & 0,0008 \\
\hline Miracema & 1 & 0,0001 \\
\hline Natividade & 1 & 0,0001 \\
\hline Nilópolis & 82 & 0,0081 \\
\hline Niterói & 406 & 0,0399 \\
\hline Nova Friburgo & 57 & 0,0056 \\
\hline Nova Iguaçu & 403 & 0,0396 \\
\hline Paracambi & 30 & 0,0029 \\
\hline Paraíba do Sul & 10 & 0,0010 \\
\hline Paraty & 7 & 0,0007 \\
\hline Paty do Alferes & 4 & 0,0004 \\
\hline Petrópolis & 94 & 0,0092 \\
\hline Pinheiral & 8 & 0,0008 \\
\hline Piraí & 5 & 0,0005 \\
\hline Porciúncula & 1 & 0,0001 \\
\hline Porto Real & 3 & 0,0003 \\
\hline Quatis & 3 & 0,0003 \\
\hline Queimados & 56 & 0,0055 \\
\hline Quissamã & 5 & 0,0005 \\
\hline Resende & 25 & 0,0025 \\
\hline Rio Bonito & 26 & 0,0026 \\
\hline Rio Claro & 3 & 0,0003 \\
\hline Rio das Flores & 3 & 0,0003 \\
\hline Rio das Ostras & 44 & 0,0043 \\
\hline Rio de Janeiro & 6189 & 0,6077 \\
\hline Santa Maria Madalena & 1 & 0,0001 \\
\hline Santo Antônio de Pádua & 3 & 0,0003 \\
\hline São Fidélis & 5 & 0,0005 \\
\hline São Francisco de Itabapoana & 11 & 0,0011 \\
\hline São Gonçalo & 279 & 0,0274 \\
\hline São João da Barra & 15 & 0,0015 \\
\hline
\end{tabular}




\begin{tabular}{lcc} 
São João de Meriti & 201 & 0,0197 \\
São José de Ubá & 3 & 0,0003 \\
São José do Vale do Rio Preto & 1 & 0,0001 \\
São Pedro da Aldeia & 24 & 0,0024 \\
São Sebastião do Alto & 2 & 0,0002 \\
Sapucaia & 19 & 0,0019 \\
Saquarema & 37 & 0,0036 \\
Seropédica & 11 & 0,0011 \\
Silva Jardim & 5 & 0,0005 \\
Sumidouro & 2 & 0,0002 \\
Tanguá & 15 & 0,0015 \\
Teresópolis & 48 & 0,0047 \\
Trajano de Moraes & 1 & 0,0001 \\
Três Rios & 20 & 0,0020 \\
Valença & 8 & 0,0008 \\
Varre-Sai & 1 & 0,0001 \\
Vassouras & 8 & 0,0008 \\
Volta Redonda & 271 & 0,0266 \\
\hline
\end{tabular}




\section{APÊNDICE III - Diagrama de filtragem da base de dados SRAG}

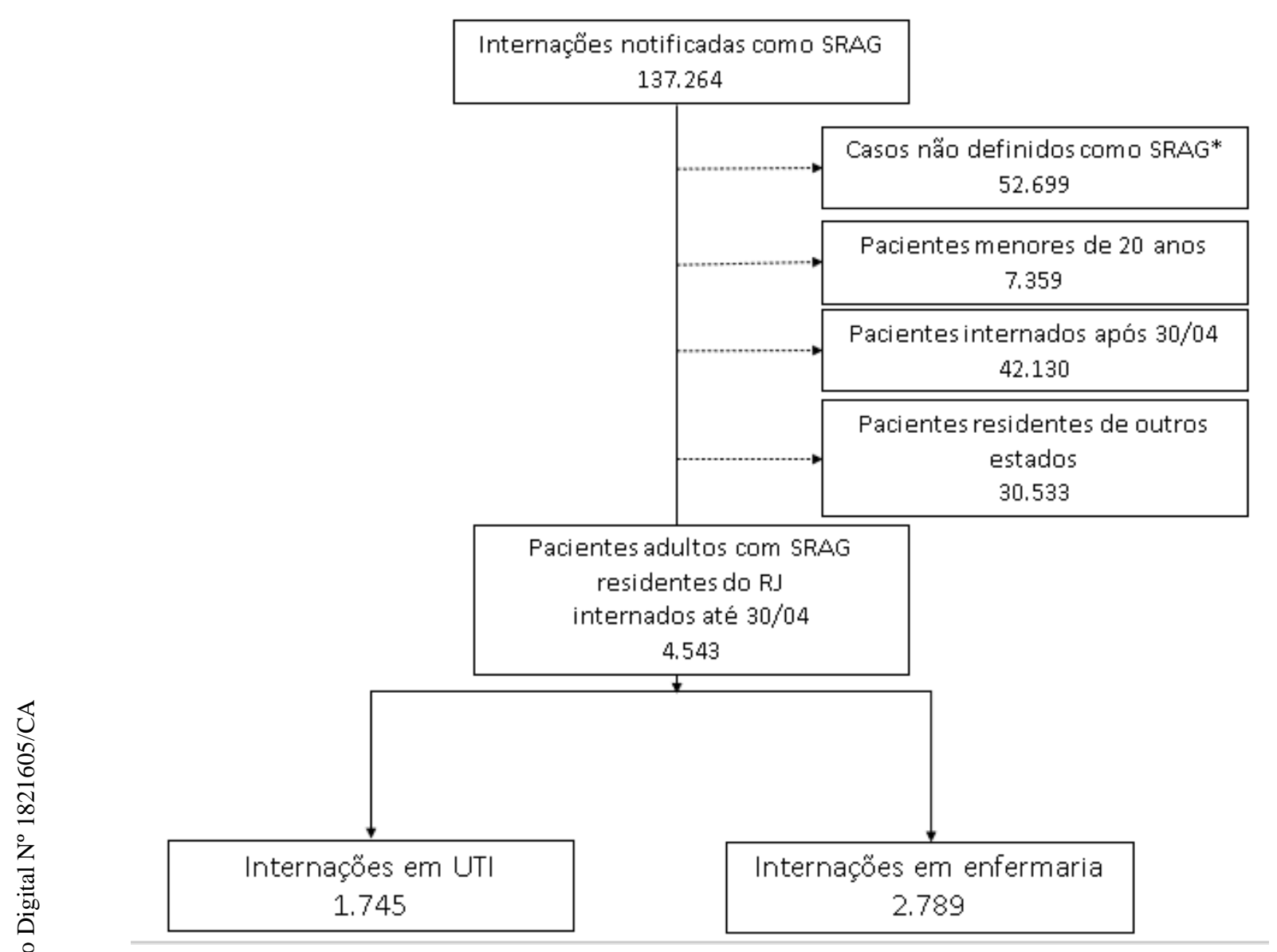

*De acordo com os critérios definidos pelo MS(2020h). 


\section{APÊNDICE IV - Estimativa da demanda de leitos de UTI para o Estado do RJ}

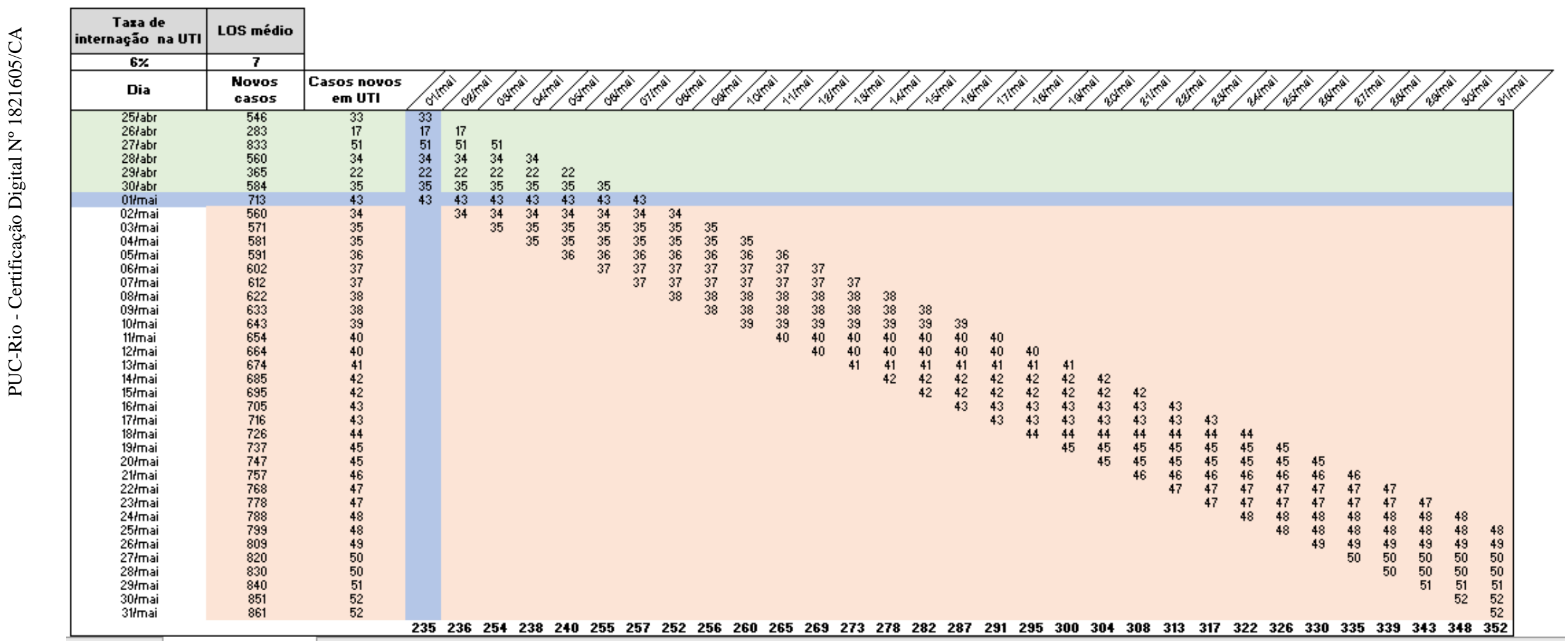




\section{APÊNDICE V - Estimativa da demanda de leitos de UTI com uso de ventilação mecânica para o Estado do RJ}

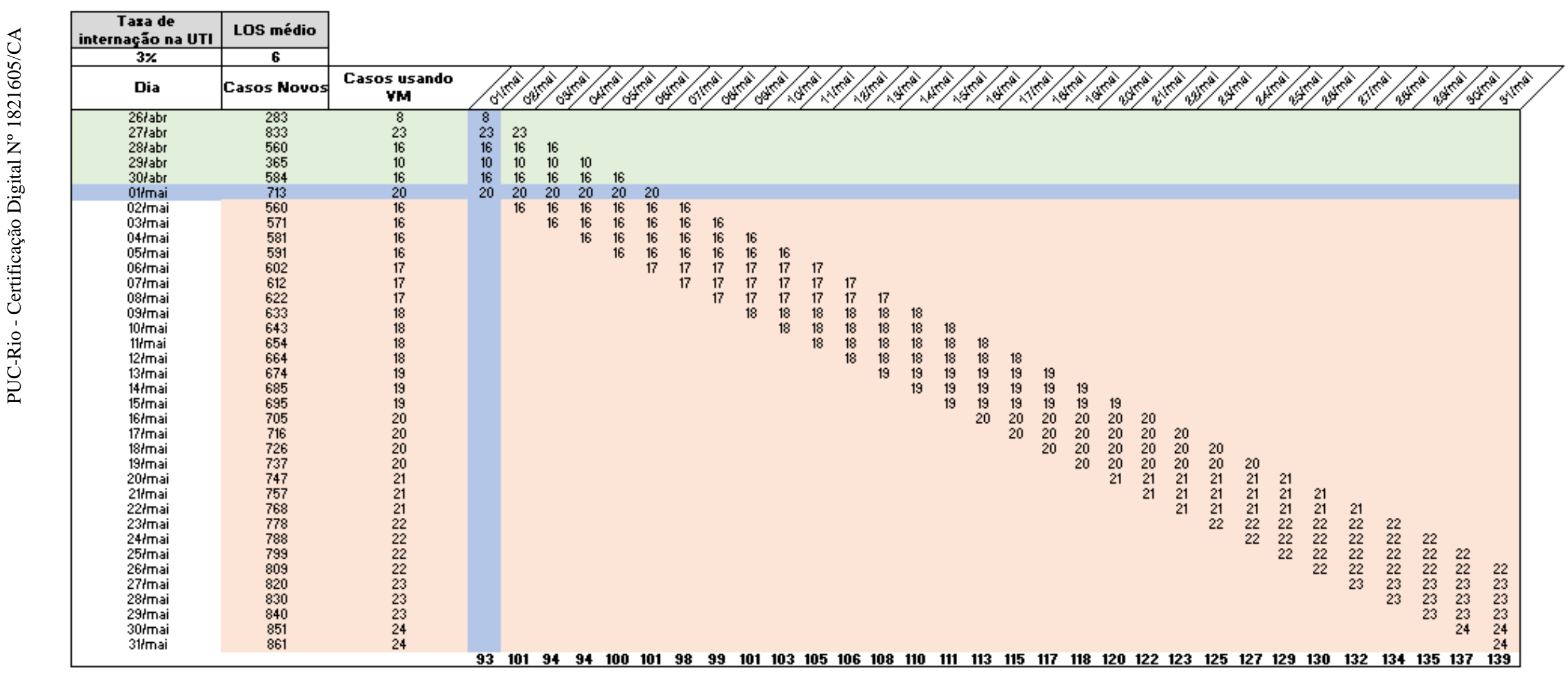


APÊNDICE VI - Estimativa da demanda de leitos de enfermaria com uso de ventilação mecânica para o Estado do RJ

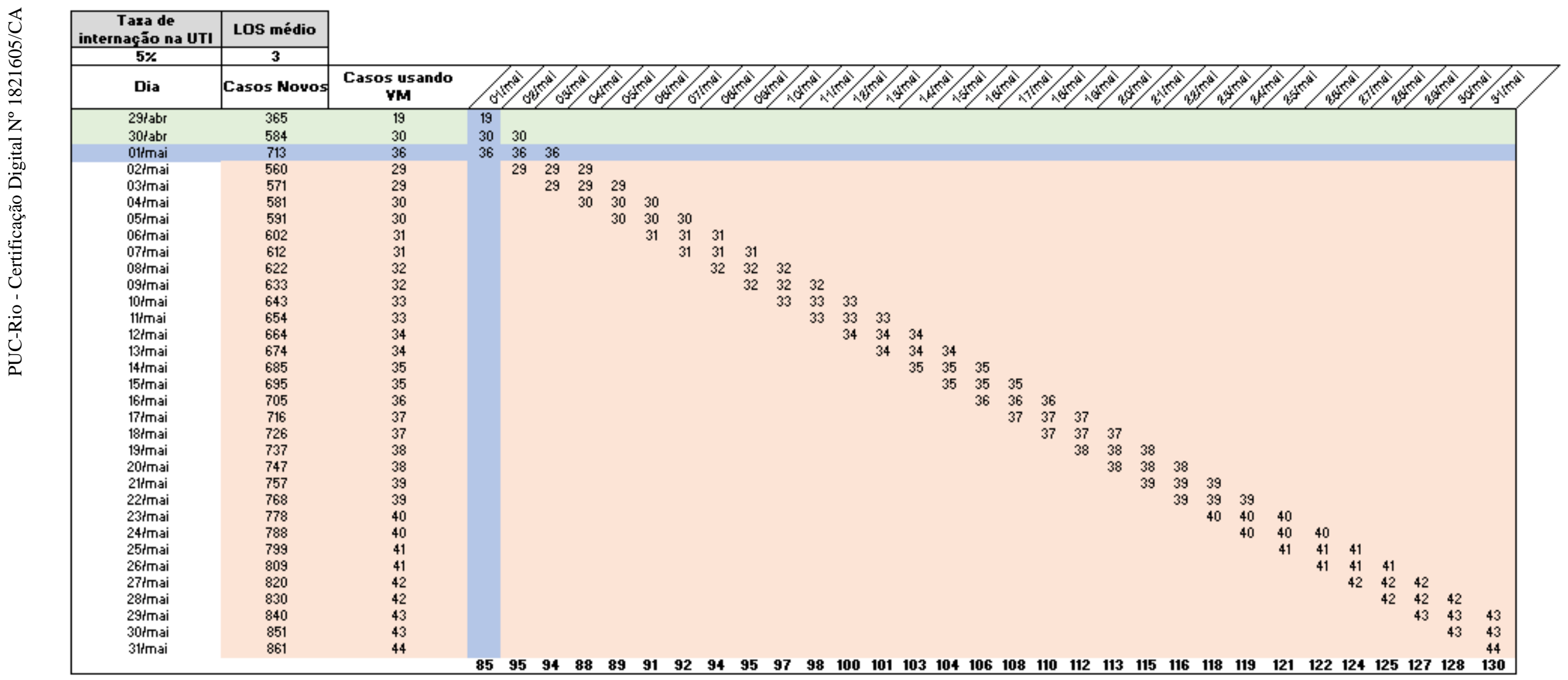




\section{APÊNDICE VII - Estimativa da demanda de leitos de enfermaria para o Estado do RJ}

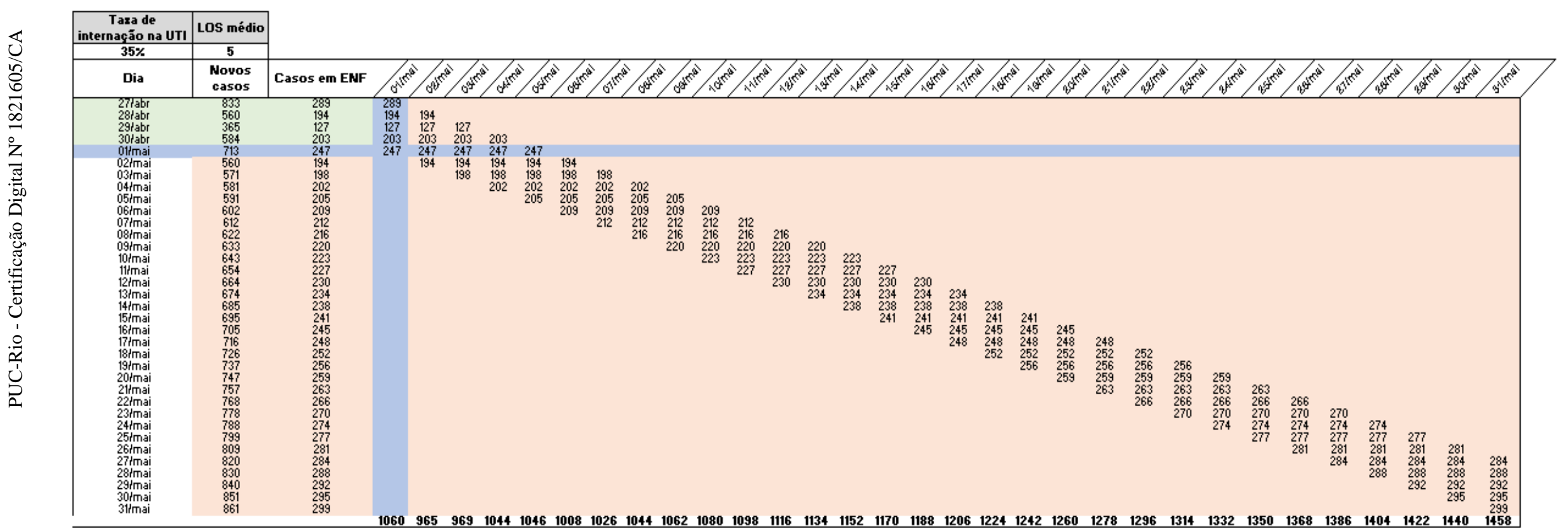


APÊNDICE VIII - Demanda estimada de leitos de UTI por município

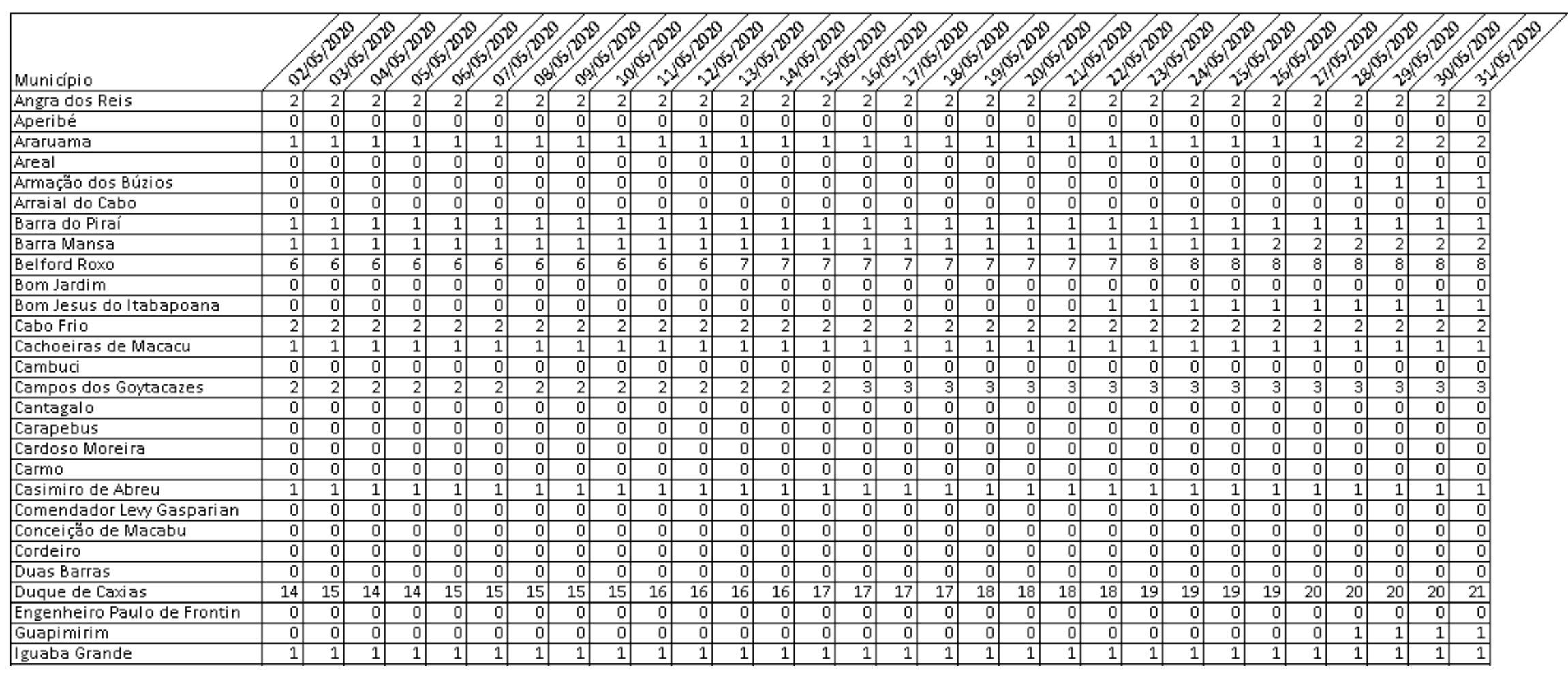




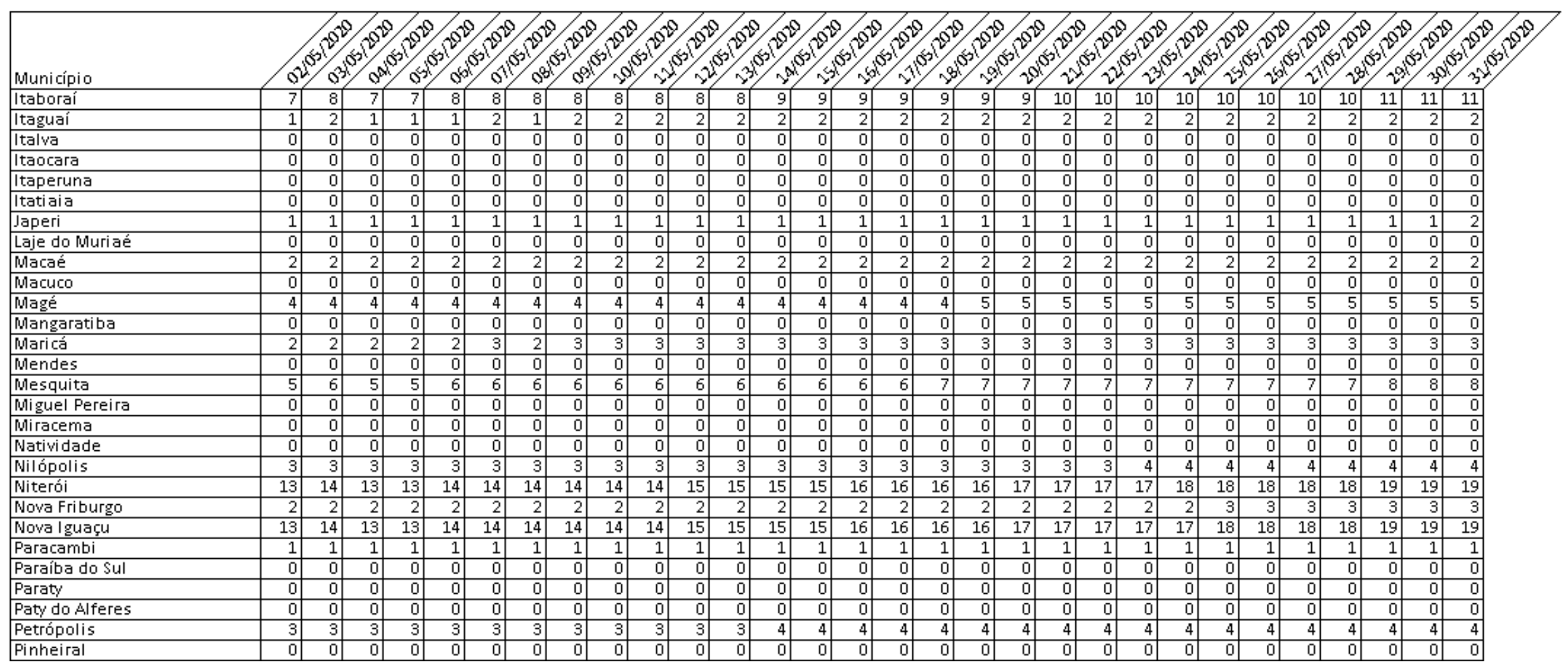




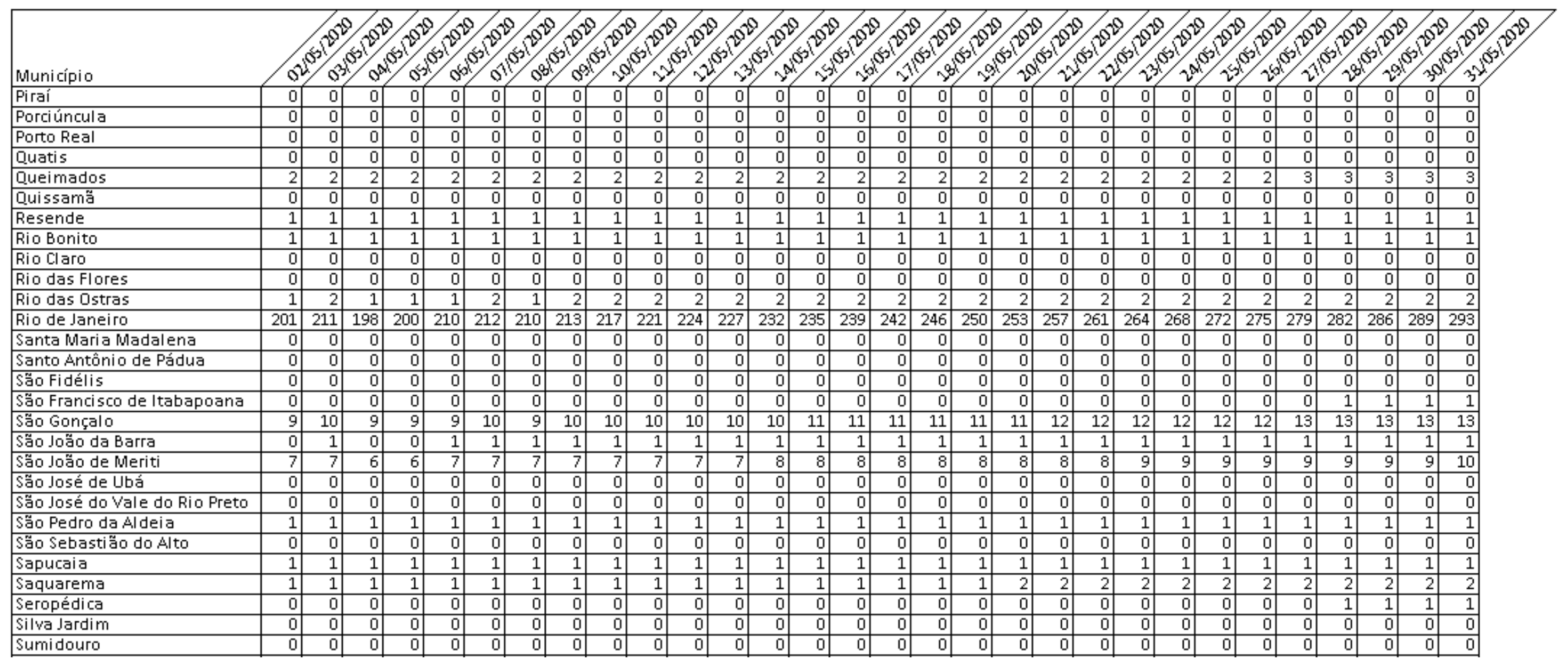




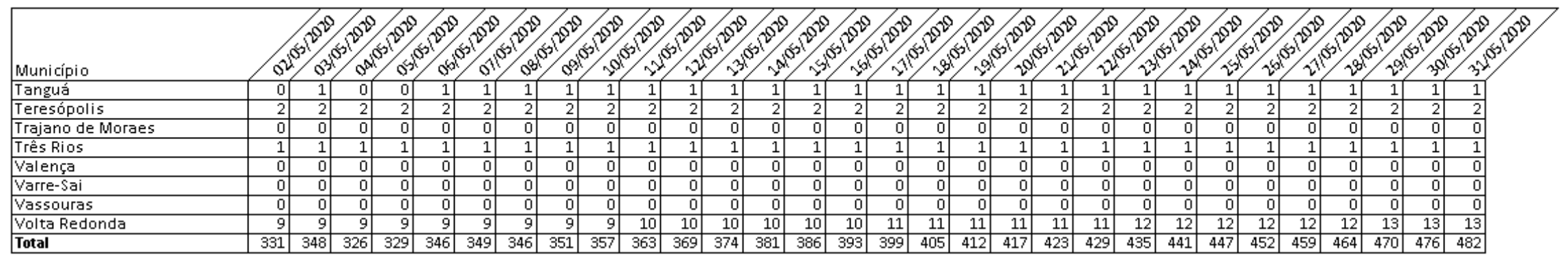




\section{APÊNDICE IX - Demanda estimada de uso de ventilação mecânica invasiva}

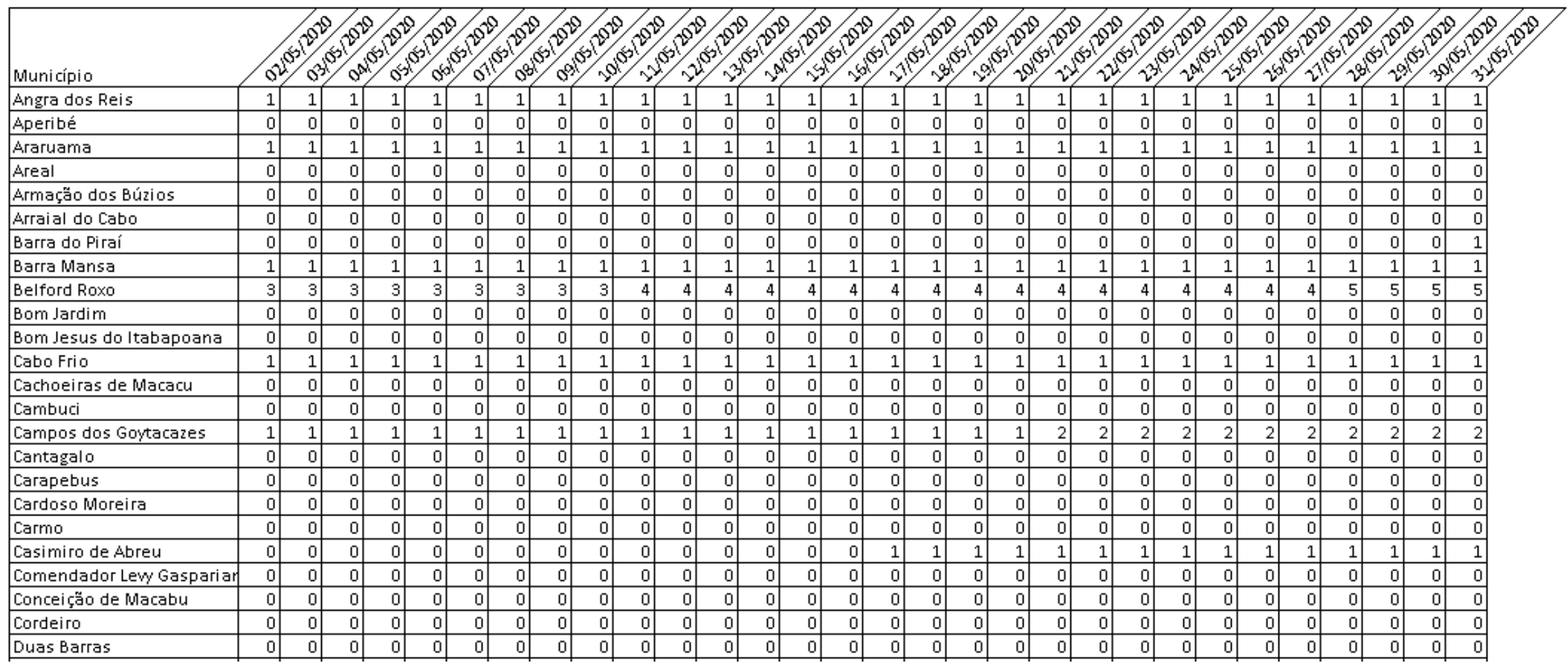


Município

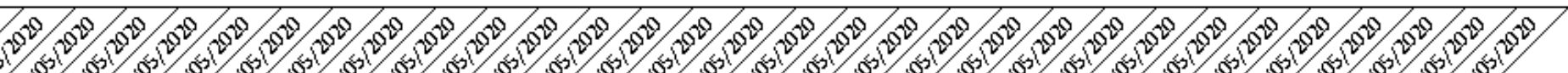

Municipio

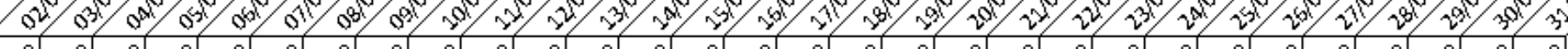

Dugue

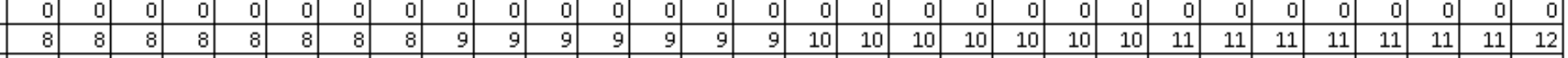

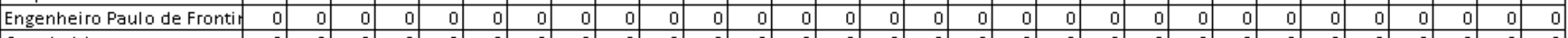

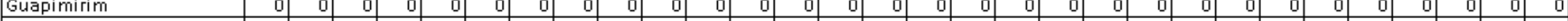

Iguaba Grande

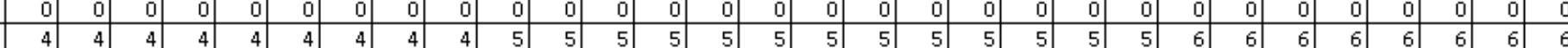

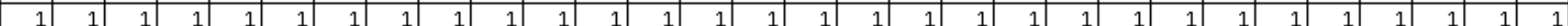

\begin{tabular}{l|l|l|l|l|l|l|l|l|l|l|l|l|l|l|l|l|l|l|l|l|l|l|l|l|l|l|l|l|}
0 & 0 & 0 & 0 & 0 & 0 & 0 & 0 & 0 & 0 & 0 & 0 & 0 & 0 & 0 & 0 & 0 & 0 & 0 & 0 & 0 & 0 & 0 & 0 & 0 & 0 & 0 & 0 & 0 \\
\hline
\end{tabular}

Italva

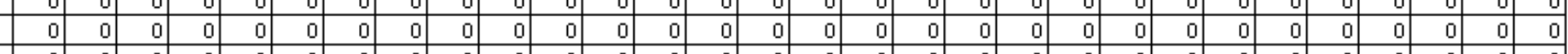

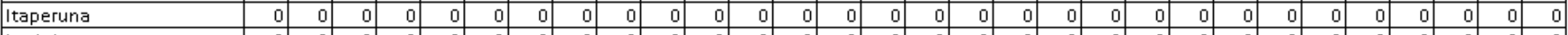

Itatiaia

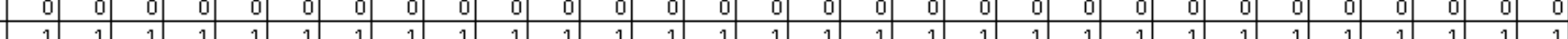

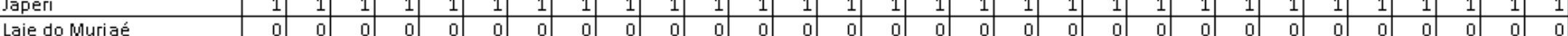

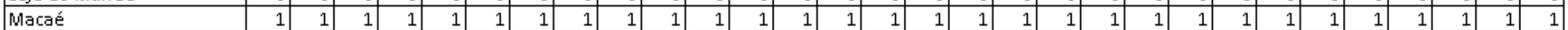

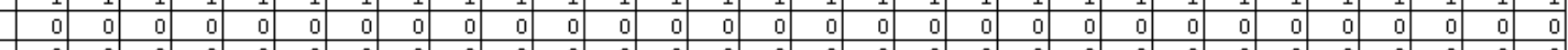

Mangaratiba

Maricá

Mendes

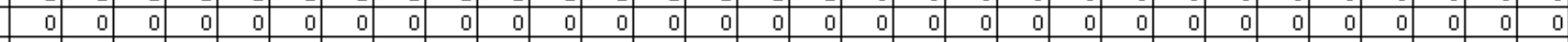

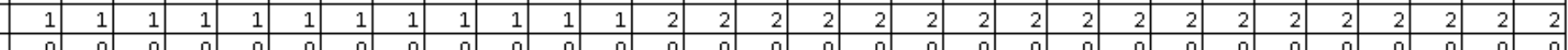

Miguel Pereira

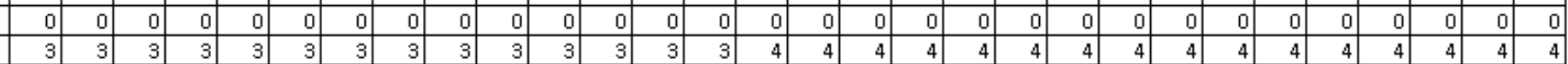

Miracema

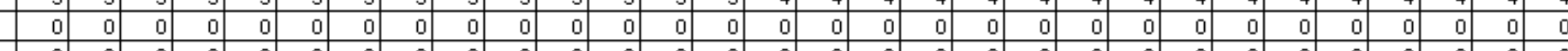

Natividade

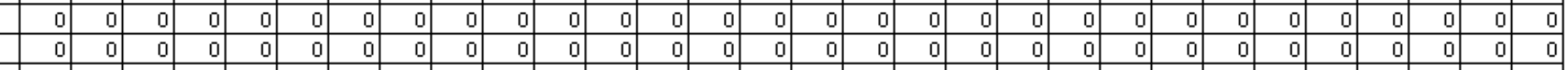

Nilópolis \begin{tabular}{|l|l|l|l|l|l|l|l|l|l|l|l|l|l|l|l|l|l|l|l|l|l|l|l|r|r|r|r|r|r|}
2 & 2 & 1 & 2 & 2 & 2 & 2 & 2 & 2 & 2 & 2 & 2 & 2 & 2 & 2 & 2 & 2 & 2 & 2 & 2 & 2 & 2 & 2 & 2 & 2 & 2 & 2 & 2 & 2 \\
\hline
\end{tabular} 


\begin{tabular}{|c|c|c|c|c|c|c|c|c|c|c|c|c|c|c|c|c|c|c|c|c|c|c|c|c|c|c|c|c|c|c|}
\hline \multicolumn{31}{|l|}{ Muni cípio } \\
\hline \begin{tabular}{|l|} 
Niterói \\
\end{tabular} & 8 & 7 & 7 & 8 & 8 & 8 & 8 & 8 & 8 & 8 & 8 & 8 & 8 & 9 & 9 & 9 & 9 & 9 & 9 & 9 & 10 & 10 & 10 & 10 & 10 & 10 & 10 & 10 & 11 & 11 \\
\hline Nova Friburgo & 1 & 1 & 1 & 1 & 1 & 1 & 1 & 1 & 1 & 1 & 1 & 1 & 1 & 1 & 1 & 1 & 1 & 1 & 1 & 1 & 1 & 1 & 1 & 1 & 1 & 1 & 1 & 1 & 1 & 2 \\
\hline Nova Iguaçu & 8 & 7 & 7 & 7 & 8 & 8 & 8 & 8 & 8 & 8 & 8 & 8 & 8 & 9 & 9 & 9 & 9 & 9 & 9 & 9 & 9 & 10 & 10 & 10 & 10 & 10 & 10 & 10 & 10 & 11 \\
\hline Paracambi & 1 & 1 & 1 & 1 & 1 & 1 & 1 & 1 & 1 & 1 & 1 & 1 & 1 & 1 & 1 & 1 & 1 & 1 & 1 & 1 & 1 & 1 & 1 & 1 & 1 & 1 & 1 & 1 & 1 & 1 \\
\hline Paraíba do Sul & 0 & 0 & 0 & 0 & 0 & 0 & 0 & 0 & 0 & 0 & 0 & 0 & 0 & 0 & 0 & 0 & 0 & 0 & 0 & 0 & 0 & 0 & 0 & 0 & 0 & 0 & 0 & 0 & 0 & 0 \\
\hline Paraty & 0 & 0 & 0 & 0 & 0 & 0 & 0 & 0 & 0 & 0 & 0 & 0 & 0 & 0 & 0 & 0 & 0 & 0 & 0 & 0 & 0 & 0 & 0 & 0 & 0 & 0 & 0 & 0 & 0 & 0 \\
\hline Paty do Alferes & 0 & 0 & 0 & 0 & 0 & 0 & 0 & 0 & 0 & 0 & 0 & 0 & 0 & 0 & 0 & 0 & 0 & 0 & 0 & 0 & 0 & 0 & 0 & 0 & 0 & 0 & 0 & 0 & 0 & 0 \\
\hline Petrópolis & 2 & 2 & 2 & 2 & 2 & 2 & 2 & 2 & 2 & 2 & 2 & 2 & 2 & 2 & 2 & 2 & 2 & 2 & 2 & 2 & 2 & 2 & 2 & 2 & 2 & 2 & 2 & 2 & 2 & 2 \\
\hline Pinheiral & 0 & 0 & 0 & 0 & 0 & 0 & 0 & 0 & 0 & 0 & 0 & 0 & 0 & 0 & 0 & 0 & 0 & 0 & 0 & 0 & 0 & 0 & 0 & 0 & 0 & 0 & 0 & 0 & 0 & 0 \\
\hline \begin{tabular}{|l|} 
Piraí \\
\end{tabular} & 0 & 0 & 0 & 0 & 0 & 0 & 0 & 0 & 0 & 0 & 0 & 0 & 0 & 0 & 0 & 0 & 0 & 0 & 0 & 0 & 0 & 0 & 0 & 0 & 0 & 0 & 0 & 0 & 0 & 0 \\
\hline Porciúncula & 0 & 0 & 0 & 0 & 0 & 0 & 0 & 0 & 0 & 0 & 0 & 0 & 0 & 0 & 0 & 0 & 0 & 0 & 0 & 0 & 0 & 0 & 0 & 0 & 0 & 0 & 0 & 0 & 0 & 0 \\
\hline Porto Real & 0 & 0 & 0 & 0 & 0 & 0 & 0 & 0 & 0 & 0 & 0 & 0 & 0 & 0 & 0 & 0 & 0 & 0 & 0 & 0 & 0 & 0 & 0 & 0 & 0 & 0 & 0 & 0 & 0 & 0 \\
\hline Quatis & 0 & 0 & 0 & 0 & 0 & 0 & 0 & 0 & 0 & 0 & 0 & 0 & 0 & 0 & 0 & 0 & 0 & 0 & 0 & 0 & 0 & 0 & 0 & 0 & 0 & 0 & 0 & 0 & 0 & 0 \\
\hline Queimados & 1 & 1 & 1 & 1 & 1 & 1 & 1 & 1 & 1 & 1 & 1 & 1 & 1 & 1 & 1 & 1 & 1 & 1 & 1 & 1 & 1 & 1 & 1 & 1 & 1 & 1 & 1 & 1 & 1 & 1 \\
\hline Quissamã & 0 & 0 & 0 & 0 & 0 & 0 & 0 & 0 & 0 & 0 & 0 & 0 & 0 & 0 & 0 & 0 & 0 & 0 & 0 & 0 & 0 & 0 & 0 & 0 & 0 & 0 & 0 & 0 & 0 & 0 \\
\hline Resende & 0 & 0 & 0 & 0 & 0 & 0 & 0 & 0 & 0 & 0 & 1 & 1 & 1 & 1 & 1 & 1 & 1 & 1 & 1 & 1 & 1 & 1 & 1 & 1 & 1 & 1 & 1 & 1 & 1 & 1 \\
\hline Rio Bonito & 1 & 0 & 0 & 0 & 0 & 0 & 0 & 1 & 1 & 1 & 1 & 1 & 1 & 1 & 1 & 1 & 1 & 1 & 1 & 1 & 1 & 1 & 1 & 1 & 1 & 1 & 1 & 1 & 1 & 1 \\
\hline Rio Claro & 0 & 0 & 0 & 0 & 0 & 0 & 0 & 0 & 0 & 0 & 0 & 0 & 0 & 0 & 0 & 0 & 0 & 0 & 0 & 0 & 0 & 0 & 0 & 0 & 0 & 0 & 0 & 0 & 0 & 0 \\
\hline Rio das Flores & 0 & 0 & 0 & 0 & 0 & 0 & 0 & 0 & 0 & 0 & 0 & 0 & 0 & 0 & 0 & 0 & 0 & 0 & 0 & 0 & 0 & 0 & 0 & 0 & 0 & 0 & 0 & 0 & 0 & 0 \\
\hline Rio das 0stras & 1 & 1 & 1 & 1 & 1 & 1 & 1 & 1 & 1 & 1 & 1 & 1 & 1 & 1 & 1 & 1 & 1 & 1 & 1 & 1 & 1 & 1 & 1 & 1 & 1 & 1 & 1 & 1 & 1 & 1 \\
\hline Rio de Janeiro & 119 & 114 & 111 & 115 & 117 & 115 & 117 & 119 & 122 & 123 & 125 & 127 & 129 & 131 & 133 & 136 & 138 & 140 & 142 & 144 & 145 & 148 & 149 & 152 & 153 & 156 & 157 & 159 & 161 & 163 \\
\hline Santa Maria Madalena & 0 & 0 & 0 & 0 & 0 & 0 & 0 & 0 & 0 & 0 & 0 & 0 & 0 & 0 & 0 & 0 & 0 & 0 & 0 & 0 & 0 & 0 & 0 & 0 & 0 & 0 & 0 & 0 & 0 & 0 \\
\hline Santo Antônio de Pádua & 0 & 0 & 0 & 0 & 0 & 0 & 0 & 0 & 0 & 0 & 0 & 0 & 0 & 0 & 0 & 0 & 0 & 0 & 0 & 0 & 0 & 0 & 0 & 0 & 0 & 0 & 0 & 0 & 0 & 0 \\
\hline São Fidélis & 0 & 0 & 0 & 0 & 0 & 0 & 0 & 0 & 0 & 0 & 0 & 0 & 0 & 0 & 0 & 0 & 0 & 0 & 0 & 0 & 0 & 0 & 0 & 0 & 0 & 0 & 0 & 0 & 0 & 0 \\
\hline
\end{tabular}




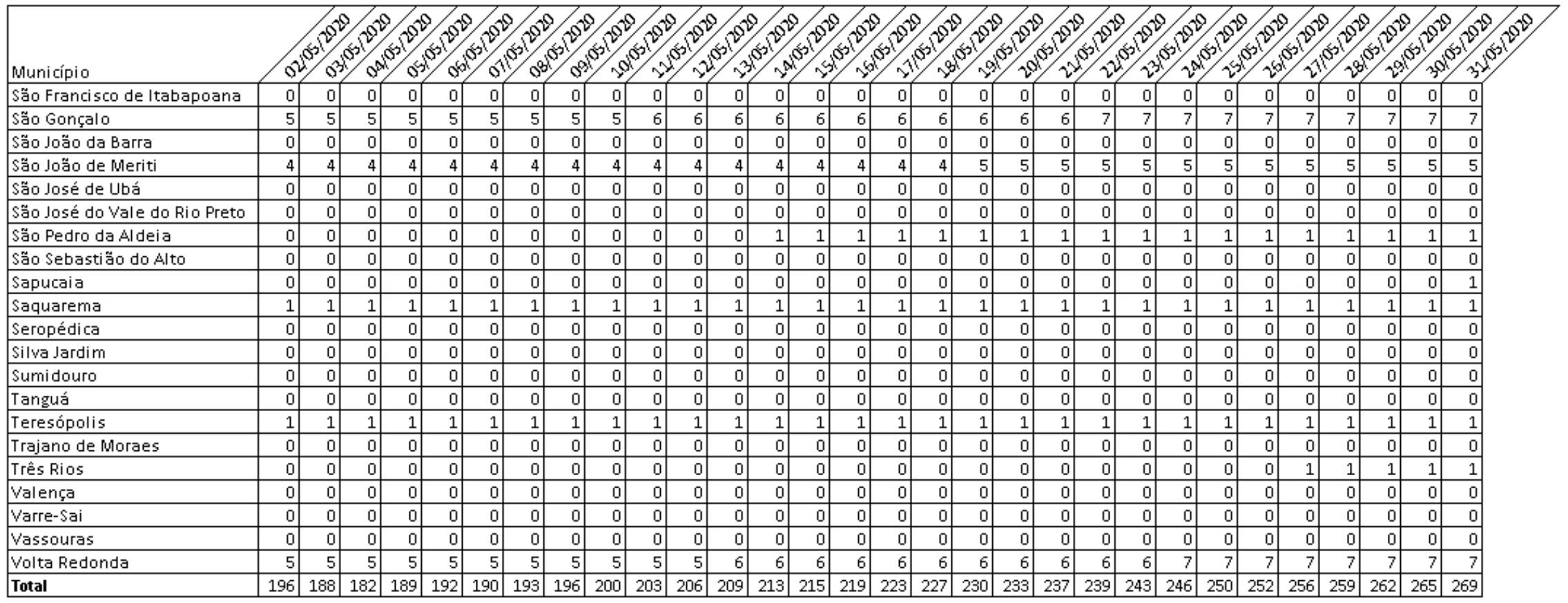


APÊNDICE X - Demanda estimada por leitos de enfermaria

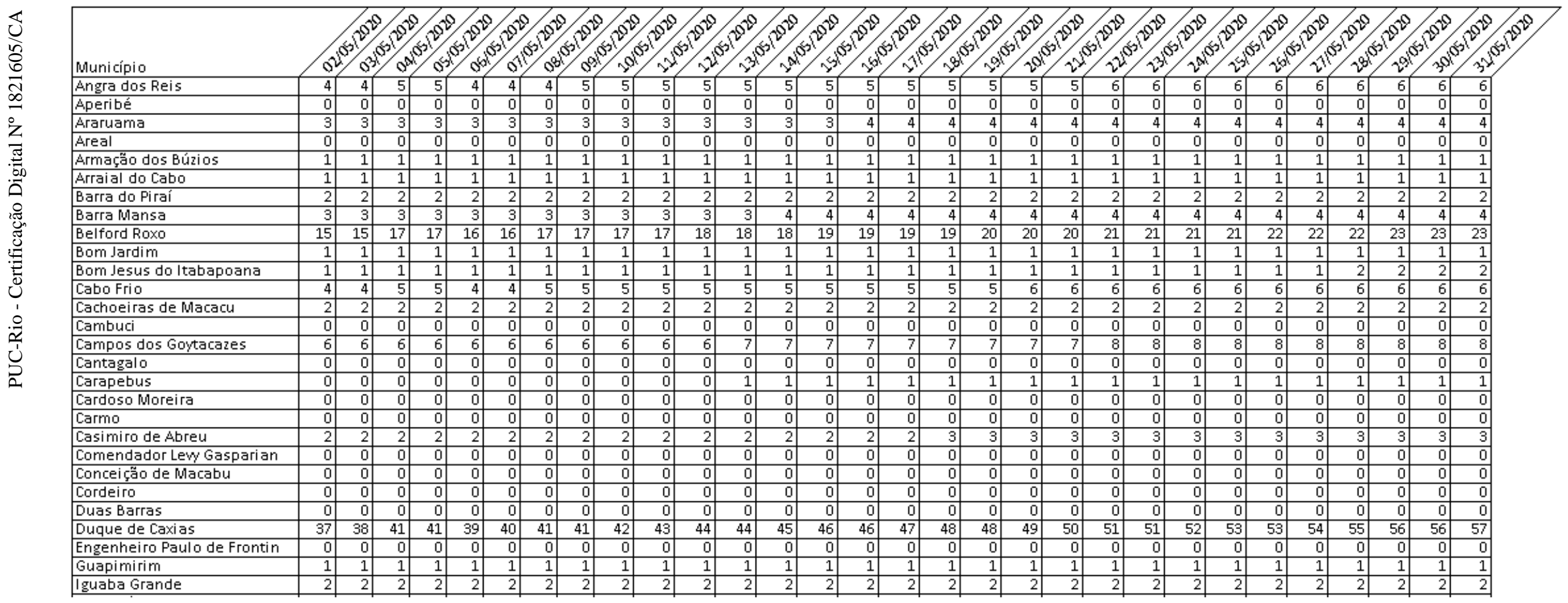




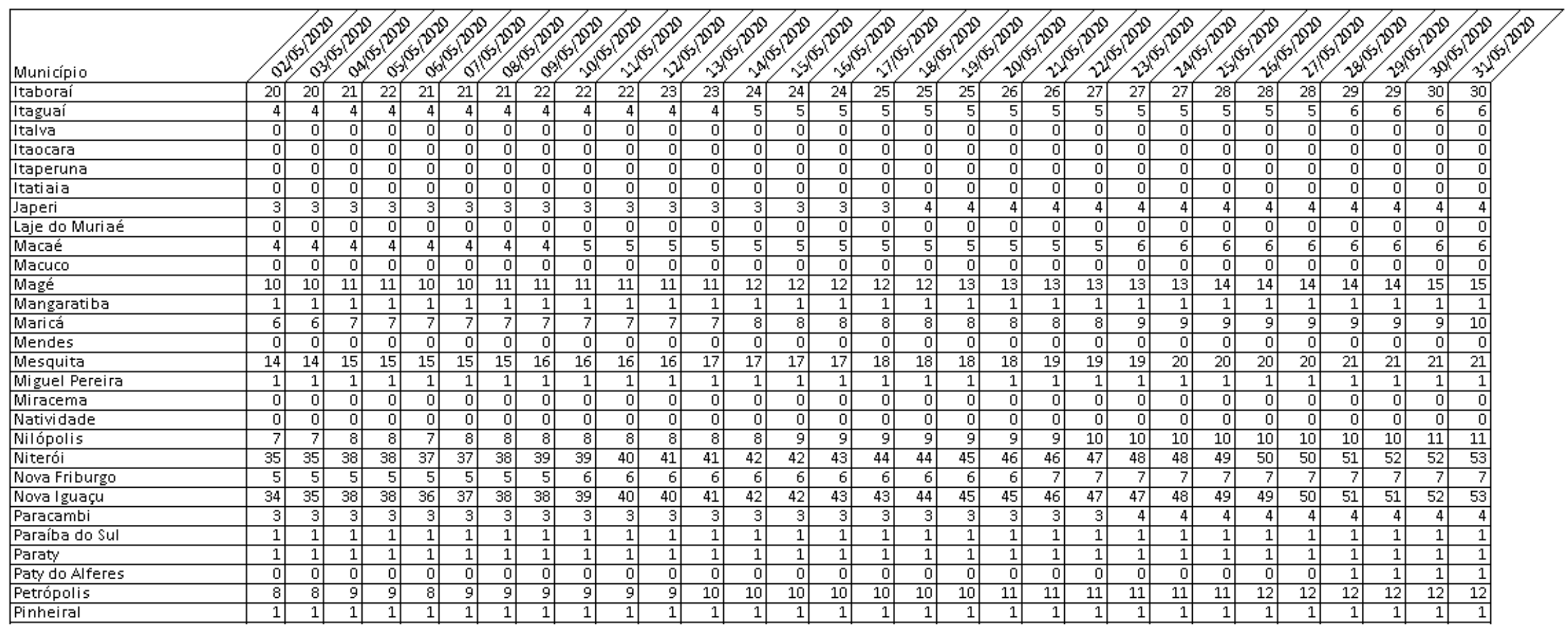




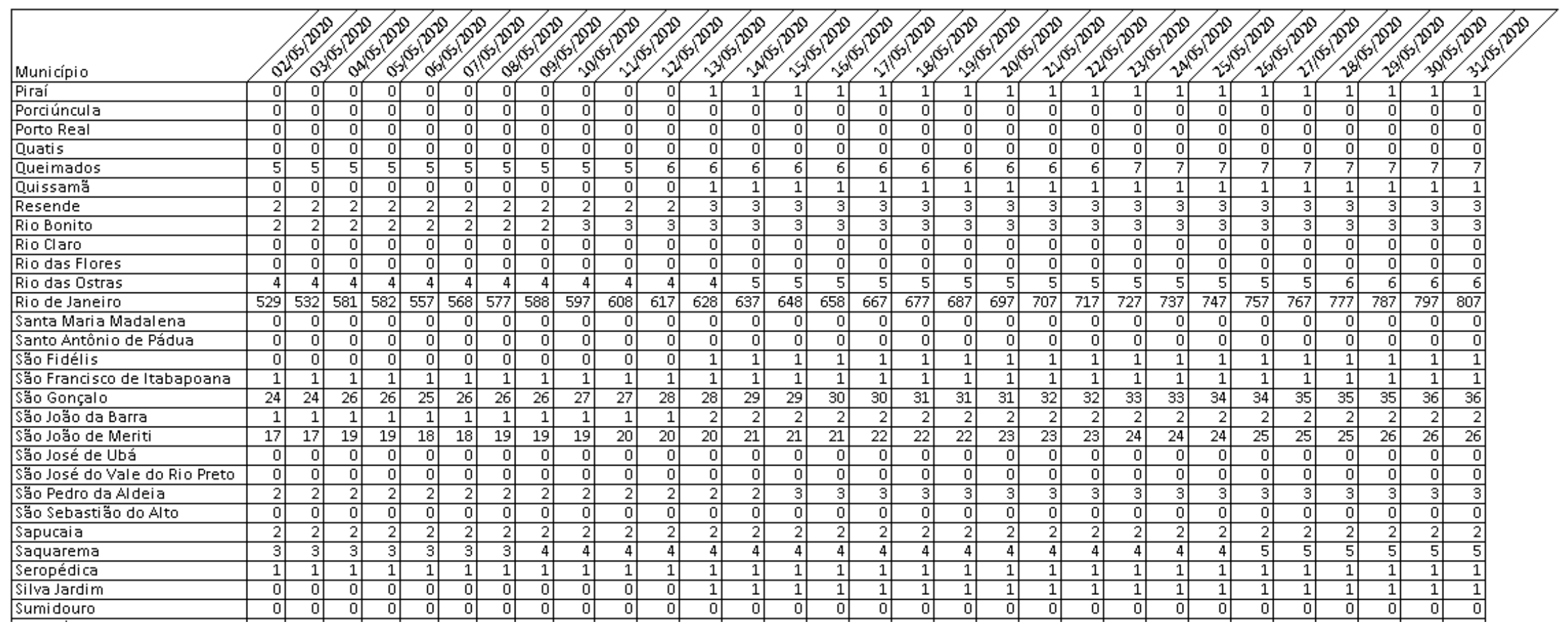


Municipio

Tanguá

Teresópolis

Trajano de Moraes

Três Rios

\begin{tabular}{|l} 
Valença \\
\hline Varre-Sai
\end{tabular}

Varre-Sai

Volta Redonda

Total

(100)

$00100100100100100 \% 100 \%$

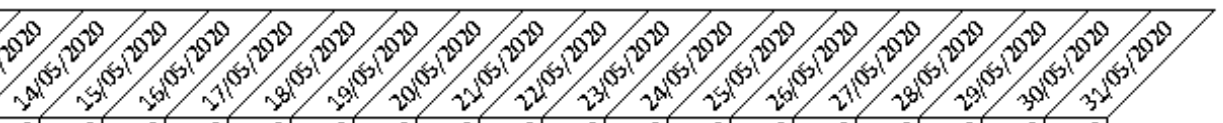

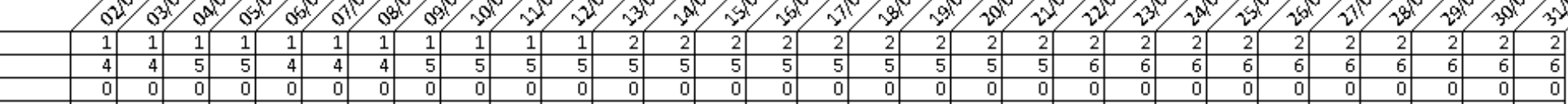


APÊNDICE XI - Municípios candidatos do modelo matemático

\begin{tabular}{|c|c|c|}
\hline Municípios & Novos casos & Representatividade \\
\hline Rio de Janeiro & 6189 & $1 \%$ \\
\hline Duque de Caxias & 437 & $2 \%$ \\
\hline Niterói & 406 & $3 \%$ \\
\hline Nova Iguaçu & 403 & $4 \%$ \\
\hline São Gonçalo & 279 & $5 \%$ \\
\hline Volta Redonda & 271 & $7 \%$ \\
\hline Itaboraí & 229 & $8 \%$ \\
\hline São João de Meriti & 201 & $9 \%$ \\
\hline Belford Roxo & 178 & $10 \%$ \\
\hline Mesquita & 164 & $11 \%$ \\
\hline Magé & 113 & $12 \%$ \\
\hline Petrópolis & 94 & $13 \%$ \\
\hline Nilópolis & 82 & $14 \%$ \\
\hline Maricá & 73 & $15 \%$ \\
\hline Campos dos Goytacazes & 65 & $16 \%$ \\
\hline Nova Friburgo & 57 & $17 \%$ \\
\hline Queimados & 56 & $18 \%$ \\
\hline Cabo Frio & 49 & $20 \%$ \\
\hline Angra dos Reis & 48 & $21 \%$ \\
\hline Teresópolis & 48 & $22 \%$ \\
\hline Macaé & 47 & $23 \%$ \\
\hline Itaguaí & 44 & $24 \%$ \\
\hline Rio das Ostras & 44 & $25 \%$ \\
\hline Saquarema & 37 & $26 \%$ \\
\hline Rio Claro & 35 & $27 \%$ \\
\hline Barra Mansa & 34 & $28 \%$ \\
\hline Araruama & 33 & $29 \%$ \\
\hline Japeri & 32 & $30 \%$ \\
\hline Paracambi & 30 & $32 \%$ \\
\hline Rio Bonito & 26 & $33 \%$ \\
\hline Resende & 25 & $34 \%$ \\
\hline São Pedro da Aldeia & 24 & $35 \%$ \\
\hline Casimiro de Abreu & 23 & $36 \%$ \\
\hline Carmo & 20 & $37 \%$ \\
\hline Duas Barras & 20 & $38 \%$ \\
\hline Macuco & 20 & $39 \%$ \\
\hline Trajano de Moraes & 20 & $40 \%$ \\
\hline Três Rios & 20 & $41 \%$ \\
\hline Barra do Piraí & 19 & $42 \%$ \\
\hline Sapucaia & 19 & $43 \%$ \\
\hline Cachoeiras de Macacu & 18 & $45 \%$ \\
\hline Iguaba Grande & 18 & $46 \%$ \\
\hline São João da Barra & 15 & $47 \%$ \\
\hline
\end{tabular}




\begin{tabular}{|c|c|c|}
\hline Tanguá & 15 & $48 \%$ \\
\hline Bom Jesus do Itabapoana & 12 & $49 \%$ \\
\hline Comendador Levy Gasparian & 12 & $50 \%$ \\
\hline Engenheiro Paulo de Frontin & 12 & $51 \%$ \\
\hline Armação dos Búzios & 11 & $52 \%$ \\
\hline Guapimirim & 11 & $53 \%$ \\
\hline São Francisco de Itabapoana & 11 & $54 \%$ \\
\hline Seropédica & 11 & $55 \%$ \\
\hline Paraíba do Sul & 10 & $57 \%$ \\
\hline Arraial do Cabo & 8 & $58 \%$ \\
\hline Bom Jardim & 8 & $59 \%$ \\
\hline Miguel Pereira & 8 & $60 \%$ \\
\hline Pinheiral & 8 & $61 \%$ \\
\hline Valença & 8 & $62 \%$ \\
\hline Vassouras & 8 & $63 \%$ \\
\hline Mangaratiba & 7 & $64 \%$ \\
\hline Paraty & 7 & $65 \%$ \\
\hline Carapebus & 5 & $66 \%$ \\
\hline Piraí & 5 & $67 \%$ \\
\hline Quissamã & 5 & $68 \%$ \\
\hline São Fidélis & 5 & $70 \%$ \\
\hline Silva Jardim & 5 & $71 \%$ \\
\hline Paty do Alferes & 4 & $72 \%$ \\
\hline Cambuci & 3 & $73 \%$ \\
\hline Cardoso Moreira & 3 & $74 \%$ \\
\hline Laje do Muriaé & 3 & $75 \%$ \\
\hline Natividade & 3 & $76 \%$ \\
\hline Varre-Sai & 3 & $77 \%$ \\
\hline Areal & 3 & $78 \%$ \\
\hline Itaperuna & 3 & $79 \%$ \\
\hline Itatiaia & 3 & $80 \%$ \\
\hline Mendes & 3 & $82 \%$ \\
\hline Porto Real & 3 & $83 \%$ \\
\hline Quatis & 3 & $84 \%$ \\
\hline Rio das Flores & 3 & $85 \%$ \\
\hline Santo Antônio de Pádua & 3 & $86 \%$ \\
\hline São José de Ubá & 3 & $87 \%$ \\
\hline Aperibé & 2 & $88 \%$ \\
\hline Conceição de Macabu & 2 & $89 \%$ \\
\hline Itaocara & 2 & $90 \%$ \\
\hline São Sebastião do Alto & 2 & $91 \%$ \\
\hline Sumidouro & 2 & $92 \%$ \\
\hline Cantagalo & 1 & $93 \%$ \\
\hline Cordeiro & 1 & $95 \%$ \\
\hline Italva & 1 & $96 \%$ \\
\hline Miracema & 1 & $97 \%$ \\
\hline
\end{tabular}


Porciúncula

Santa Maria Madalena

São José do Vale do Rio Preto
1

1

1
$98 \%$

$99 \%$

$100 \%$

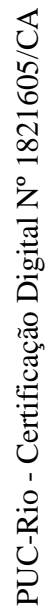




\section{APÊNDICE XII - Informações sobre a performance do modelo matemático}

O modelo possui 355.277 variáveis e 14.784 restrições. A seguir é apresentado o tempo de execução de cada caso, em segundos.

\begin{tabular}{lr}
\multicolumn{1}{c}{ Caso } & Tempo (s) \\
\hline Base & 7,94 \\
$\# 1$ & 4,69 \\
$\# 2$ & 86,00 \\
$\# 3$ & 1668,55 \\
\hline
\end{tabular}




\section{APÊNDICE XIII - Alocação de leitos de UTI no Estado do RJ por município com hospital de campanha - caso base}

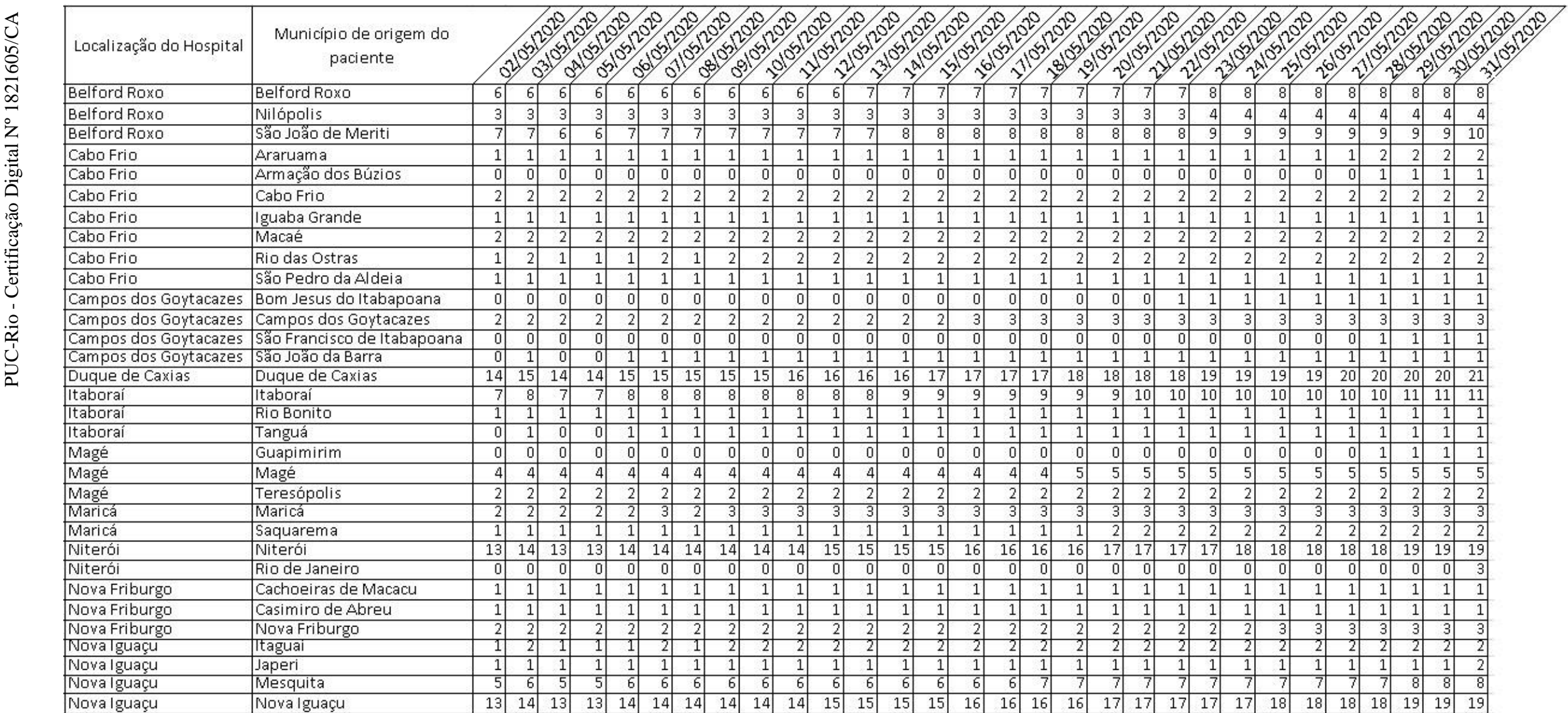




\section{APÊNDICE XIV - Alocação de VMI no Estado do RJ por município com hospital de campanha - caso base}

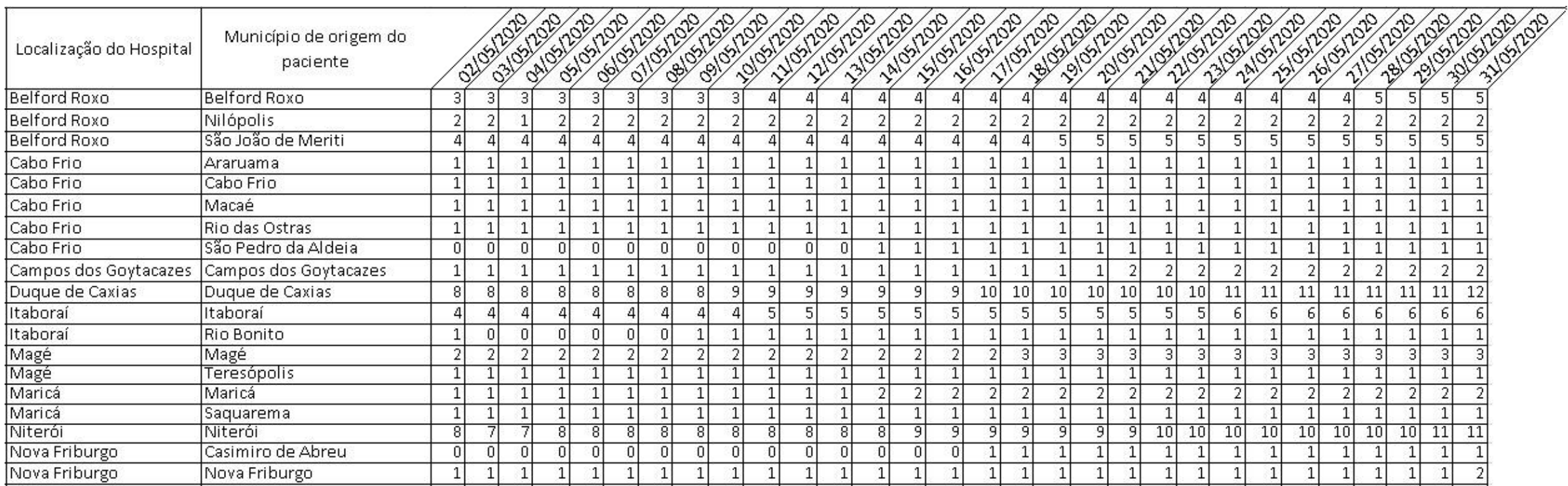




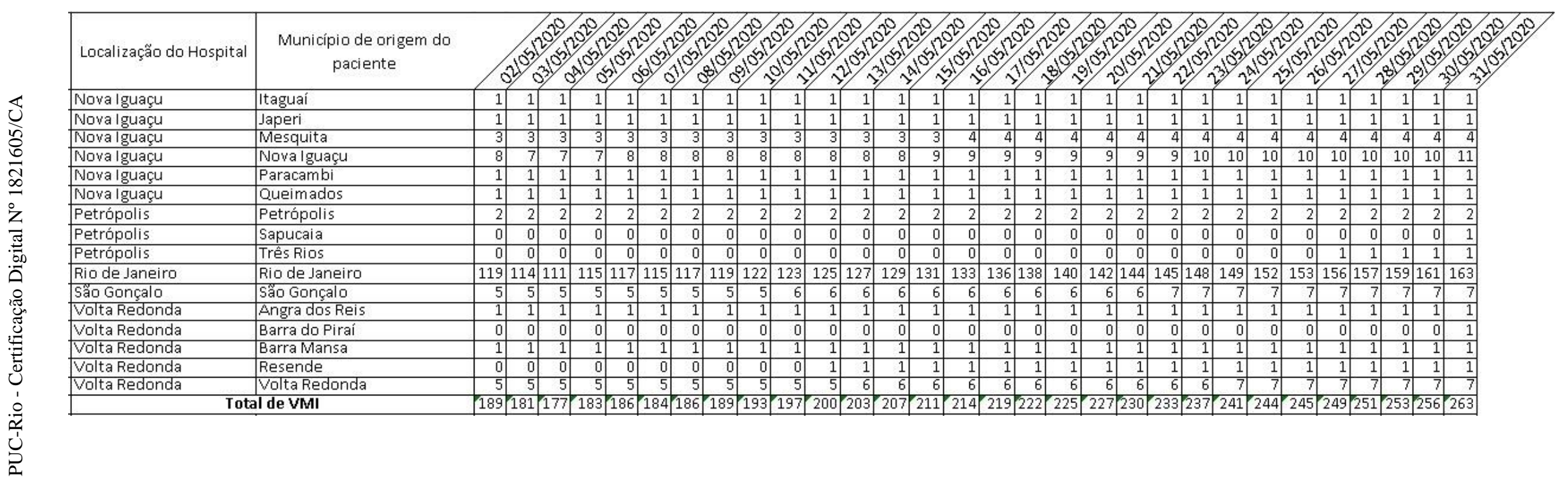


APÊNDICE XV - Alocação de leitos de enfermaria no Estado do RJ por município com hospital de campanha - caso base

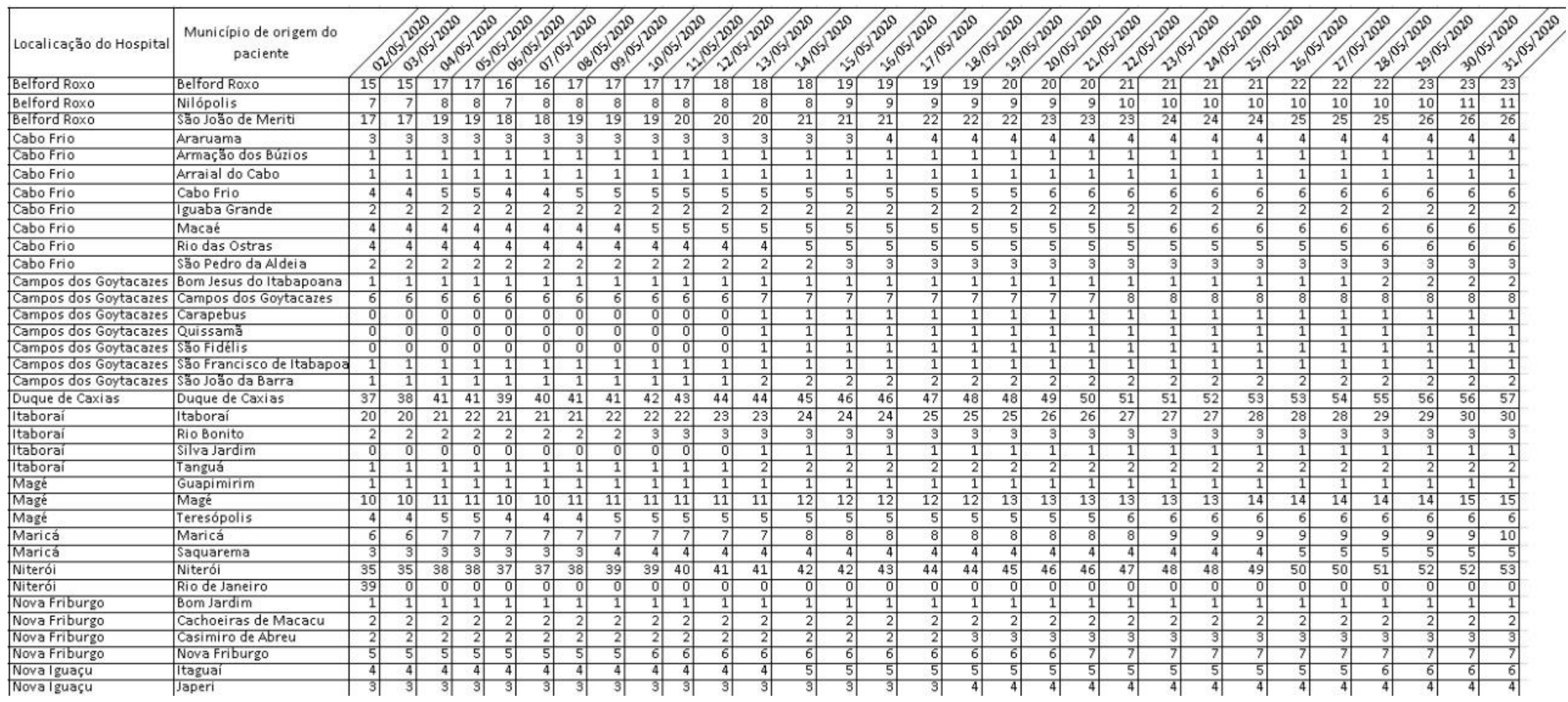




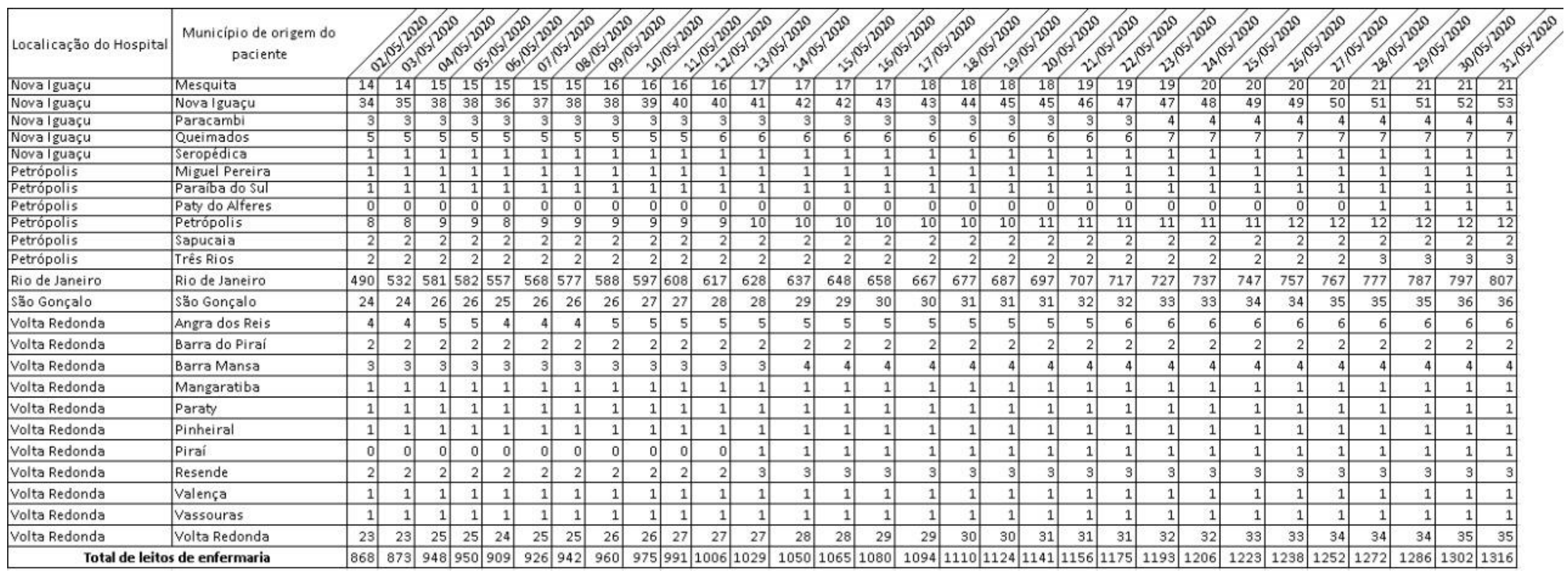


APÊNDICE XVI - Alocação de leitos de UTI no Estado do RJ por município com hospital de campanha - caso 1

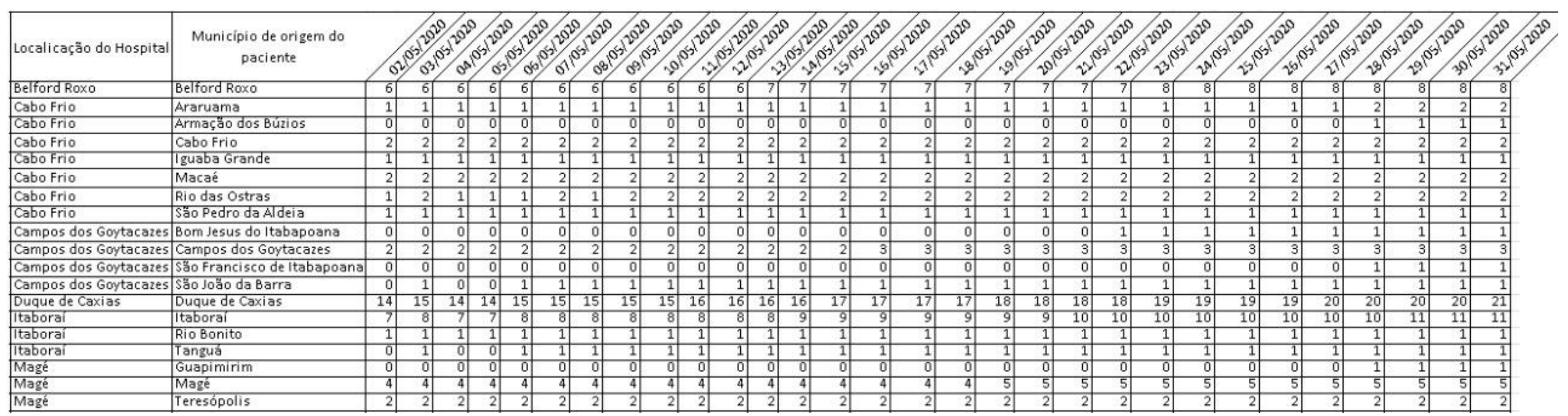




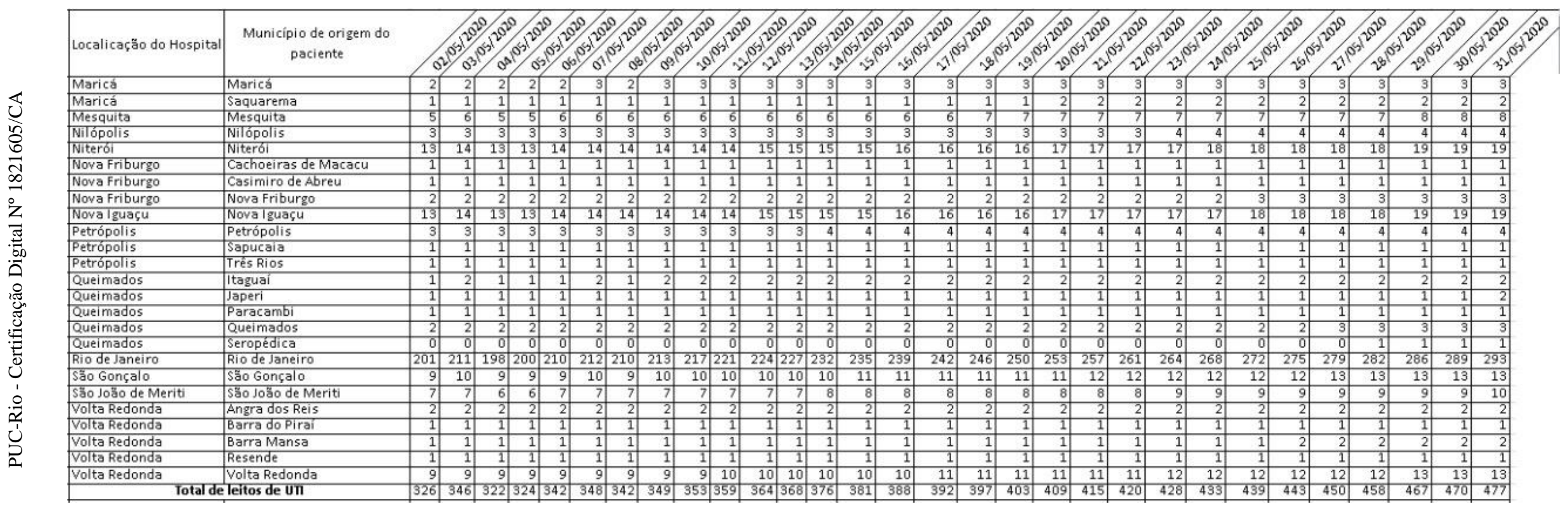


APÊNDICE XVII - Alocação de VMI no Estado do RJ por município com hospital de campanha - caso 1

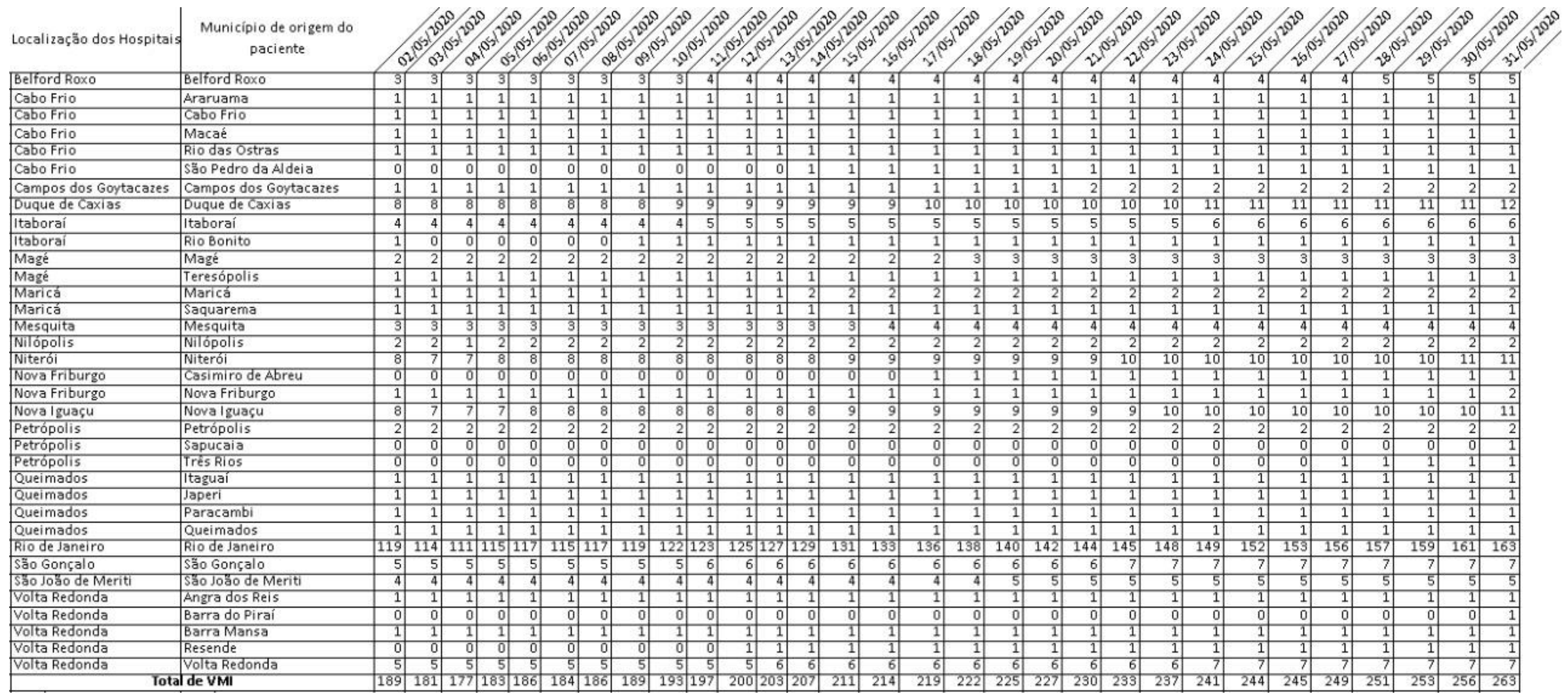


APÊNDICE XVIII - Alocação de leitos de enfermaria no Estado do RJ por município com hospital de campanha - caso 1

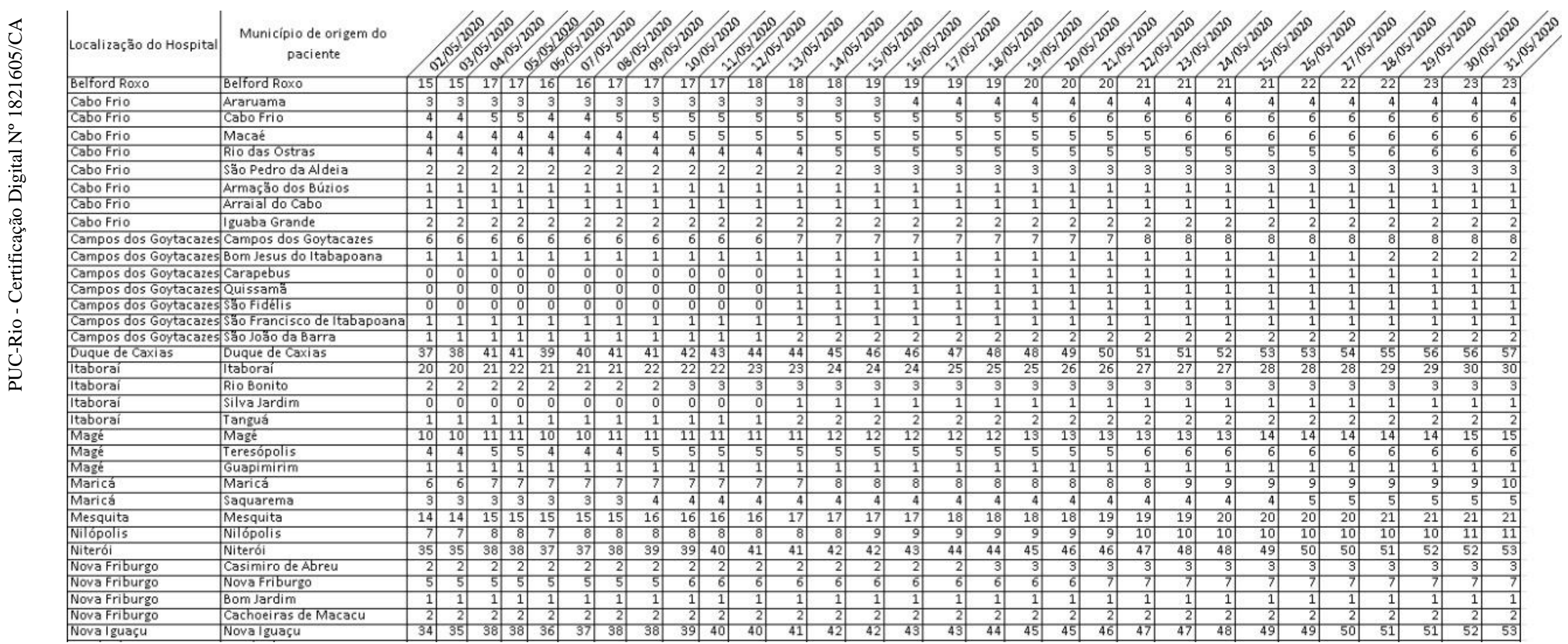




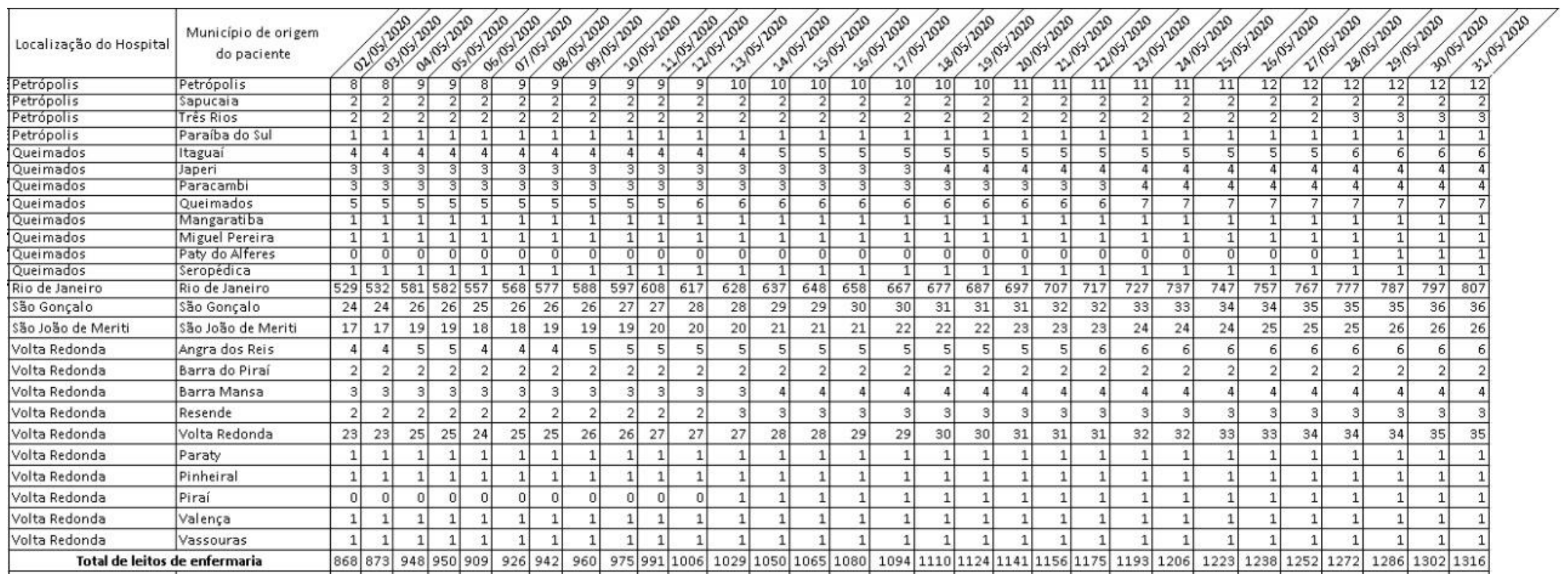


APÊNDICE XIX - Alocação de leitos de UTI no Estado do RJ por município com hospital de campanha - caso 2

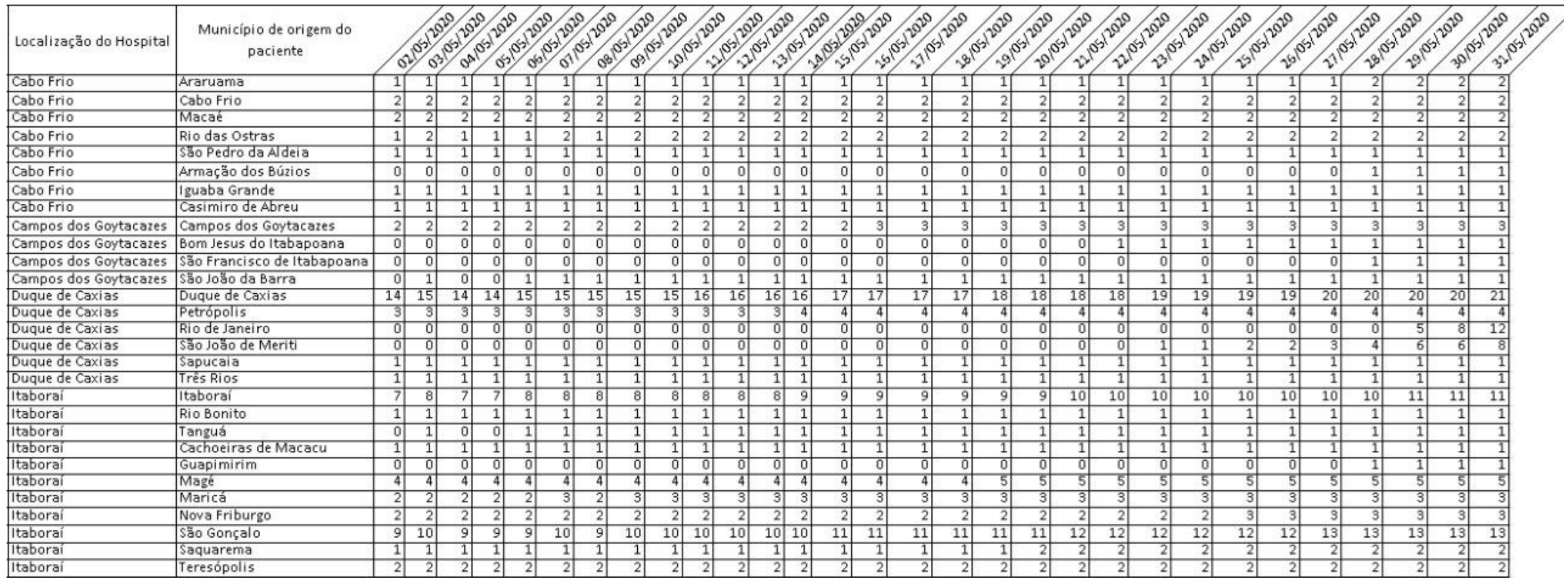




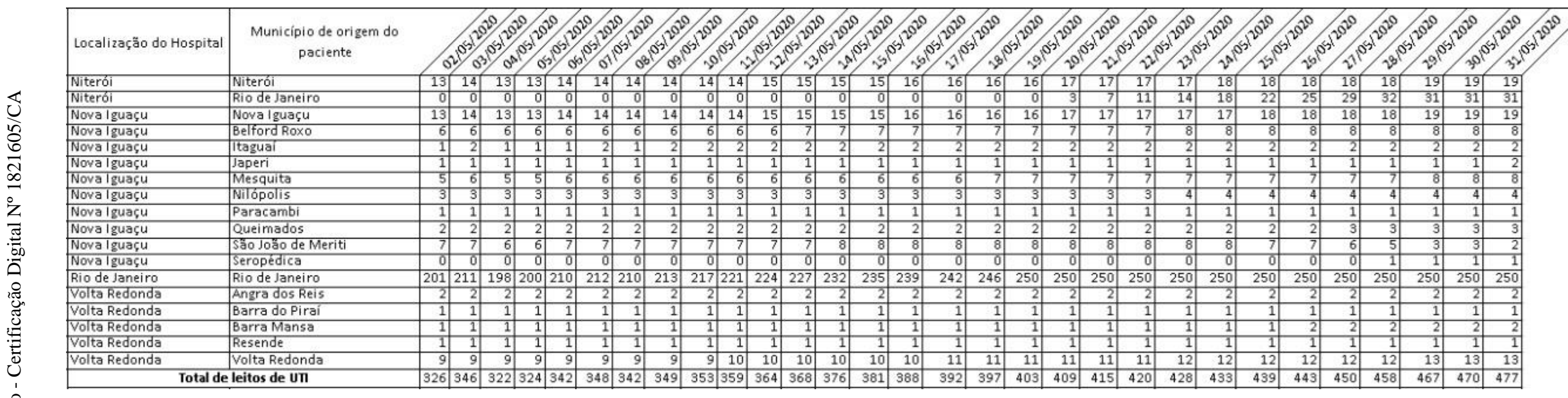


APÊNDICE XX - Alocação de VMI no Estado do RJ por município com hospital de campanha - caso 2

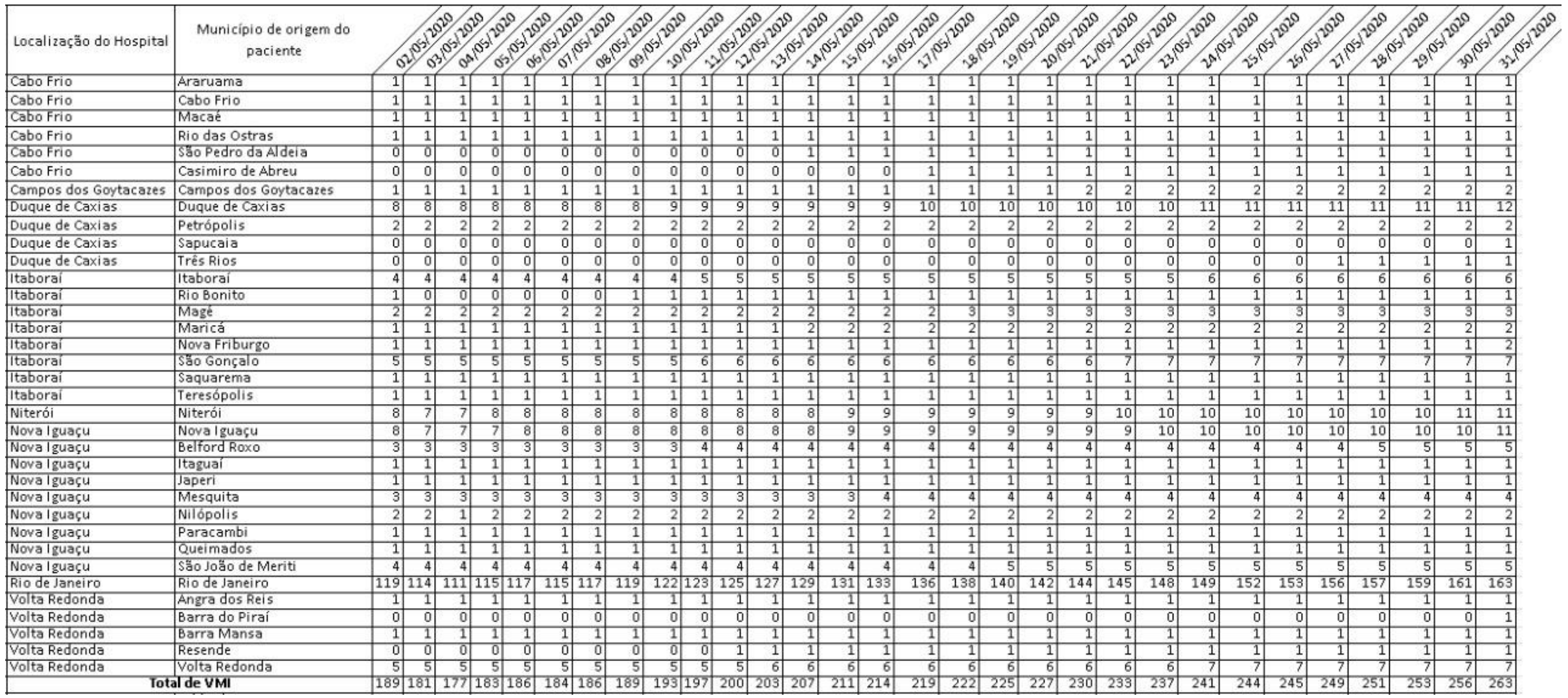


APÊNDICE XXI - Alocação de leitos de enfermaria no Estado do RJ por município com hospital de campanha - caso 2

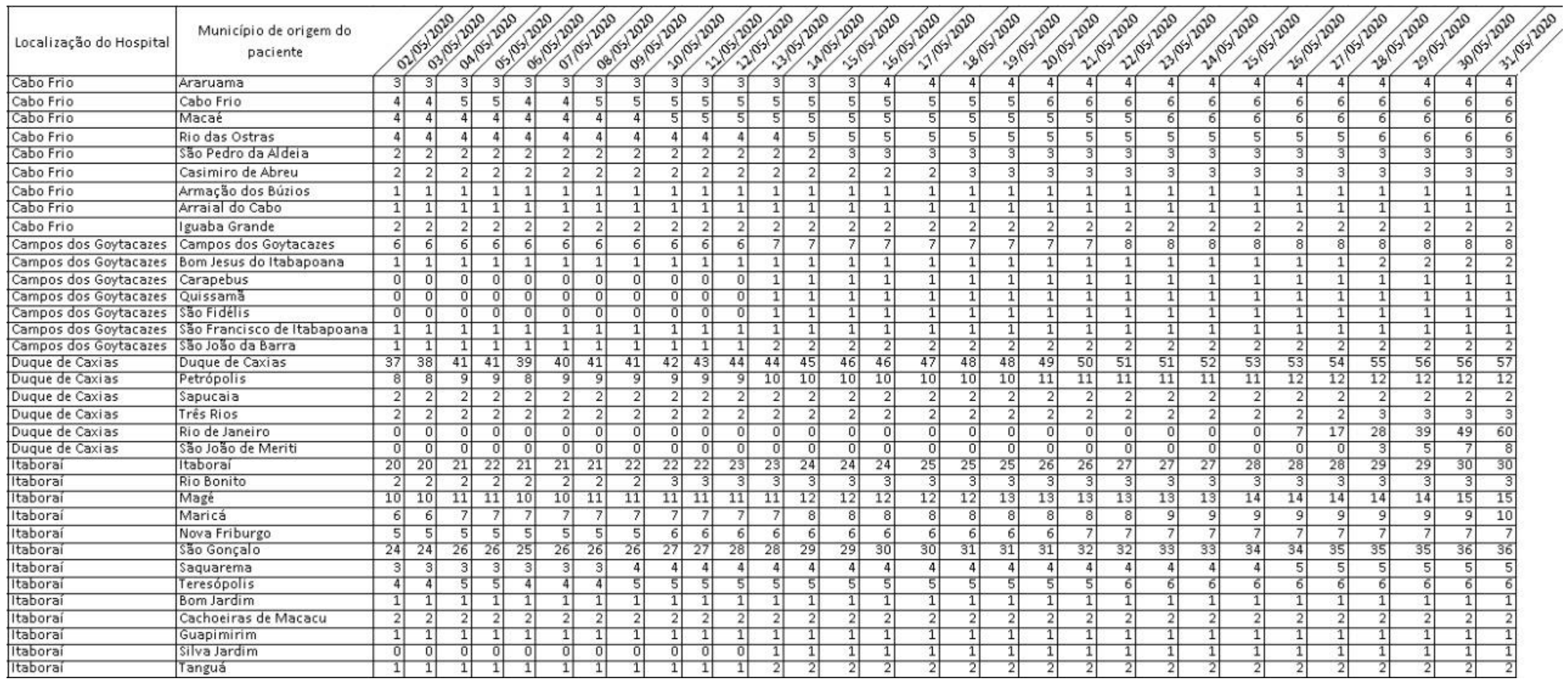




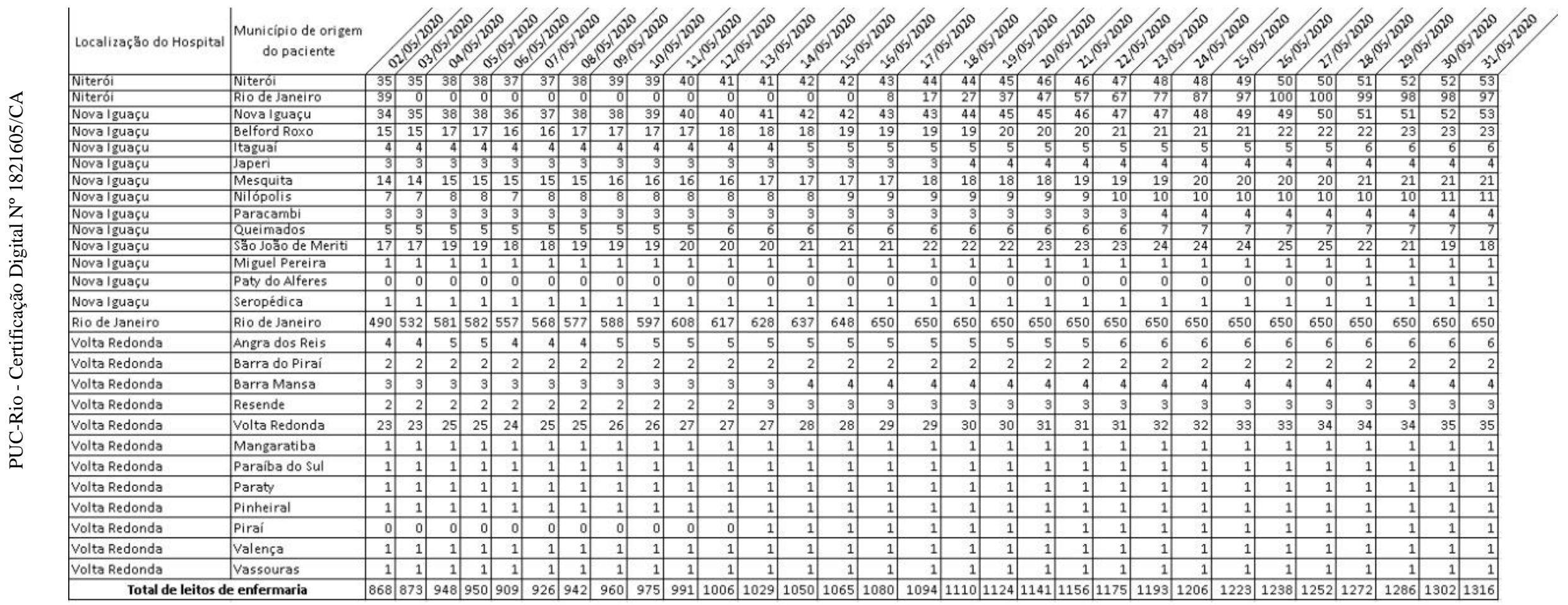


APÊNDICE XXII - Alocação de leitos de UTI no Estado do RJ por município com hospital de campanha - caso 3

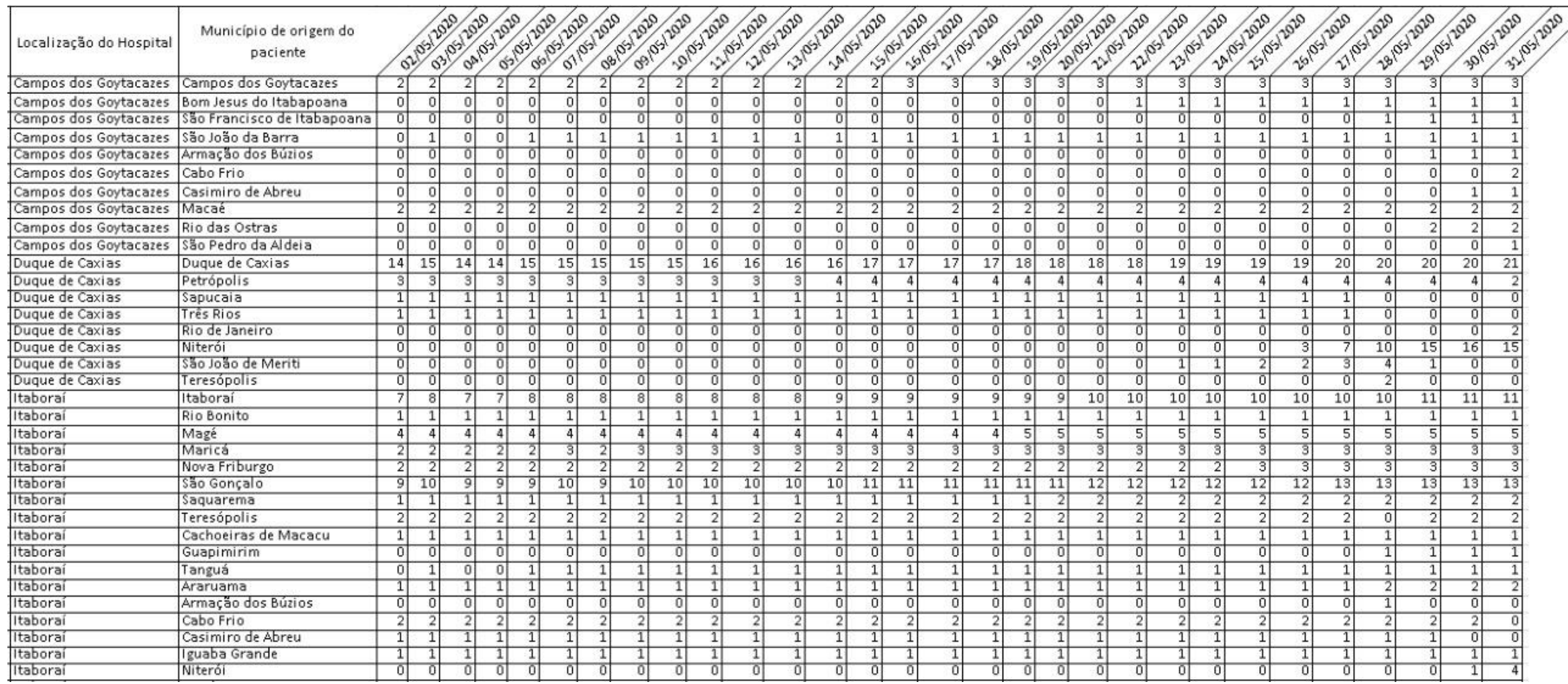




$$
\begin{array}{l|l}
\hline \text { Localização do Hospital } & \text { Município de origem do }
\end{array}
$$

$$
\text { paciente }
$$

Compos

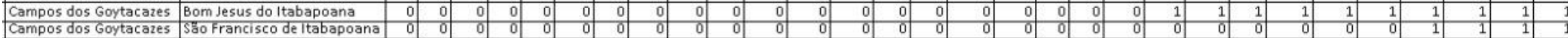

Campos dos Goytacazes São Joäo da Barr

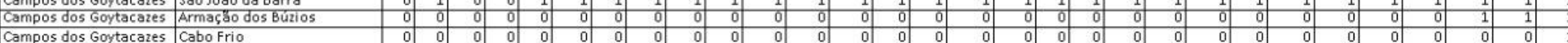

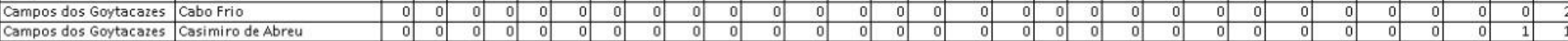

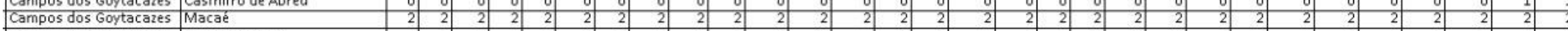

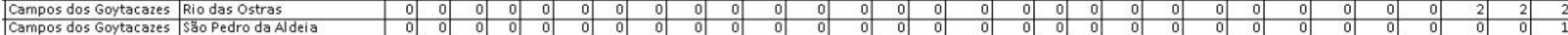

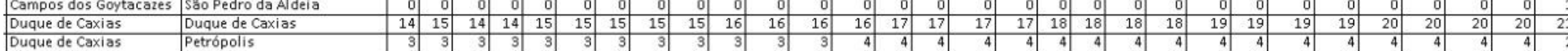
Dugue caxis

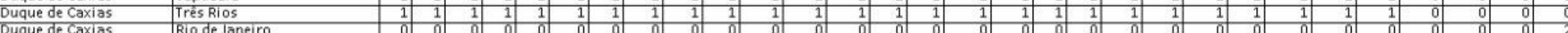
\begin{tabular}{|lllllllllllllllllllllllllllllllll}
\hline Duque de Caxias & Niterói & 0 & 0 & 0 & 0 & 0 & 0 & 0 & 0 & 0 & 0 & 0 & 0 & 0 & 0 & 0 & 0 & 0 & 0 & 0 & 0 & 0 & 0 & 0 & 0 & 3 & 7 & 10 & 15 & 16 & 15 \\
\hline
\end{tabular}

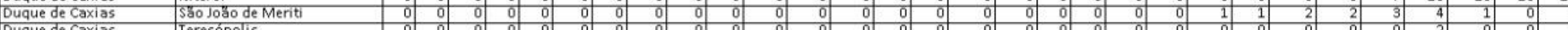

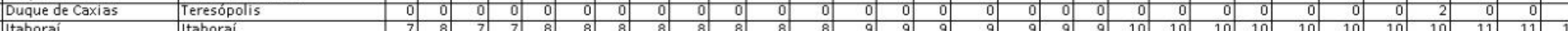

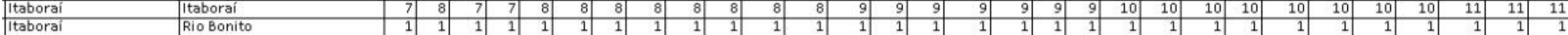

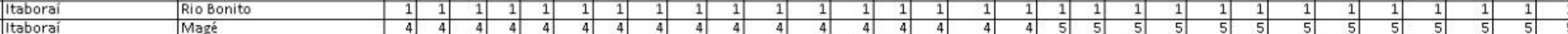

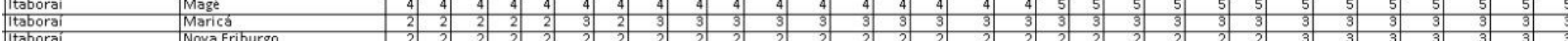

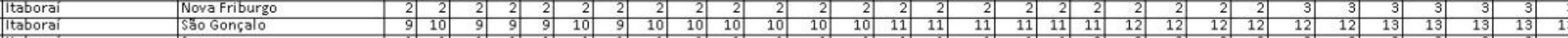

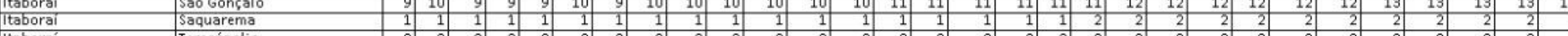

Itaborai

rá

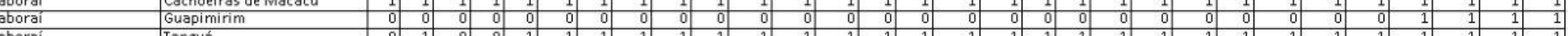

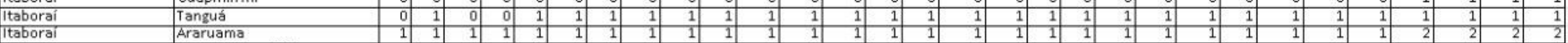

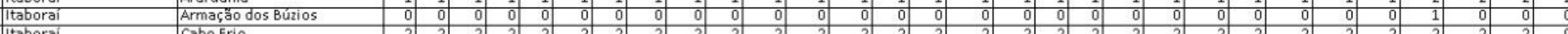

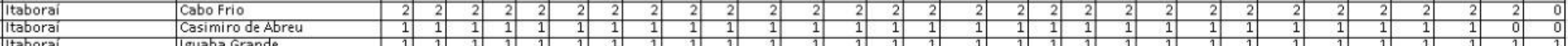

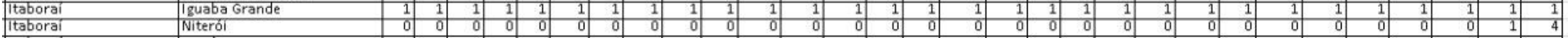


APÊNDICE XXIII - Alocação de VMI no Estado do RJ por município com hospital de campanha - caso 3

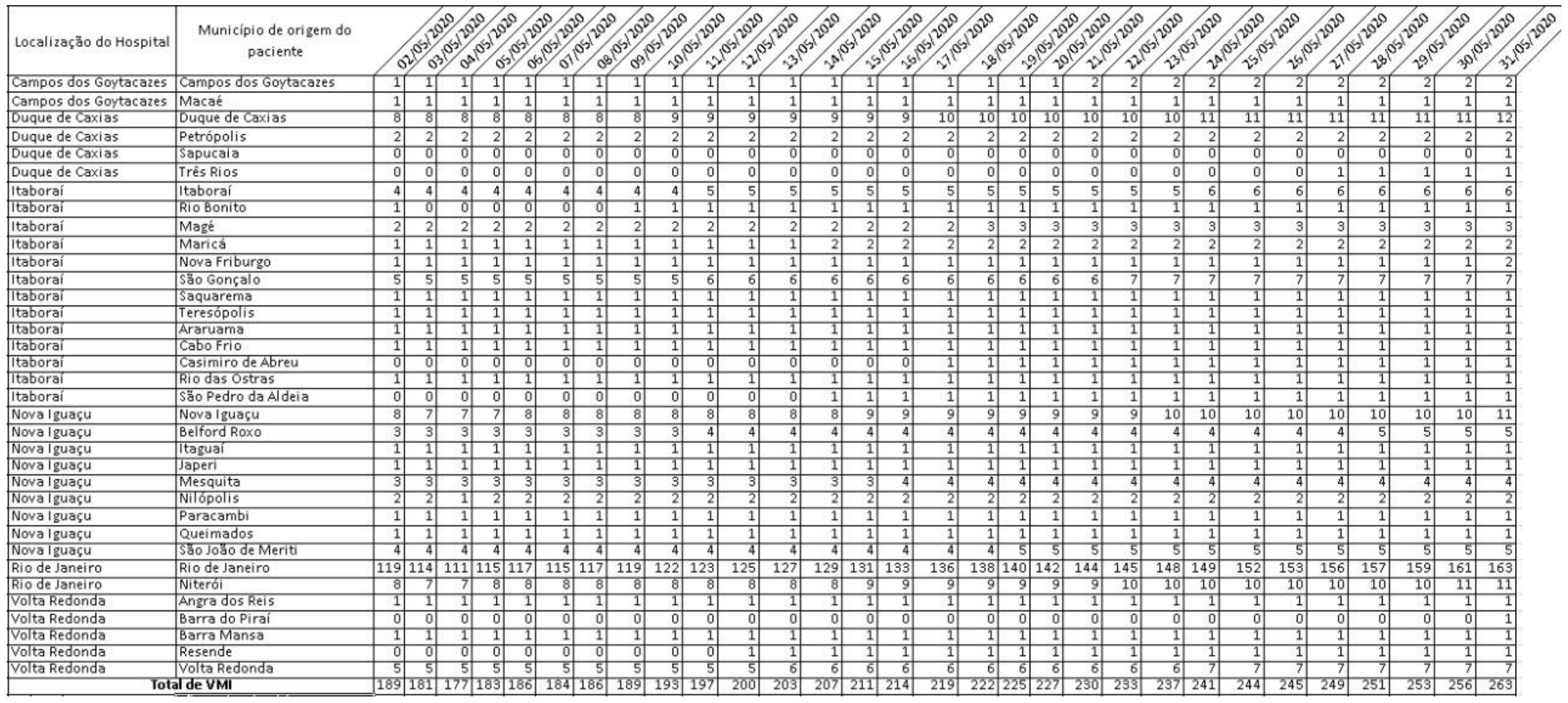


APÊNDICE XXIV - Alocação de leitos de enfermaria no Estado do RJ por município com hospital de campanha - caso 3

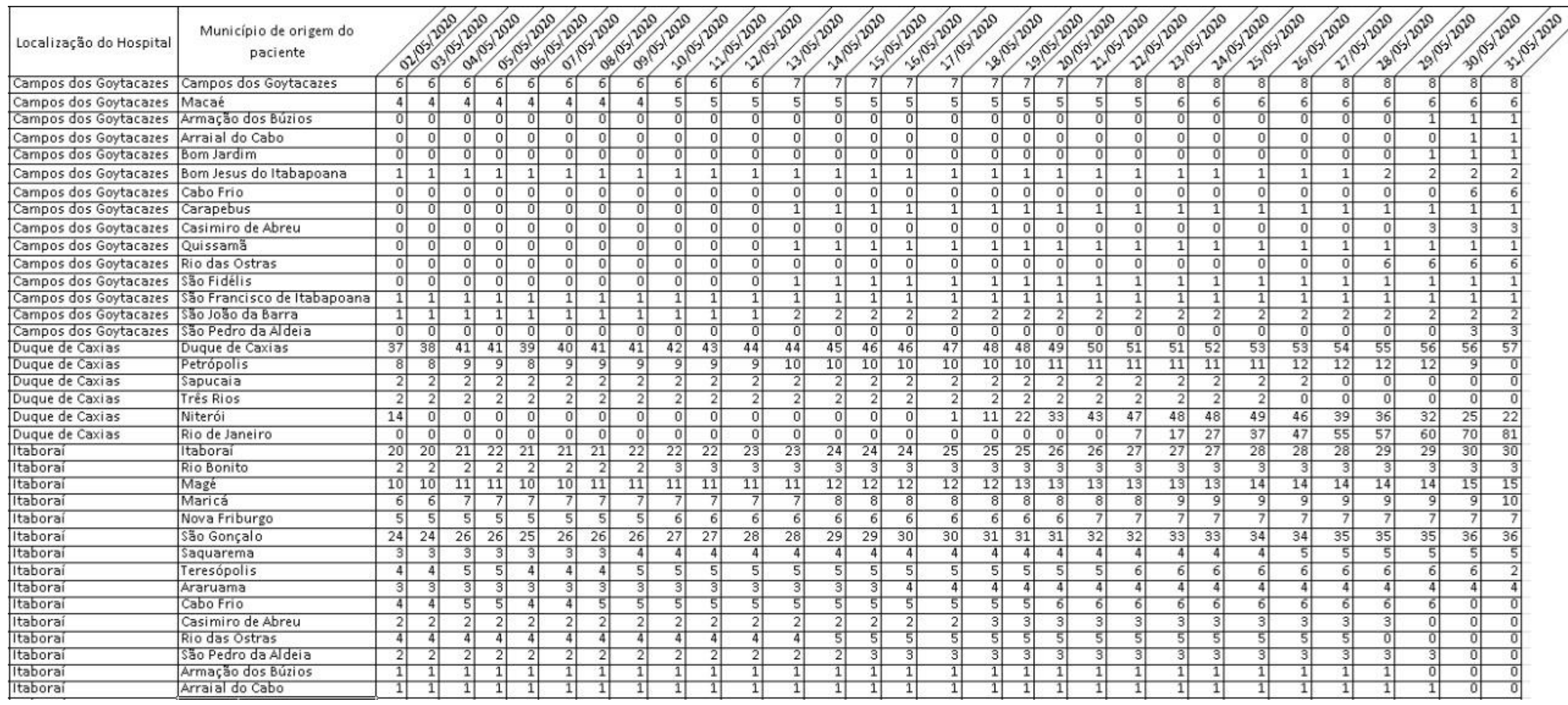




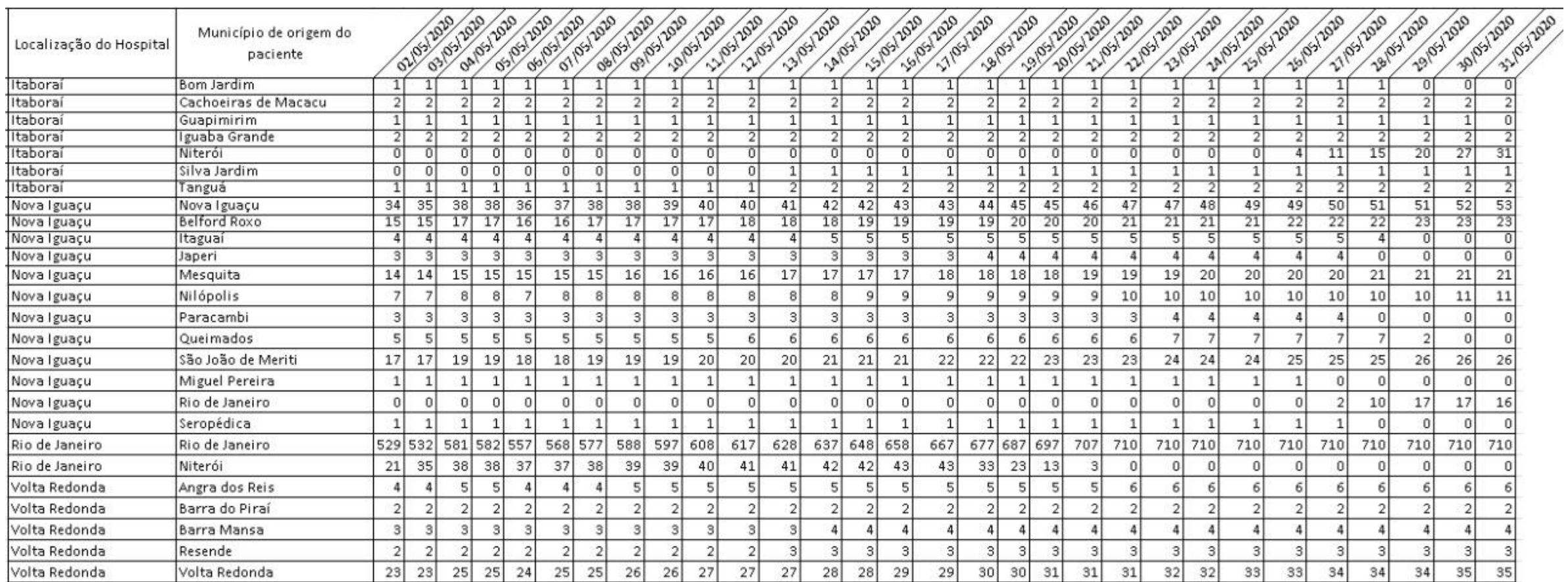




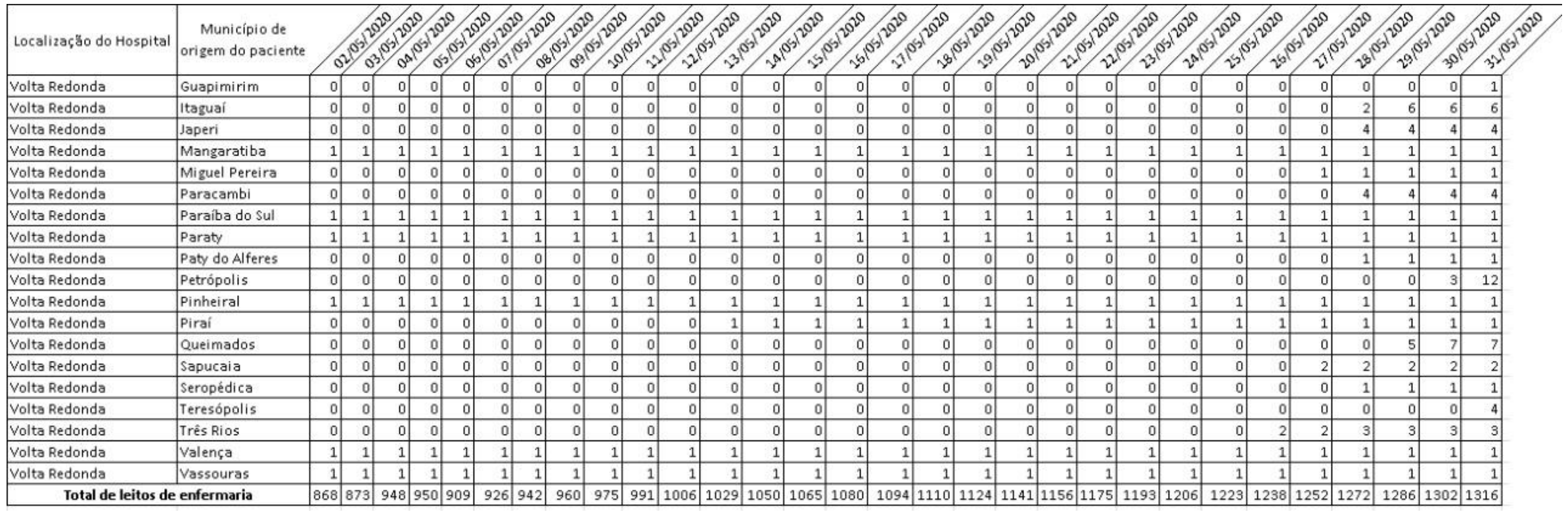

